University of Tennessee Health Science Center

UTHSC Digital Commons

\title{
Age-Associated Expression Patterns of OATP 1B1 and OATP 1B3 and Their Effect on the Disposition of Fexofenadine
}

Margaret Mary Thomson

University of Tennessee Health Science Center

Follow this and additional works at: https://dc.uthsc.edu/dissertations

Part of the Medicinal and Pharmaceutical Chemistry Commons, and the Pharmaceutics and Drug Design Commons

\section{Recommended Citation}

Thomson, Margaret Mary (http://orcid.org/0000-0002-2147-6943), "Age-Associated Expression Patterns of OATP 1B1 and OATP 1B3 and Their Effect on the Disposition of Fexofenadine" (2017). Theses and Dissertations (ETD). Paper 430. http://dx.doi.org/10.21007/etd.cghs.2017.0440.

This Dissertation is brought to you for free and open access by the College of Graduate Health Sciences at UTHSC Digital Commons. It has been accepted for inclusion in Theses and Dissertations (ETD) by an authorized administrator of UTHSC Digital Commons. For more information, please contact jwelch30@uthsc.edu. 


\title{
Age-Associated Expression Patterns of OATP 1B1 and OATP 1B3 and Their Effect on the Disposition of Fexofenadine
}

\author{
Abstract \\ As part of the drug disposition process (absorption, distribution, metabolism, excretion), an often \\ overlooked aspect is transport. In order for drugs to be metabolized and excreted from the body they go \\ through the liver or other drug removal organs. For drugs that are polar or are large they must rely upon \\ transport mechanisms to transport them across the biomembranes of the drug removal organs. \\ OATP1B1 and OATP1B3 are transporters on the sinusoidal membrane of the liver which work in concert \\ with the drug metabolizing enzymes as part of the drug removal process. It is known that the \\ development of each drug metabolizing enzyme follows a unique pattern that is determined in part by \\ age. This is not unique to drug metabolizing enzymes or even drug disposition processes. All aspects of \\ physiologic development are governed in part by age from gastric $\mathrm{pH}$, and kidney function, to skin \\ thickness. With the knowledge that age is a major determinant of expression of drug metabolizing \\ enzymes it was hypothesized that age would also impact the expression of drug transporters. The \\ developmental protein expression pattern of the closely related hepatic uptake transporters, OATP1B1 \\ and OATP1B3, was examined in human liver tissue samples. Samples were obtained from donors aged \\ 14 days to 12 years. Western blot analysis revealed a very intriguing pattern. OATP1B3 showed very high \\ expression at birth but tapered down to minimal expression by 6 months of age. The intriguing aspect of \\ this data was that the protein expression level of OATP1B3 started to increase during the pre-adolescent \\ period. When comparing the protein expression levels in infants less than 3 months to children aged 6-12 \\ years, protein expression was $237 \%$ higher in the infants. The expression decreased to $33 \%$ in the 3 \\ months to 2 years group as compared to the 6-12 years group with the 2-6 years group starting to \\ increase expression to 50\%. OATP1B1 showed large inter-individual variability but failed to show a \\ significant difference in protein expression amongst the age groups examined. While ontogeny is a very \\ important part of overall development, genetics is also very important. The term developmental \\ pharmacogenetics describes the inter-play between age and genetics, as phenotypes can only be \\ expressed if physiological development is at a point where it is possible to be seen. In order to learn more \\ about the expression of OATP1B1 and OATP1B3 several common SNPs were examined, OATP1B1 388 \\ $A \rightarrow G$ and $521 \mathrm{~T} \rightarrow C$ as well as OATP1B3 334T $\rightarrow \mathrm{G}$ and $699 \mathrm{G} \rightarrow \mathrm{A}$. All four SNPs were found to be in Hardy- \\ Weinberg equilibrium. The allele frequencies for each SNP were in agreement with previously published \\ reports. OATP1B3 334T $\rightarrow \mathrm{G}$ and $699 \mathrm{G} \rightarrow$ A were in complete linkage disequilibrium. The linkage \\ disequilibrium that was found between the SNPs in OATP1B3 and OATP1B1 $388 \mathrm{~A} \rightarrow \mathrm{G}$ was a novel finding \\ that deserves further exploration. Examination of protein expression and each SNP failed to show any \\ association between the two which also deserves further exploration with a larger number of samples to \\ confirm. Lastly, the functional consequences of the loss of OATP1B activity was explored using the \\ Oatp1b2-/- mouse model. Oatp1b2-/- is the rodent member of the OATP1B family and shares greater than \\ $65 \%$ homology to the human members. Using fexofenadine as a probe for Oatp 1 b2 activity, it was found \\ that Oatp1b2-/- mice had 2.1 fold higher exposure as compared to the wild-type mice. The Oatp1b2-/- \\ also had $55 \%$ of the fexofenadine clearance and $63 \%$ the volume of distribution as compared to wild-type \\ mice. These findings underscore the importance that Oatp $1 \mathrm{~b}$ activity has in determining exposure, and \\ thus efficacy and potential toxicity, to substrates. Drug transport is a very important part of drug \\ disposition that has yet to be extensively studied especially in terms of drug uptake. The following studies \\ examined the developmental expression patterns of hepatic uptake transporters OATP1B1 and OATP1B3, \\ common genetic variations of the transporters, as well as the consequences the loss of OATP1B activity \\ has on substrates. Understanding the developmental expression pattern of OATP1B will allow for better \\ dosing strategies for patients, particularly infants and children who rarely participate in clinical trials. \\ Better dosing strategies ultimately lead to improved outcomes and reduced toxicity in the pediatric \\ population.
}




\section{Document Type}

Dissertation

\section{Degree Name}

Doctor of Philosophy (PhD)

\section{Program}

Pharmaceutical Sciences

\section{Research Advisor}

Bernd Meibohm, Ph.D.

\section{Keywords}

Drug Transport, Fexofenadine, OATP1B1, OATP1B3, Ontogeny, Pediatrics

\section{Subject Categories}

Medicinal and Pharmaceutical Chemistry | Medicine and Health Sciences | Pharmaceutics and Drug Design | Pharmacy and Pharmaceutical Sciences

\section{Comments}

One year embargo expires May 2018. 


\title{
Age-Associated Expression Patterns of OATP 1B1 and OATP 1 B3 and Their Effect on the Disposition of Fexofenadine
}

\author{
A Dissertation \\ Presented for \\ The Graduate Studies Council \\ The University of Tennessee \\ Health Science Center \\ In Partial Fulfillment \\ Of the Requirements for the Degree \\ Doctor of Philosophy \\ From The University of Tennessee
}

By

Margaret Mary Thomson

May 2017 
Portions of Chapter 1 (C) 2015 by John Wiley and Sons.

Chapter 3 (C) 2016 by American Society of Pharmacology and Experimental Therapeutics.

All other material (C) 2017 by Margaret Mary Thomson.

All rights reserved. 


\section{DEDICATION}

To Robert, Nicholas, and Lexie for showing me faith, love, and joy 


\section{ACKNOWLEDGEMENTS}

First and foremost I need to thank Dr. Bernd Meibohm for his guidance and patience throughout this entire process. I also want to thank Dr. Alex Sparreboom for the cells and mice used in the pharmacokinetic experiments as well as facility space to conduct those experiments. Without that assistance there would definitely be holes in the information we were trying to gain. The guidance and support that I received from my committee members, Dr. C. Ryan Yates, Dr. Michael Christensen, and Dr. Sarka Beranova was invaluable throughout this entire journey. I would like to acknowledge both Dr. Erin Schuetz and Dr. Ronald Hines who provided the liver samples that were the foundation of the work presented.

I also need to thank all the other students in the Meibohm and Yates' labs. Without the shoulders to cry on or the shared laughter this journey would not have been the same, so thank you Dr. Yi Zhang, Dr. Nageshwar Budha, Dr. Nathanel Dirks, Dr. Ashit Trivedi, Dr. Pavan Vaddady, Dr. Josiah Ryman, Dr. Wararat Limothai, Dr. Chaela Presley, Dr. Chetan Rathi and Dr. Jordan Toutouchian. The ground work of this work was laid by Dr. Wenhui Zhang and Dr. Lisa Tang. Ms. Brenda Thornton and Ms. Faith Barcroft must also be acknowledged for all the work that they have done for the department and me personally. Finally I need to thank my family for always believing in me.

Support for this work was provided in part through the Seldon D. Feurt Memorial Fund at the University of Tennessee College of Pharmacy and the American Foundation for Pharmaceutical Education. 


\begin{abstract}
As part of the drug disposition process (absorption, distribution, metabolism, excretion), an often overlooked aspect is transport. In order for drugs to be metabolized and excreted from the body they go through the liver or other drug removal organs. For drugs that are polar or are large they must rely upon transport mechanisms to transport them across the biomembranes of the drug removal organs. OATP1B1 and OATP1B3 are transporters on the sinusoidal membrane of the liver which work in concert with the drug metabolizing enzymes as part of the drug removal process.
\end{abstract}

It is known that the development of each drug metabolizing enzyme follows a unique pattern that is determined in part by age. This is not unique to drug metabolizing enzymes or even drug disposition processes. All aspects of physiologic development are governed in part by age from gastric $\mathrm{pH}$, and kidney function, to skin thickness. With the knowledge that age is a major determinant of expression of drug metabolizing enzymes it was hypothesized that age would also impact the expression of drug transporters.

The developmental protein expression pattern of the closely related hepatic uptake transporters, OATP1B1 and OATP1B3, was examined in human liver tissue samples. Samples were obtained from donors aged 14 days to 12 years. Western blot analysis revealed a very intriguing pattern. OATP1B3 showed very high expression at birth but tapered down to minimal expression by 6 months of age. The intriguing aspect of this data was that the protein expression level of OATP1B3 started to increase during the preadolescent period. When comparing the protein expression levels in infants less than 3 months to children aged 6-12 years, protein expression was $237 \%$ higher in the infants. The expression decreased to $33 \%$ in the 3 months to 2 years group as compared to the 612 years group with the 2-6 years group starting to increase expression to $50 \%$. OATP1B1 showed large inter-individual variability but failed to show a significant difference in protein expression amongst the age groups examined.

While ontogeny is a very important part of overall development, genetics is also very important. The term developmental pharmacogenetics describes the inter-play between age and genetics, as phenotypes can only be expressed if physiological development is at a point where it is possible to be seen. In order to learn more about the expression of OATP1B1 and OATP1B3 several common SNPs were examined, OATP1B1 $388 \mathrm{~A} \rightarrow \mathrm{G}$ and $521 \mathrm{~T} \rightarrow \mathrm{C}$ as well as OATP1B3 334T $\rightarrow \mathrm{G}$ and $699 \mathrm{G} \rightarrow \mathrm{A}$. All four SNPs were found to be in Hardy-Weinberg equilibrium. The allele frequencies for each SNP were in agreement with previously published reports. OATP1B3 334T $\rightarrow \mathrm{G}$ and $699 \mathrm{G} \rightarrow \mathrm{A}$ were in complete linkage disequilibrium. The linkage disequilibrium that was found between the SNPs in OATP1B3 and OATP1B1 $388 \mathrm{~A} \rightarrow \mathrm{G}$ was a novel finding that deserves further exploration. Examination of protein expression and each SNP failed to show any association between the two which also deserves further exploration with a larger number of samples to confirm. 
Lastly, the functional consequences of the loss of OATP1B activity was explored using the Oatp $1 \mathrm{~b} 2^{-/}$mouse model. Oatp $1 \mathrm{~b} 2^{-/}$is the rodent member of the OATP1B family and shares greater than $65 \%$ homology to the human members. Using fexofenadine as a probe for Oatp1b2 activity, it was found that Oatp $1 \mathrm{~b} 2^{-/-}$mice had 2.1 fold higher exposure as compared to the wild-type mice. The Oatp $1 \mathrm{~b} 2^{-/-}$also had $55 \%$ of the fexofenadine clearance and $63 \%$ the volume of distribution as compared to wild-type mice. These findings underscore the importance that Oatp $1 \mathrm{~b}$ activity has in determining exposure, and thus efficacy and potential toxicity, to substrates.

Drug transport is a very important part of drug disposition that has yet to be extensively studied especially in terms of drug uptake. The following studies examined the developmental expression patterns of hepatic uptake transporters OATP1B1 and OATP1B3, common genetic variations of the transporters, as well as the consequences the loss of OATP1B activity has on substrates. Understanding the developmental expression pattern of OATP1B will allow for better dosing strategies for patients, particularly infants and children who rarely participate in clinical trials. Better dosing strategies ultimately lead to improved outcomes and reduced toxicity in the pediatric population. 


\section{TABLE OF CONTENTS}

CHAPTER 1. ONTOGENY AND DRUG DISPOSITION .............................................1

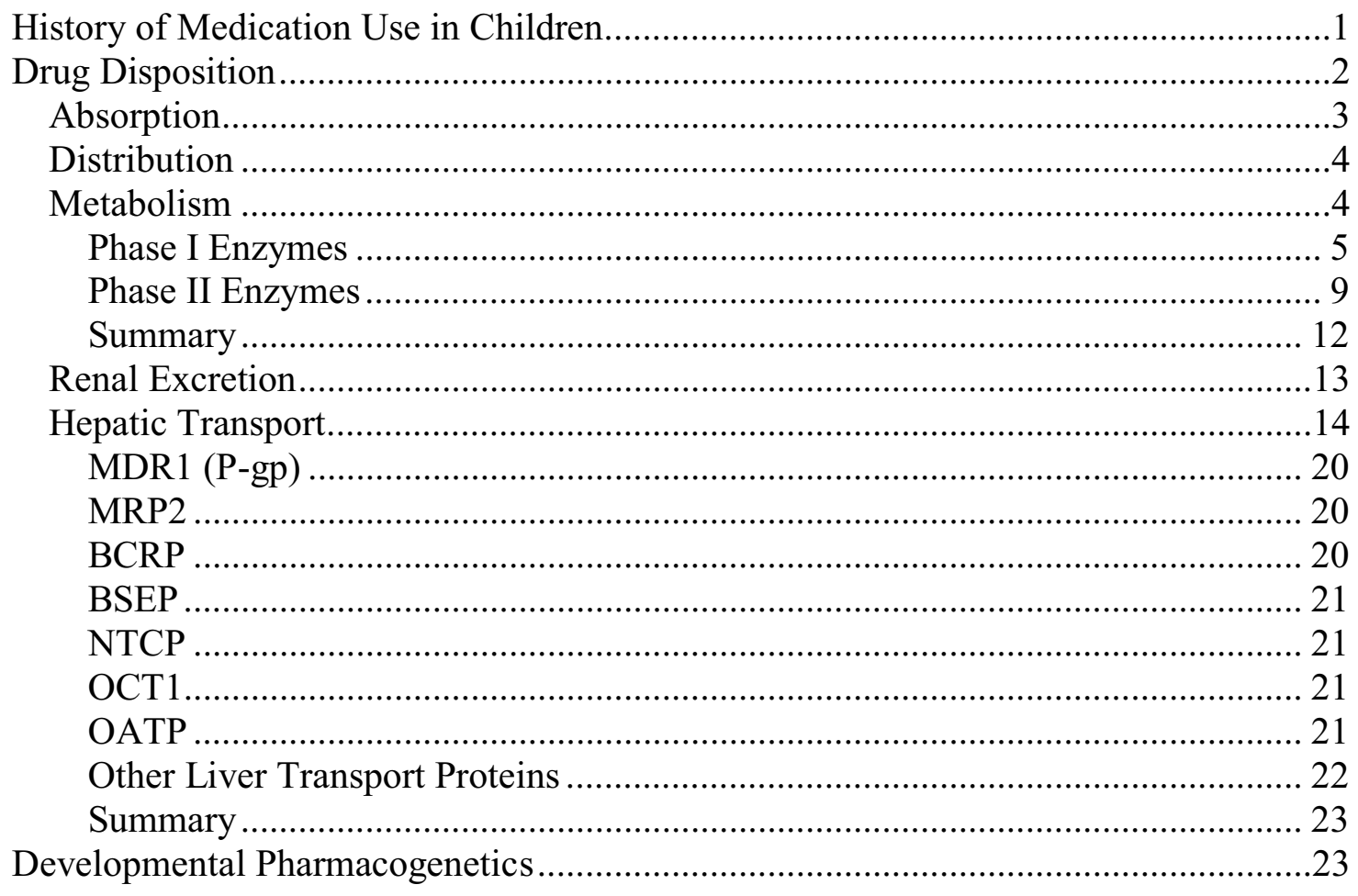

CHAPTER 2. HYPOTHESIS AND SPECIFIC AIMS ..................................................26

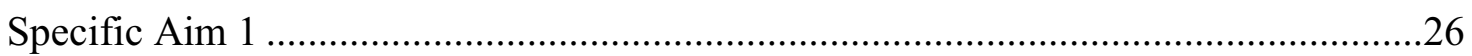

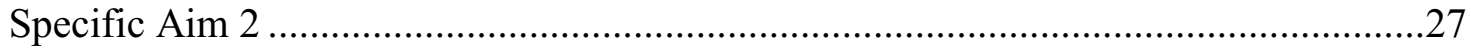

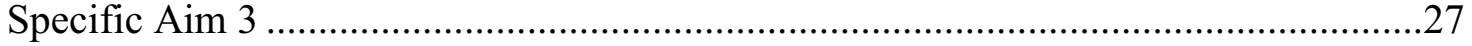

\section{CHAPTER 3. EXPRESSION PATTERNS OF OATP1B1 AND OATP1B3}

PROTEIN IN HUMAN, PEDIATRIC LIVER ............................................................28

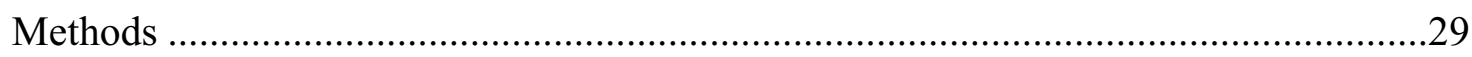

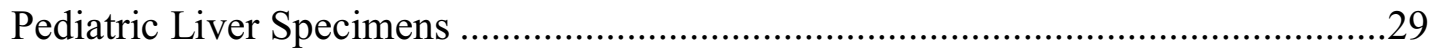

Relative Protein Quantification..............................................................................29

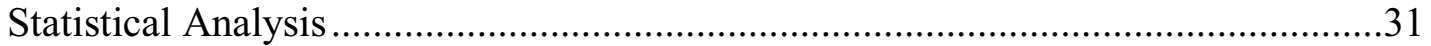

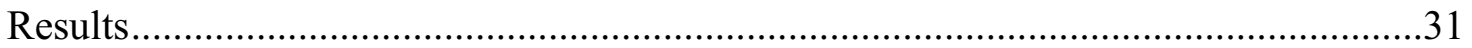

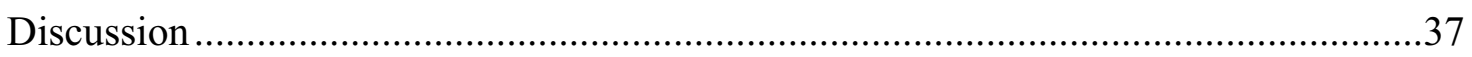

CHAPTER 4. GENENTIC VARIABILITY OF OATP1B1 AND OATP1B3 .............40

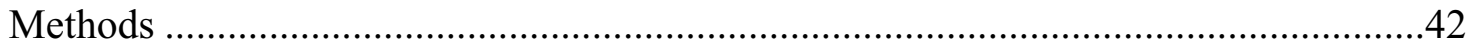

Pediatric Liver Specimens ……………........................................................42

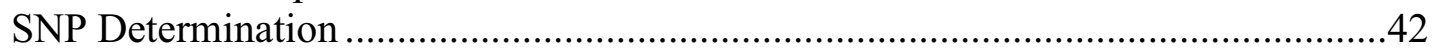

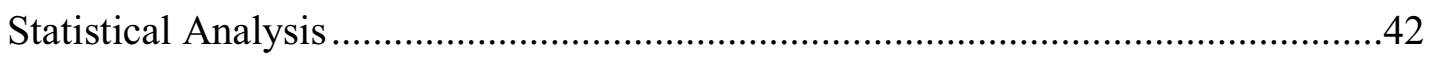

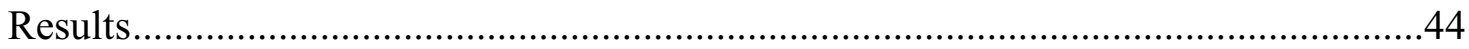


Discussion

\section{CHAPTER 5. FEXOFENADINE DISPOSITION IN OATP1B2 KNOCKOUT}

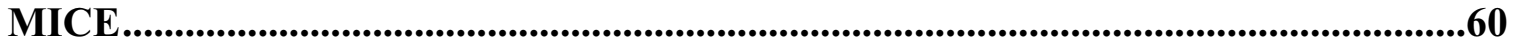

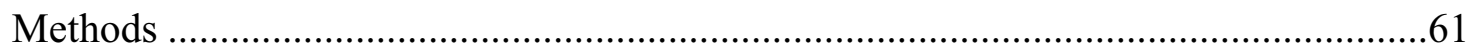

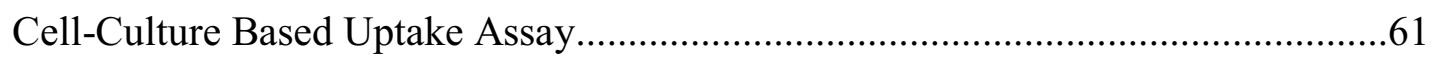

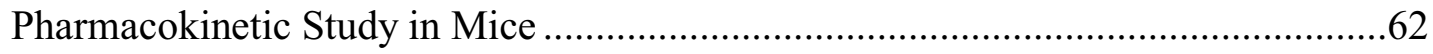

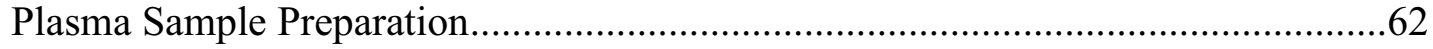

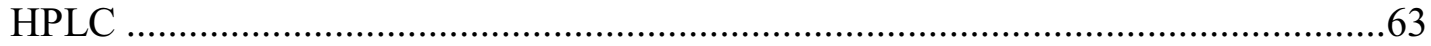

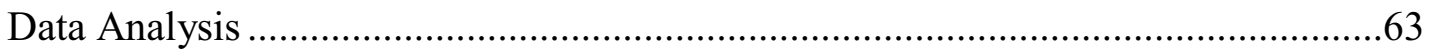

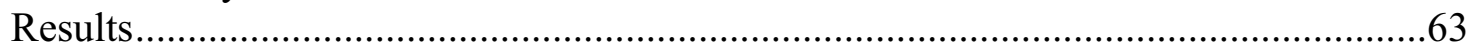

Cell-Culture Based Uptake Assay..................................................................63

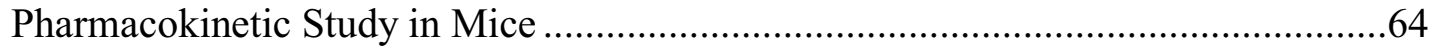

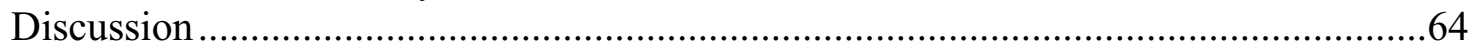

CHAPTER 6. SUMMARY ..........................................................................................72

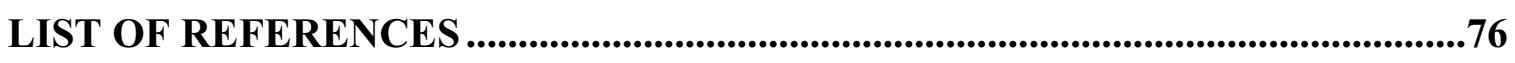

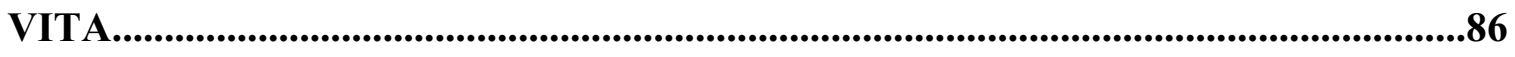




\section{LIST OF TABLES}

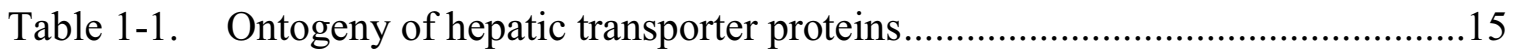

Table 3-1. Demographic information of study individuals ........................................30

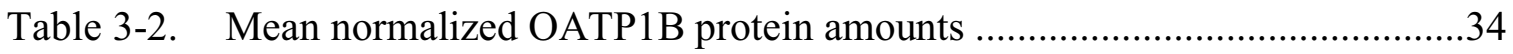

Table 4-1. PCR primers used for allelic discrimination assay ...................................43

Table 4-2. Allelic frequencies for OATP1B1 SNPs $388 \mathrm{~A} \rightarrow \mathrm{G}$ and $521 \mathrm{~T} \rightarrow \mathrm{C} \ldots \ldots \ldots . . . .45$

Table 4-3. Allelic frequencies for OATP1B3 SNPs $334 \mathrm{~T} \rightarrow \mathrm{G}$ and $699 \mathrm{G} \rightarrow \mathrm{A} \ldots \ldots \ldots \ldots . . . . .46$

Table 5-1. Pharmacokinetic parameters of fexofenadine after IV bolus into wild-

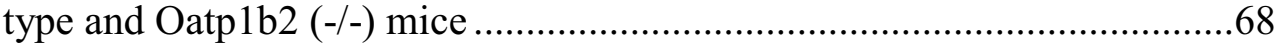




\section{LIST OF FIGURES}

Figure 1-1. Protein expression of CYP enzymes normalized to adult values .................6

Figure 3-1. Representative Western blot analysis of OATP1B1 and OATP1B3 ...........32

Figure 3-2. Box and whisker plots of OATP expression normalized to GAPDH

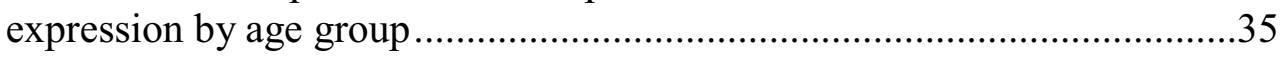

Figure 3-3. Scatter plot of OATP protein expression normalized to GAPDH protein

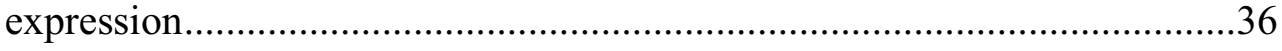

Figure 4-1. Normalized OATP1B1 protein and SNP 388 genotype ...........................47

Figure 4-2. Normalized OATP1B1 protein compared to SNP 521 genotype ................48

Figure 4-3. Normalized OATP1B3 glycosylated and non-glycosylated protein compared to SNP 334 genotype

Figure 4-4. Normalized OATP1B3 glycosylated and non-glycosylated protein compared to SNP 699 genotype

Figure 4-5. Scatterplot of normalized OATP1B1 protein expression compared to age by SNP388

Figure 4-6. Scatterplot of normalized OATP1B1 protein expression compared to age by SNP 521

Figure 4-7. Scatterplot of normalized OATP1B3 non-glycosylated protein compared to age by SNP 334.

Figure 4-8. Scatterplot of normalized OATP1B3 glycosylated protein compared to age by SNP 334

Figure 4-9. Normalized OATP1B3 non-glycosylated protein compared to age by SNP 699

Figure 4-10. Normalized OATP1B3 glycosylated protein compared to age by SNP 699

Figure 5-1. Fexofenadine uptake assay performed in mOatp1b2 and vector transfected HEK 293 cells

Figure 5-2. Individual concentration-time profiles for Oatp1b2 (-/-) mice represented by $\circ$ symbols and wild-type mice represented by $\Delta$ symbols

Figure 5-3. Average concentration-time profiles for Oatp1b2 (-/-) mice, represented by $\Delta$ symbols, and wild-type mice, represented by $\circ$ symbols. 


\section{LIST OF ABBREVIATIONS}

\begin{tabular}{|c|c|}
\hline ADE & Adverse Drug Event \\
\hline ANOVA & Analysis of Variance \\
\hline AUC & Area Under the Concentration-Time Curve \\
\hline BCRP & Breast Cancer Resistance Protein \\
\hline BSEP & Bile Salt Export Pump \\
\hline CAR & Constitutive Androstane Receptor \\
\hline $\mathrm{CL}$ & Clearance \\
\hline $\mathrm{C}_{\mathrm{t}}$ & Concentration at time $\mathrm{t}$ \\
\hline $\mathrm{C}_{0}$ & Initial Concentration \\
\hline CYP & Cytochrome P-450 Enzyme \\
\hline $\mathrm{D}$ & Dose \\
\hline DHEA-S & dehydroepiandrosterone 3-sulfate \\
\hline DMEM & Dulbecco's Modified Eagle Medium \\
\hline DNA & Deoxyribonucleic Acid \\
\hline FDA & Food and Drug Administration \\
\hline FMO & Flavin-Containing Monooxygenases \\
\hline FXR & Farnesoid X Receptor \\
\hline GAPDH & Glyceraldehyde-3-phosphate Dehydrogenase \\
\hline GFR & Glomerular Filtration Rate \\
\hline GIT & Gastrointestinal tract \\
\hline GST & Glutathione-S-Transferase \\
\hline $\mathrm{HCl}$ & Hydrochloric Acid \\
\hline HEK & Human Embryonic Kidney Cells \\
\hline HPLC & High Pressure Liquid Chromatography \\
\hline $\operatorname{IgG}$ & Immuonoglobulin $\mathrm{G}$ \\
\hline IV & Intravenous \\
\hline $\mathrm{k}$ & Elimination Rate Constant \\
\hline MATE & Multidrug and Toxin Extrusion Protein \\
\hline MDR & Multi-drug Resistance \\
\hline mMDQ & Monoclonal Antibody MDQ Clone \\
\hline mOatp & Murine Organic Anion Transporting Polypeptide \\
\hline mRNA & Messenger Ribonucleic Acid \\
\hline MRP & Multidrug Resistance Protein \\
\hline $\mathrm{NaOH}$ & Sodium Hydroxide \\
\hline NAPQI & N-acetyl-p-benzoquinone \\
\hline nmol & nanomole \\
\hline NTCP & $\mathrm{Na}+/$ Taurocholate Co-Transporting Polypeptide \\
\hline OAT & Organic Anion Transporter \\
\hline OATP & Organic Anion Transporting Polypeptide \\
\hline OCT & Organic Cation Transporter \\
\hline OST & Organic Solute Transporter \\
\hline $\mathrm{PAH}$ & p-aminohippurate \\
\hline PBS & Phosphate Buffered Saline \\
\hline
\end{tabular}




$\begin{array}{ll}\text { PBS-T } & \text { Phosphate Buffered Saline with Tween } \\ \text { PBS-T-M } & \text { Phosphate Buffered Saline with Tween and milk } \\ \text { PCR } & \text { Polymerase Chain Reaction } \\ \text { pmol } & \text { picomole } \\ \text { p-gp } & \text { p-glycoprotein } \\ \text { PVDF } & \text { Polyvinylidene Fluoride } \\ \text { PXR } & \text { Pregnane X Receptor } \\ \text { SD } & \text { Standard Deviation } \\ \text { SNP } & \text { Single Nucleotide Polymorphism } \\ \text { SULT } & \text { Sulfotransferases } \\ \text { t } & \text { Time } \\ \text { TBS-T } & \text { Tris Buffered Saline with Tween } \\ \text { TBS-T-M } & \text { Tris Buffered Saline with Tween and milk } \\ \text { UGT } & \text { Uridine 5'-diphosphate-glucuronosyltransferases } \\ V_{\text {ss }} & \text { Volume at Steady State }\end{array}$




\section{CHAPTER 1. ONTOGENY AND DRUG DISPOSITION}

Often our tiniest patients, newborns, infants and children, are given drug therapy without the full benefit of formal testing in that patient population. In these situations where there are no results from clinical trials doses are extrapolated from adult data often on the basis of size alone. Unfortunately the differences between children and adults are not just an issue of size. Children undergo many developmental changes as they mature into adults which impact drug therapy. Compounding these developmental changes is the impact of a patient's individual genetic code.

\section{History of Medication Use in Children}

The ability to medicate the youngest patients has been an ongoing struggle throughout the last century. Medication misadventures have shaped the way that drugs are administered to children through various acts of legislation. As early as 1906 medication use in infants has been a legislative issue. A syrup preparation meant to treat colic led to the death of many of the infants given the syrup due to its morphine content.[1] This incident led to the requirement that all ingredients in a preparation must be listed which had not been necessary prior to this time.[1] In an effort to solubilize the antibiotic sulfanilamide, chemists used diethylene glycol to create an elixir easy for administration to infants and children.[2] While the intent was to make a medication in a form accessible to children, tragically the result was the death of over 100 patients.[2] This incident led to the enactment of the Food, Drug and Cosmetic Act of 1938, which for the first time, required the safety of medications be demonstrated prior to marketing.[1] In the 1950s and 1960s pregnant women were given thalidomide to ease morning sickness. Unfortunately many of their offspring either died or were born with physical malformations. This incident led to more legislation requiring that medications actually demonstrate effectiveness prior to marketing.[1] In an effort to focus on the lack of information on safety and efficacy of medications in children, the FDA Modernization Act of 1997 allowed for an additional 6 months of exclusivity if pediatric trials for the medication were conducted.[3] This legislation was followed by the Pediatric Rule and the Best Pharmaceuticals for Children Act in 1998 and 2002 respectively.[3] While all of these legislations have been helpful in making medications safer they have not eliminated or focused on the cause of serious events in dosing infants and children.

The 1950s saw a condition known as Gray Baby Syndrome. Many infants given the antibiotic chloramphenicol suffered from respiratory distress, cardiovascular collapse and death.[4] Unfortunately the legislation most likely to have prevented these deaths only started to be enacted 40 years after this incident. Clinical trials would have illustrated that neonates required substantially lower doses as compared to adult patients. This finding would further emphasize that children are not miniature adults. For the case of chloramphenicol neonates have several potential physiologic differences that alter the disposition of the antibiotic which resulted in the fatally toxic concentrations seen in the 1950 's. The major route of metabolism for chloramphenicol is glucuronidation with 
several alternate pathways and final elimination from the body through urinary excretion.[5] Along with physiologic reductions in renal function, it was discovered that one of the enzymes, UDP-glucuronosyltransferase 2B7 (UGT 2B7), required for metabolizing chloramphenicol was immature in infants, and the resulting diminished UGT 2B7 increased systemic exposure resulting in toxicity.[6]

While most of the focus in drug disposition and ontogeny is aimed at avoiding toxicity in children, there are a few examples of drugs which appear to be "safer" in children as compared to adults. One such example is acetaminophen. This medication undergoes extensive conjugation either by glucuronidation or sulfation. A small percentage of the drug is converted by CYP 2E1 to a toxic entity, N-acetyl-pbenzoquinone (NAPQI), which if not conjugated to glutathione causes severe liver injury and possible death. It has been noticed that young children tend to fare much better than adults when overdosed with acetaminophen. The reasons for the protection from acetaminophen toxicity are believed to be due to differences in metabolism - reduced glucuronidation, increased sulfation, decreased CYP 2E1 metabolism, as well as increased liver size relative to body size.[5, 7] In other words, the immaturity of the drug disposition systems in children can in some rare cases offer protection.

This brief introduction on the history of medication misadventures in children is meant to underscore the importance and need for extensive studies of novel and established medications in pediatric populations to facilitate safer pharmacotherapy in children. As the examples of chloramphenicol and acetaminophen illustrate, an understanding of the normal physiologic growth and development of infants and children will help designing safer and more appropriate dosing regimens for these patients. The remainder of this introduction will focus on the drug disposition processes and their development in children as well as how individual genetics may influence drug disposition.

\section{Drug Disposition}

There are many dramatic changes that occur in the pediatric population especially in the first months and years of life. Within the neonatal intensive care unit there is a one $\log$ difference in weight ranging from 0.5 to $5 \mathrm{~kg}$.[8] There is another one log weight difference seen in the regular pediatric population of term neonates to adolescents. [8] In the normal course of development a neonate will double the body weight within four months and triple it within the first year of life. [8] These changes in weight are also accompanied by corresponding changes in size or length. The growth rate during the last trimester of pregnancy and the first few months of life is estimated to be $10-20 \mathrm{~cm} /$ year which is even at least twice the rate seen in adolescence.[8] These very visible examples illustrate that infancy, especially the first few months, are very dynamic. There are numerous physiologic changes that occur internally that impact the functionality of all systems including those involved in drug disposition. The following sections will describe the development of the drug disposition. While drug disposition will be discussed in terms of individual components it is important to recognize that these 
components work in concert to ultimately remove administered medications from the body.

\begin{abstract}
Absorption
The absorption process simply involves the movement of medication across a barrier. The process relies largely upon the thickness of the barrier, concentration of the medication, and the state of ionization of the medication. Most often medications are given orally to patients which mandates that the medication must be absorbed by the gastrointestinal tract (GIT). The stomach is the site where the medication will undergo most of its dissolution, if not already in liquid solution. This is also a site where medication can undergo ionization. While predicting the absorption of orally administered medications during the first days of life is difficult, it is much more so after that first week of life. Adults have an acidic environment in the stomach. Neonates are born with a stomach environment that is neutral in terms of $\mathrm{pH} .[9,10]$ This neutral $\mathrm{pH}$ rapidly becomes acidic in the 48 hours of life but turns neutral again within another 24 hours.[10] The stomach environment in the infant eventually declines back to the acidic $\mathrm{pH}$ characteristic of older children and adults which can take 18-24 months.[7, 10] The $\mathrm{pH}$ environment is essential in determining the ionization status of orally administered medications. These changes in $\mathrm{pH}$ alter the extent of absorption for acid labile and weak acid drugs.[10] Infants experience much greater absorption of acid labile drugs such as penicillin $\mathrm{G}$ and erythromycin compared to older children and adults. [9, 10] The shift towards more ionization of weak acid drugs such as phenytoin or phenobarbital decreases the extent of absorption for these types of medications. $[9,10]$
\end{abstract}

The stomach may be considered a holding vessel for the medication which relies upon contractions to allow for entry into the small intestine. In neonates this residence time in the stomach is prolonged due to decreased motility and peristalsis.[11, 12] This decrease in gastric emptying time delays entry into the small intestine which is where most absorption occurs resulting in a decrease in the rate of absorption and an increase in time to peak concentration. $[10,11]$ While neonates experience a decrease in gastric emptying, older infants display the opposite phenomenon with an increase in gastric emptying.[10] The small intestine is the site of most absorption for orally administered medications. There are several other factors related to the intestine that may also impact absorption of orally administered medications. The surface area of the intestine has been mentioned as a source of reduced absorption in neonates. A decrease in surface area would result in decreased absorption. The length of villi in the small intestine appear to be fully formed by the end of the second trimester which makes this unlikely to be a contributing factor to decreased absorption seen for many orally administered medications in infants.[12] There may be some support for decreased blood flow across the intestine which would contribute to smaller concentration gradients for medications and an associated decrease in absorption.[12] The biliary system is still developing at birth which results in decreased absorption of lipophilic medications.[12] The bacterial composition of the intestine is different in infants as compared to adults which may alter the amount of medication available for absorption. $[12,13]$ 


\section{Distribution}

Distribution or rather the volume of distribution is a measure of where medication is stored in the body while awaiting for removal. There are several factors that determine the size of physiological spaces available for medication to be stored including total body water, fat stores and protein concentrations. Neonates have an increased total body water to body fat ratio. $[9,12]$ Total body water in neonates is approximately $80-90 \%$ of total body weight while total body water in adults comprises $55-60 \%$ of total body weight.[10, 14] These changes in total body water carry over to individual compartments such that extracellular water is also increased in the neonate at 45\%.[14] In adults extracellular water is $20 \%$ of body weight.[14] These changes in body water alter the physiological spaces that medications are able to enter. Hydrophilic medications have a larger space available in neonates. This larger volume of distribution necessitates much larger loading doses per kilogram for medications such as gentamicin or phenobarbital in neonates as compared to adults.[9]

Changes in body water composition are not the only alterations in distribution seen in neonates. Many medications bind to circulating plasma proteins. Concentrations of albumin and $\alpha 1$-acid glycoprotein, the most common plasma proteins bound to medications, are decreased in neonates.[15] Concentrations of unbound medication are higher than seen in properly nourished, otherwise healthy adults due to the decrease in binding capacity seen with the decreased protein concentrations. For many medications the percentage unbound remains relatively constant within the therapeutic range which allows for a straightforward approach to calculating the unbound concentration of medication. Several medications such as valproate acid and phenytoin saturate albumin binding capacity within the therapeutic range meaning that the free, unbound concentrations cannot be predicted if there are even minor changes in dose or protein concentrations. An added complication to changes in protein concentrations and binding capacities is competition for binding. Endogenous substances such as bilirubin also bind to albumin. In the neonate there is an increased presence of bilirubin, combined with lower albumin concentrations there is a decreased capacity to bind to medications. [16, 17] Higher unbound concentrations of protein bound medications in neonates result due to the differences in protein concentrations between neonates and adults.

\section{Metabolism}

Metabolism refers to chemical changes that occur to medications in order to aid in the removal from the body. These chemical modifications increase the water solubility of substances such that they can be excreted in the urine. $[5,18,19]$ The modifications are carried out by enzymes situated on the endoplasmic reticulum of the liver (or other organs such as small intestine).[7,20] The smooth endoplasmic reticulum is consistently seen in the fetus from 12 weeks and continues to develop throughout gestation. [7] Well into young childhood there is substantial hyperplasia and hypertrophy within the liver that results in a liver mass to body mass that is substantially greater in infants and young children as compared to adults.[7, 20] These findings of greater liver to body mass ratio 
in young children would suggest that they may have greater enzyme content as well. The average microsomal content in a 30 year old is estimated to be $40 \mathrm{mg} / \mathrm{g}$ liver while that for an infant is $26 \mathrm{mg} / \mathrm{g}$ liver.[7, 21] This indicates that infants for the same amount of liver they have less metabolizing capability than an adult which alters both potential efficacy and toxicity.

In addition to changes in liver size there are many other physiological changes which occur with birth. In the fetal liver there is a patent ductus venosus which shunts blood from the umbilical vein to the inferior vena cava bypassing most of the liver cells.[18] The closure of the ductus venosus substantially changes liver blood flow. In the fetal liver blood flow is comprised mostly of the umbilical vein $(70 \%)$, hepatic artery $(10 \%)$ and the portal vein (25\%).[18] After birth there is a transition in blood flow such that it is comprised of the portal vein $(75 \%)$ and hepatic artery $(25 \%)$ which is a significant reduction in oxygenated blood reaching the liver.[18] These physiological changes are important in that they affect the delivery of blood and substances in need of removal to the liver. The main focus of drug removal in the liver is metabolism, of which there are two types - Phase I and Phase II - as well as biliary excretion.

\section{Phase I Enzymes}

Phase I metabolism involves the chemical transformation of a substance such that it is more water soluble.[18, 22] These transformations are often the precursor for Phase II reactions which result in easy removal from the body in urine.[22] The most common enzymes involved in Phase I reactions are the Cytochrome P450 (CYP) enzymes, although there are others that will be discussed as well. The investigation into the ontogeny of the drug metabolizing enzymes has led to a classification system. This system has grouped the enzymes into three categories: (1) those that are present at high levels in the fetus and/or at birth and decrease expression in early childhood, (2) those that have mostly consistent levels with no discernible pattern throughout childhood, and, (3) those that have low expression at birth and increase expression throughout childhood.[7] Figure 1-1 illustrates protein expression of several CYP enzymes for different time points after birth normalized to adult expression values. As will be discussed, enzymes within a particular family appear to work in concert with one another such that one isoform dominates early after birth and then decreases expression while another isoform from the same family has low expression early after birth and increases expression throughout infancy and childhood.

CYP1A. The CYP1A family consists of 2 members CYP1A1 and CYP1A2.[7] CYP1A1 is considered the fetal isoform of the CYP1A family in that it is expressed during the first trimester of pregnancy.[7, 22] There is inconsistent evidence for the expression of CYP1A1 during the second and third trimesters.[7] CYP1A2 is the major CYP1A isoform found in human, adult liver responsible for the metabolism of methylxanthine substrates, such as caffeine and theophylline.[18] CYP1A2 has not been found in fetal liver samples and is not detected in newborn liver samples until 1-3 months after birth making this CYP enzyme the last to be expressed in children.[22] Expression increases such that levels reach adult levels in late infancy and exceeds those values 


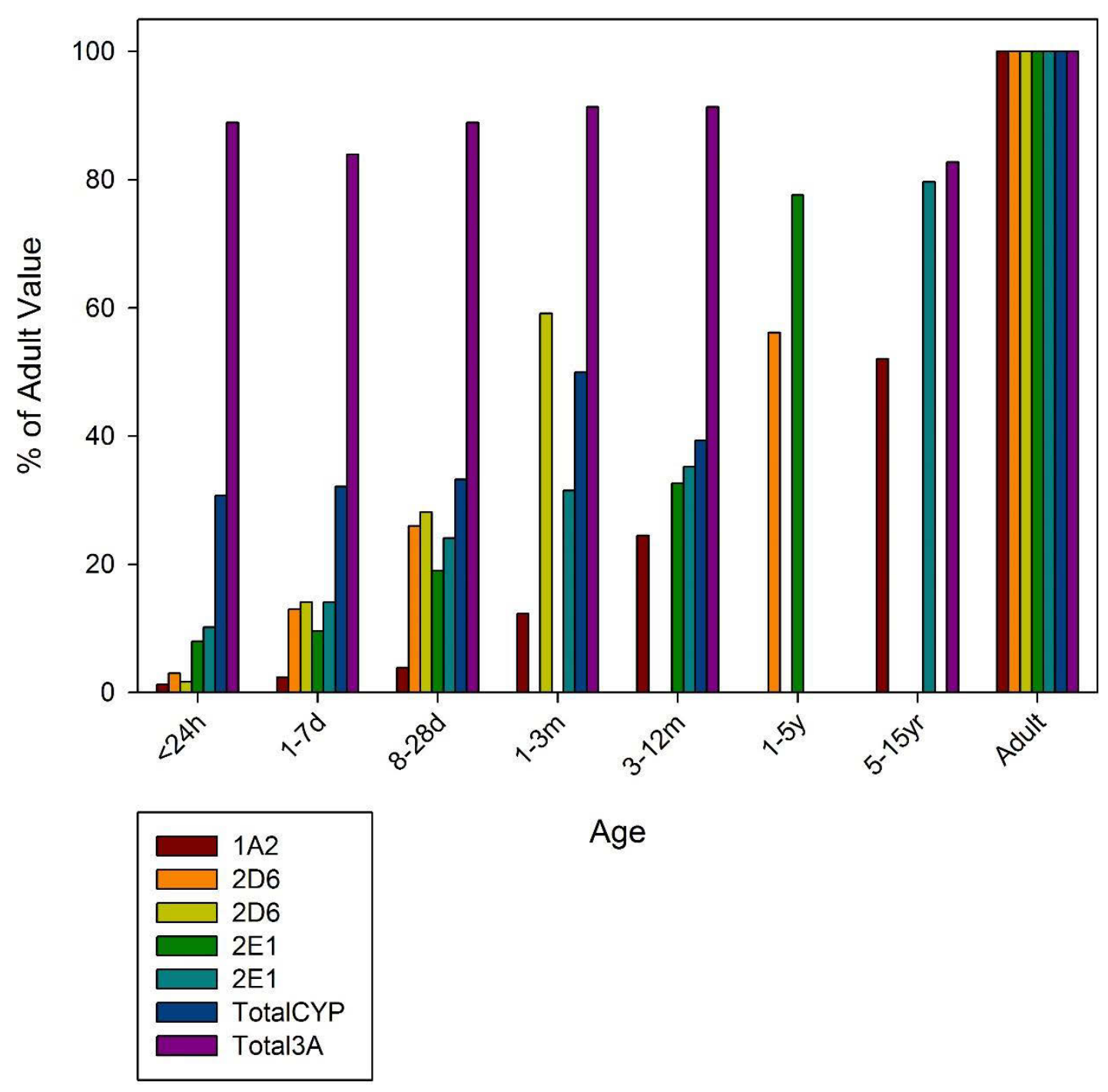

Figure 1-1. Protein expression of CYP enzymes normalized to adult values

Protein expression data was obtained for CYP1A2 (red bar), CYP2D6 (orange and yellow bars), CYP2E1 (green and light blue bars), Total CYP content (dark blue bar), and Total CYP3A content (purple bar). All time points are relative to time after birth.

Data Source: Alcorn, J. and P.J. McNamara, Ontogeny of hepatic and renal systemic clearance pathways in infants: part I. Clin Pharmacokinet, 2002. 41(12): p. 959-98.[18] 
during most of childhood.[12, 18] Activity of CYP1A2 mimics that of expression. Caffeine clearance reaches adult values at about 6 months of age.[9] Clearance of caffeine is $150 \%$ of adult values between 3-9 years, and $133 \%$ of adult values between 915 years. [9, 20] In addition to developmental acquisition of CYP1A2, environmental factors can induce expression of this enzyme making expression highly variable.[10] The most basic environmental factor influencing expression is exposure to infant formula. Breastfed infants have a longer caffeine half-life compared to formula fed infants.[7, 20] Exposure to cruciferous vegetables, such as broccoli, carrots, charcoal grilled meats, cigarette smoke, and the proton pump inhibitor omeprazole have resulted in the induction of CYP1A2 with anticipated increases in clearance for CYP1A2 substrates.[20]

CYP2C. The pharmacologically important isoforms of the CYP2C family in human liver consist of $\mathrm{CYP} 2 \mathrm{C} 8,2 \mathrm{C} 9,2 \mathrm{C} 18,2 \mathrm{C} 19$. These isoforms are responsible for the metabolism of almost $20 \%$ of medications including ibuprofen, warfarin, omeprazole, diazepam, and phenytoin. [7, 23] CYP2C is minimally expressed in the fetus but has a marked increase within 24 hours after birth.[18,22] By 1 month of age expression of CYP2C is approximately a third of adult expression.[18] When the ontogenic profile for individual isoforms was examined, increases in expression could be attributed to increases in CYP2C9 expression that had large inter-individual variability in the first months of life.[23] CYP2C19 had a higher percentage of expression measured to adult values when compared to CYP2C9. Expression of CYP2C19 is relatively stable throughout the gestation with increasing levels after birth.[23] Non-linear increases in CYP2C19 expression with large inter-individual is seen in CYP2C19 expression between 5 months and 10 years of age from $50-75 \%$ of adult values to adult values. [7, 23] CYP2C8 protein has not been detected in fetal liver samples although mRNA has been found.[20]

With approximately $20 \%$ of medications being metabolized by the CYP2C family, there are several medications commonly used in neonates that are CYP2C substrates. Phenytoin, an anticonvulsant, metabolized predominantly by CYP2C9 requires monitoring in adult patients and this requirement is intensified in the neonate. The half-life of phenytoin in premature neonates is $75 \mathrm{~h} .[5,12]$ This value decreases to $20 \mathrm{~h}$ in the term neonate and is approximately $8 \mathrm{~h}$ after 2 weeks of life when saturable, dose-dependent clearance is acquired.[5, 12] Between 3-10 years CYP2C9 substrates have greater $\mathrm{mg} / \mathrm{kg}$ dose requirements as compared to adults. [20] While this could be the result of increased enzyme activity in these young children, it could also be the result of increased liver size in young children relative to body size. Regardless of the cause the dose of a CYP2C9 substrate for a young child is much larger relative to body size compared to adults.

The delayed acquisition of CYP2C19 can be exemplified by the metabolism of diazepam. The half-life of diazepam in neonates has been measured at $50-90 \mathrm{~h}$ which is reduced to approximately $45 \mathrm{~h}$ by 1 year of age.[10] The urinary excretion of diazepam metabolites also demonstrates a delay in maximum CYP2C19 activity with increases in excretion after 1 week of life.[18] The diazepam-related toxicity of lethargy and weight 
loss seen in neonates who have received diazepam through breastmilk has been attributed to decreased CYP2C19 activity.[5]

CYP2D. CYP2D accounts for approximately $2 \%$ of total CYP content but is responsible for the metabolism of many medications. [7] The list of medications metabolized by CYP2D6 includes tricyclic antidepressants (amitriptyline), selective serotonin reuptake inhibitors (fluoxetine), beta blockers (propranolol), antitussives (dextromethorphan), and opioid analgesics (codeine, oxycodone, hydrocodone). When examining protein expression in liver samples from fetuses less than 30 weeks, studies have found little to no protein expression.[7] Protein expression of CYP2D6 increases after birth with expression levels at approximately 5\% of adult levels 7 days after birth and $30 \%$ by 1 month after birth.[24] This increase after birth occurs regardless of gestational age indicating that the increase in protein expression is triggered by birth itself.[25] These findings were confirmed in a study looking at protein expression and dextromethorphan O-demethylase activity in liver samples from donors 8 weeks postconception to 18 years old.[25] Samples from fetal donors had lower protein expression and activity as compared to those from donors aged 0-7 days and those aged greater than 7 days.[25] In another study assessing dextromethorphan conversion in infants at $0.5,1$, $2,4,6$, or 12 months of age it was found no significant difference in activity amongst any of the age groups.[26] These findings are not inconsistent with the previous study using liver samples as they could not break the samples from 7 days to 18 years into smaller groupings.

CYP3A. The CYP3A family is comprised of CYP3A4, CYP3A5, and CYP3A7 which share over 80\% homology.[27] Together these isoforms constitute approximately $30 \%$ of total CYP content yet metabolize approximately $50 \%$ of medications. [18] While these three isoforms work in an apparent organized fashion; the three isoforms are not expressed together. CYP3A7 has been labelled the fetal CYP3A isoform.[18] This isoform is detected in fetal liver as early as 50-60 days gestation.[22] CYP3A7 is involved mostly in the metabolism of endogenous substances. These substances include estriol which plays a role in the development of the fetus as well as determining the timing of parturition, as well as cis- and trans- retinoic acid.[12, 20] CYP3A7 provides the fetus protection from potential toxicity from retinoic acid.[5] DHEA-S hydroxylation is carried out by CYP3A7.[28] High concentrations of DHEA-S inhibits cell proliferation, hence the metabolism of this substance is protective in the developing fetus.[5] This activity can be seen in fetuses 10-20 weeks and peaks 1-7 days after birth.[28] By 1 year DHEA-S hydroxylation is 10\% of the peak value.[28] Expression of CYP3A7 peaks two weeks after birth and decreases by half one month after birth.[7, 20] During the second trimester CYP3A7 protein expression using microsome preparations from fetal liver samples has been measured at $311 \mathrm{pmol} / \mathrm{mg}$ protein.[29] CYP3A7 protein expression decreased in the third trimester to $201 \mathrm{pmol} / \mathrm{mg}$ protein.[29] By one year of age CYP3A7 expression is undetectable in most individuals with protein expression measuring less than $5 \mathrm{pmol} / \mathrm{mg}$ protein.[27, 29]

At the time that CYP3A7 expression is waning, expression of CYP3A4 is starting to rise. CYP3A7 expression remains higher than that of CYP3A4 until 6 months of 
age.[10] While there is a surge of CYP3A4 expression the week following birth, mRNA expression remains only $50 \%$ of adult values at a year.[18, 20] The acquisition of CYP3A4 has been tracked in vivo using probe substrates. Midazolam, a benzodiazepine used for sedation, is metabolized by CYP3A4 and 3A5 to 1-OH-midazolam, 4-OHmidazolam, and 1,4-OH-midazolam.[27] Over the first three months of life midazolam clearance increases from $1.2 \mathrm{ml} / \mathrm{min} / \mathrm{kg}$ to greater than $9 \mathrm{ml} / \mathrm{min} / \mathrm{kg}$ with premature neonates born prior to 39 weeks gestational age having a midazolam clearance $30 \%$ lower than those born full term.[12,28] The increase in midazolam clearance is attributed to an increase in CYP3A4 and 3A5 expression. This assertion is made due to the fact that CYP3A5 expression while exhibiting large inter-individual variability is considered to exhibit no discernible expression pattern as opposed to both CYP3A7 and CYP3A4 which have very pronounced expression patterns.

CYP2E. CYP2E1 is known primarily for the metabolism of ethanol as well as the conversion of acetaminophen to its toxic metabolite, $\mathrm{N}$-acetyl-p-benzoquinone, although it also is responsible for the metabolism of several anesthetics such as halothane, sevoflurane and isoflurane. Detection of protein increases throughout the second and third trimesters of pregnancy.[30] Protein levels increase within the first 24 hours after birth reaching approximately $10 \%$ of adult levels. $[7,18]$ During infancy and childhood CYP2E1 protein levels continue to increase reaching a third of adult levels by a year of age and approximating adult levels by 10 years of age.[22]

FMO. The flavin-containing monooxygenases (FMO) is a family of enzymes of which FMO1 and FMO3 are considered the only isoforms expressed in the liver. These isoforms are responsible for the metabolism of many mediations including the antihistamines ranitidine and promethazine which are used frequently in young children.[20, 31] FMO1 protein expression has been found to be highest at the end of the first trimester at $7.8 \mathrm{pmol} / \mathrm{mg}$ protein with declining expression throughout the remainder of gestation to $2.1 \mathrm{pmol} / \mathrm{mg}$ in the third trimester.[31] Within days after birth FMO1 expression was not detected in most samples examined.[31] FMO3 expression appears to be multi-phasic. Expression of FMO3 is not detected during the second and third trimesters.[31] Although there is large inter-individual variability in terms of onset of FMO3 expression, most samples had detectable FMO3 by 1 year of age with steady increases in expression until approximately 11 years of age.[31] In the first weeks following birth FMO3 expression is $1.1 \mathrm{pmol} / \mathrm{mg}$ which increases to $4.7 \mathrm{pmol} / \mathrm{mg}$ by approximately 1 year.[31] The onset of puberty seems to trigger an increase in FMO3 expression with an increase in expression from $12.7 \mathrm{pmol} / \mathrm{mg}$ at the beginning of puberty to $26.9 \mathrm{pmol} / \mathrm{mg}$ by adulthood.[31] The birthing process appears to be an important switch in terms of FMO expression with the cessation of FMO1 expression within days of birth.

\section{Phase II Enzymes}

After undergoing transformation by phase I enzymes many substances will then undergo phase II transformation. Phase I transformation provides a hook, a functional group, onto which a molecule that enhances water solubility may be attached if such a 
functional group is not already present on the drug molecule.[18] The addition of these small molecules to the drug is meant to enhance removal from the body. Phase II conjugation may result in elimination of the drug metabolite in the urine or feces either passively or through active transport mechanisms. [6] While the reactions of these enzymes are understood, the ontogeny of these enzymes and the impact that development has on drug disposition in infants and children has not been fully examined. The following paragraphs provide a summary on the known development of three of the most common Phase II enzymes.

$\boldsymbol{U G T}$. Uridine 5'-diphosphate-glucuronosyltransferases (UGT) are responsible for the transfer of glucuronic acid to substrates rendering them water soluble for easier elimination from the body. There are four families of UGT enzymes with the UGT1 and UGT2 families being the most important in the drug disposition. [32] Within the UGT1A family there are UGT1A1, UGT1A3, UGT1A4, UGT1A6, UGT1A9, and UGT1A10 which are the result of alternative splicing of a unique exon 1 and shared exons 2-5.[33] This alternate splicing allows for a broad but overlapping substrate specificity which includes substrates such as bilirubin, ethinyl estradiol, estrone, amitriptyline, acetaminophen, naproxen, and propofol.[33] The UGT2 family is most notably represented by UGT2B7 and UGT2B17 responsible for the glucuronidation of testosterone, androsterone, morphine, midazolam, lorazepam, and propranolol.[33] The multiple isoforms of each UGT family allow for a diverse substrate pool which makes this superfamily of enzymes important not only for the disposition of endogenous substrates but also for that of medications. Several of these substrates, such as bilirubin, are extremely important in the neonate which makes understanding the ontogeny of these enzymes critical.

As the UGT enzymes are responsible for the glucuronidation of many clinically useful substrates, the ontogeny of the individual enzymes has been investigated in detail. Many of the conclusions drawn about the development of glucuronidation have been from microsomes obtained from pediatric, adult, and fetal liver samples used to measure activity of the enzymes. Protein levels of UGT1A1, UGT1A6, and UGT2B7 in children 6 months of age and older were found to be similar to those found from adult samples.[34] An investigation of mRNA levels of 13 UGT enzymes gave similar results with the exception of UGT1A9 and UGT2B4 which both showed lower expression from $6-18$ months and 6--24 months respectively.[34] These findings are limited in the fact that there were only 16 pediatric samples in the age range of 6-24 months used in the study, thereby missing the crucial months immediately following birth. [34] Protein levels, in 50 samples from donors aged 13 days- 20 years, of UGT1A1 and UGT1 A6 also showed expression similar to adults.[35]

When development is assessed using enzyme activity a more complicated pattern emerges. Investigation into the development of activity includes microsomes from younger donors routinely incorporating fetal and neonatal samples; however, older samples tend to be lacking. This approach provides useful information in the same way that examining mRNA or protein is useful; but, in the case of UGT enzymes both approaches leave an incomplete picture. Overall UGT expression is first detected in the late second to early third trimester of gestation with maturation occurring anywhere from 
3 months to 20 years depending upon the individual isoform.[36] UGT1A1 activity towards bilirubin increases immediately after birth with adult levels reached between 3-6 months.[35, 36] UGT1 A3 levels are approximately $30 \%$ of adult activity in samples from fetal and neonatal donors. [33, 36] It is unknown when mature UGT1 A3 activity is acquired. By 6 years of age $80 \%$ of UGT1 A4 activity is reached with full maturation occurring sometime after puberty.[36, 37] In microsomes from donors aged 13-24 months activity towards amitriptyline, a UGT1A3 substrate, was 16 fold lower than that from adult donors.[34] Activity of fetal UGT1 A6 has been found to be as high as $10 \%$ of mature levels with $50 \%$ acquired by 6 months after birth.[33] Full maturation is achieved after puberty.[35, 36] Activity towards 4-tert-butylphenol, a UGT1A6 substrate, was 40 fold lower in microsomes from donors aged 13-24 months as compared to adult donors.[34] Neonatal UGT1A9 has approximately $50 \%$ of mature activity with full acquired by 12 months of age.[36] Weight normalized activity shows that young children exhibit higher activity towards UGT1A9 substrates compared to adults resulting in higher doses required for UGT1 A9 substrates such as propofol.[36, 38] Children aged 1-11 years have a body-weight normalized clearance of propofol that is $20-50 \%$ higher than adults.[33] Little is known about the development of UGT2B4 other than at 2 years of age less than $50 \%$ of mature levels have been achieved with the remainder of development remaining a mystery.[36] Fetal UGT2B7 has 10-20\% of mature activity.[36] The remainder of development remains equivocal with reports indicating that mature activity is achieved anywhere from 2 months to 20 years of age.[36] Body weight normalized clearance values of lorazepam were similar between children aged 2.3-17.8 years but when clearance was normalized to body surface area clearance was lower in children.[33] In microsomes from donors aged 13-24 months activity towards ibuprofen and buprenorphine, both UGT2B7 substrates, was 24 and 12 fold lower respectively than that from adult donors.[34] Microsomes obtained from fetuses in the second trimester only registered activity $10-20 \%$ of adult microsomes in morphine glucuronidation.[20] Very little is known about the development of UGT2B17. It is detected in fetal livers with activity less than $10 \%$ of mature values which approaches $10 \%$ in neonates.[36]

SULT. Sulfotransferases (SULT) are responsible for the addition of inorganic sulfate to hydroxyl groups that have either been created by Phase I metabolism or are a natural part of the substrate.[18] There are 11 distinct isoforms of SULT although only SULT1 A1, SULT1A3, SULT2A1, and SULT2E1 appear to have been studied in any depth in regards to ontogeny.[20] There is some substrate overlap between UGT and SULT as exemplified by acetaminophen metabolism.[18] The urinary excretion ratio of acetaminophen-glucuronide versus acetaminophen-sulfate shows a shift from sulfation in neonates with a ratio of 0.39 towards glucuronidation in adults with a ratio of 0.1.8.[39] The shift towards acetaminophen glucuronidation appears to be gradual with a ratio of 0.75 in 3-9 year olds and 1.61 in 12 year olds.[39] The activity of SULT1A3 and SULT1A1 were examined using dopamine and p-nitrophenol, respectively.[6] SULT1A3 activity towards dopamine was found to be higher in fetal liver tissue compared to adult tissue activity, with highest activity found in the second trimester and decreasing thereafter.[6] The converse was found to be true with SULT1A1 in which activity was low early in development and increases towards adult values had not been seen by 1.5 
years.[6] Protein expression of SULT1A1 exhibited no differences amongst the age range 8 weeks gestation to 18 years, although large inter-individual variation was seen within the groupings.[40] SULT2A1 also showed large inter-individual variability in protein expression. Protein expression increased from a fetal level of $7.4 \mathrm{ng} / \mu \mathrm{g}$ cystolic protein to a postnatal level of $178.4 \mathrm{ng} / \mu \mathrm{g}$ cystolic protein.[40] The last SULT for which there is ontogeny information is SULT1E1. Protein expression for SULT1E1 is highest during gestation with a level of $7.8 \mathrm{ng} / \mu \mathrm{g}$ cystolic protein which decreased by half at 1 year and then decreased by yet another half by 18 years with a level of $2.3 \mathrm{ng} / \mu \mathrm{g}$ cystolic protein.[40] These findings suggest that SULT1A3 and SULT1E1 are important during fetal development but there is a transition that occurs in early postnatal life that makes SULT1A1 and SULT2A1 the main enzymes responsible for sulfation in the adult.

GST. There are thirteen members of the glutathione S-transferase family of enzymes organized into five classes. $[18,20]$ These classes are $\alpha$ (GSTA), $\mu$ (GSTM), $\pi$ (GSTP), $\Theta$ (GSTT), and $\zeta$ (GSTZ).[6] Members within a particular family are able to dimerize with other members within the same family but not with members of a different family. GSTA1 protein has been detected in liver samples from donors as early as 10 weeks gestation. These levels increased in the first 1-2 years after birth by 1.5 -fold to attain adult values.[6] GSTA2 shares a similar development pattern with protein detected at 10 weeks gestation and increasing by 4 -fold after birth to achieve adult values. [6] Following in the same development pattern, GSTM is minimally expressed during gestation but increases 5-fold at birth.[6] GSTP1 has the highest expression during the second trimester with decreasing expression levels thereafter.[6] In the neonate GSTP1 was minimally detected and was not detected in the adult.[6] When prenatal and adult liver samples were examined with regards to 4-hydroxynon-3-enal metabolism, the metabolic rate was not found to be different between the two groups with values of 2200 $\pm 270 \mathrm{nmol} / \mathrm{min} / \mathrm{mg}$ protein and $2900 \pm 340 \mathrm{nmol} / \mathrm{min} / \mathrm{mg}$ protein, respectively.[41] The perplexing aspect of this finding is that 4-hydroxynon-3-enal is metabolized by multiple

GST isoforms which was not examined in the study. While overall GST activity may not be significantly different in different age groups the specific developmental pattern of GST isoforms is not very well understood.

\section{Summary}

As described above there are three expression patterns that are typically used to describe drug metabolizing enzymes. The first pattern has high expression in the fetus and/ or early neonatal that declines to negligible expression in early childhood.[22] The classic example of an enzyme following this pattern is CYP3A7 with expression peaking at 2 weeks after birth and subsequently declining by the first month of life. [7, 20] Other enzymes that share this expression profile are CYP1A1 and FMO1. While there are multiple isoforms of the UGT phase II enzyme family, there currently is not an isoform known to exhibit this expression pattern. The phase II enzymes SULT1A3, SULT2E1, and GSTP1 also exhibit high expression in the fetus or neonate with rapid decreases shortly after birth. 
The third expression pattern shows low expression in infancy with increasing expression throughout childhood.[22] The classic example of this expression pattern is CYP3A4 with its expression overtaking that of CYP3A7 by 6 months of age.[10] Other enzymes that fall into this category include CYP1A2, CYP2E1, and FMO3. The phase II enzymes SULT1A1, GSTA1, GSTA2, and GSTM also demonstrate low expression at birth with increasing expression throughout childhood. Most of the UGT family also shares this expression pattern.

\section{Renal Excretion}

The kidney is the primary site of excretion of most substances, endogenous, medications or metabolites. The kidney filters all water soluble substances. In addition to the normal filtration that occurs in the nephrons, the kidney is also able to reabsorb and actively secrete substances. Nephrogenesis begins at approximately 9 weeks gestation and is generally considered complete at 36 weeks gestation.[12] When nephrogenesis is complete maturation of normal nephron function dominates after birth. In the term neonate the glomerular filtration rate (GFR) is $2-4 \mathrm{ml} / \mathrm{min} / 1.73 \mathrm{~m}^{2} .[11,12]$ The first few weeks of birth see rapid increases in GFR which then slows and keeps that steady rate until almost a year of age.[12] Clinically the completion of nephrogenesis is very important for drugs and metabolites that are renally excreted. The aminoglycoside, tobramycin, which relies upon filtration for removal requires substantially different dosing intervals based on whether the neonate is premature or term.[12] The dosing interval is 24 hours in term neonates but increases to $36-48$ hours in the premature neonate.[12] In addition to the immature nephron function seen in the term neonate, the premature neonate also has incomplete nephron formation which necessitates the much longer dosing interval seen with aminoglycosides in order to decrease the risk of toxicity. GFR is determined by a number of factors including renal blood flow and protein binding of substances.[18] At birth renal blood flow is only 5-6\% of cardiac output, by one year that value approaches the adult value of $15-25 \%$.[18] The early increases in GFR can be attributed to increases in renal blood flow.[10]

Renal elimination is determined by filtration but also tubular secretion and reabsorption.[18] Tubular secretion like filtration is an immature function at birth. Secretory function approaches that seen in adults around one year.[12, 14] Various substances have been used to determine secretory function of the kidney. In adults the substance $\mathrm{p}$-aminohippurate $(\mathrm{PAH})$ can be used as a perfect marker for secretion as it is completely removed via the kidney.[14] In neonates less than 3 months of age the extraction of PAH is approximately $60 \%$ that of adult values. [18] By five months of age PAH removal approximates that of adults.[18] Clinically the development of tubular secretion has been observed with digoxin. Digoxin is a cardiac glycoside that is filtered and secreted by the kidney.[18] Infants have a digoxin clearance of $32.9 \mathrm{ml} / \mathrm{min} / \mathrm{m}^{2}$ which increases rapidly over the next three months to $88.9 \mathrm{ml} / \mathrm{min} / \mathrm{m}^{2}$ with further increases over the next year.[18] 
Renal function is an important factor when administering medications that are renally eliminated but there are some factors other than nephron function that also complicate the process. Urine output while a function of the kidney relies on other systems that undergo their own development process. The development of the cardiovascular system including increases in cardiac output and regional perfusion deliver an increasing larger blood supply to the kidneys.[8] Infants have a decreased ability to concentrate urine which will impact the ability to reabsorb substances.[18] There are multiple calculations that can be used to predict renal function in an individual infant but each method has limitations which make predictions complicated and less than ideal in certain situations. Those using serum creatinine such as Cockcroft-Gault tries to relate age, gender, and muscle mass as a surrogate for GFR. Controversy regarding the validity of this approach revolve around the use of serum creatinine especially in the first days and weeks after birth. At birth there is maternal creatinine that is still circulating in the neonate which will artificially elevate the serum creatinine value in the neonate.[10, 14] Directly measuring GFR using a probe such as inulin, which is inert, involves time, money, and active intervention with the newborn which seems wasteful when it has been determined that even in preterm neonates inulin and serum creatinine clearance correlate by 3 days.[10] The Jaffe method can interact with medications but also with endogenous substances such as bilirubin which is known to be elevated in the neonate.[10] These various obstacles reinforce that the physiology of the neonate is a dynamic entity. The changes that occur during this rapid phase of development are not on an exact time table and constant monitoring of these processes with different developmental trajectories is necessary.

\section{Hepatic Transport ${ }^{1}$}

For the liver, all transport proteins designated by the International Transporter Consortium as important for drug disposition were reviewed.[42, 43] These include the efflux transporters P-gp, BSEP, BCRP, MRP2, MRP3, MRP4, MRP6, MATE1, the uptake transporters NTCP, OATP1B1, OATP1B3, OATP2B1, OAT2, OCT1, and the bidirectional transporters OAT7 and OST $\alpha / \beta$. Similar to the other organs, this review on hepatic transporters exclusively focuses on human data, if available, but resorts to animal data in the absence of any relevant human information (Table 1-1). Similar to intestinal transporters, most published data on the ontogeny of hepatic transport proteins is available for efflux transporters, particularly P-gp.

\footnotetext{
${ }^{1}$ Reprinted with permission Brouwer, K.L., et al., Human Ontogeny of Drug Transporters: Review and Recommendations of the Pediatric Transporter Working Group. Clin Pharmacol Ther, 2015. 98(3): p. 266-87.
} 
Table 1-1. Ontogeny of hepatic transporter proteins

\begin{tabular}{|c|c|c|c|c|c|}
\hline Protein & $\begin{array}{c}\text { Human/ } \\
\text { animal }\end{array}$ & $\begin{array}{c}\text { Age range and } \\
\text { number of samples }\end{array}$ & Methods used & Major results & $\begin{array}{c}\text { Reference } \\
\text { first } \\
\text { author }\end{array}$ \\
\hline P-gp & $\begin{array}{l}\text { Human } \\
\text { Postmortem }\end{array}$ & $\begin{array}{l}\mathrm{N}=35 \\
\text { Fetal: } 14-28 \text { weeks of } \\
\text { gestation }\end{array}$ & $\begin{array}{l}\text { IHC, } \\
\text { mRNA (RNAse } \\
\text { protection assay) }\end{array}$ & $\begin{array}{l}\text { Staining for P-gp in bile canaliculi already at } 14 \\
\text { weeks of gestation. No apparent difference in } \\
\text { staining intensity in different fetal stages. Presence } \\
\text { of mRNA confirmed in one specimen (16 weeks). }\end{array}$ & $\begin{array}{l}{[44]} \\
\text { Van } \\
\text { Kalken }\end{array}$ \\
\hline P-gp & Human & $\mathrm{N}$ not determined & $\mathrm{IHC}$ & Immunopositivity of P-gp and MRP2 was & [45] \\
\hline MRP2 & Postmortem & $\begin{array}{l}\text { Fetal: } 14 \text { and } 19 \text { weeks of } \\
\text { gestation }\end{array}$ & & $\begin{array}{l}\text { localized to the canalicular membrane of } \\
\text { differentiating and mature hepatocytes. MPR2 was } \\
\text { detectable in liver of } 14 \text {-week old fetuses, but had } \\
\text { strong expression at } 19 \text { weeks. P-gp was } \\
\text { detectable at very low levels at } 14 \text { weeks, and was } \\
\text { moderately expressed at } 19 \text { weeks. }\end{array}$ & Cizkova \\
\hline P-gp & $\begin{array}{l}\text { Human } \\
\text { Postmortem }\end{array}$ & $\begin{array}{l}\mathrm{N}=3 \\
\text { Fetal: } 15,27 \text { and } 42 \text { weeks of } \\
\text { gestation }\end{array}$ & mRNA (RT-PCR) & $\begin{array}{l}\text { Expression of P-gp was detectable in the } 15 \text { week } \\
\text { samples, and gradually increased with gestational } \\
\text { age until } 42 \text { weeks. }\end{array}$ & $\begin{array}{l}{[46]} \\
\text { Fakhoury }\end{array}$ \\
\hline $\begin{array}{l}\text { P-gp } \\
\text { MRP2 } \\
\text { OATP1B1 } \\
\text { OATP1B3 }\end{array}$ & $\begin{array}{l}\text { Human } \\
\text { Postmortem }\end{array}$ & $\begin{array}{l}\mathrm{N}=72 \\
\text { Fetal: } \mathrm{N}=9(8-23 \text { wks }) \\
\text { Pediatric: } \mathrm{N}=52(0-17 \text { yrs }) \\
\text { Adult: } \mathrm{N}=11\end{array}$ & mRNA (RT-PCR) & $\begin{array}{l}\text { mRNA for P-gp expression in fetal and neonatal } \\
\text { groups was } 20 \text { - } 30 \text { fold lower than in adults. } \\
\text { Expression in infants was slightly lower than in } \\
\text { adults, with no difference between children } 1-7 \\
\text { years and adults. MRP2 mRNA was } 30 \text {-fold lower } \\
\text { in fetal, } 200 \text {-fold lower in neonatal, and } 100 \text {-fold } \\
\text { lower in infant liver compared to adults. } \\
\text { OATP1B1 expression was } 20 \text {-fold lower in fetal, } \\
500 \text {-fold lower in neonatal, and } 90 \text {-fold lower in } \\
\text { infant liver compared to adults. OATP1B3 mRNA } \\
\text { was } 30 \text {-fold lower in fetal, } 600 \text {-fold lower in } \\
\text { neonatal and } 100 \text {-fold lower in infant liver } \\
\text { compared to adults. }\end{array}$ & $\begin{array}{l}{[47]} \\
\text { Mooij }\end{array}$ \\
\hline
\end{tabular}


Table 1-1. (Continued)

\begin{tabular}{|c|c|c|c|c|c|}
\hline Protein & $\begin{array}{l}\text { Human/ } \\
\text { animal }\end{array}$ & $\begin{array}{c}\text { Age range and } \\
\text { number of samples }\end{array}$ & Methods used & Major results & $\begin{array}{l}\text { Reference } \\
\text { first } \\
\text { author }\end{array}$ \\
\hline $\begin{array}{l}\text { P-gp } \\
\text { MATE1 } \\
\text { BCRP } \\
\text { BSEP } \\
\text { MRP2 } \\
\text { MRP3 } \\
\text { MRP4 } \\
\text { MRP6 } \\
\text { OAT2 } \\
\text { OCT1 } \\
\text { OATP1B1 } \\
\text { OATP1B3 }\end{array}$ & Human & $\begin{array}{l}\text { Perinatal }(0-30 \text { days }): \mathrm{N}=6 \\
0-4 \text { years: } \mathrm{N}=8 \\
>7 \text { years: } \mathrm{N}=6\end{array}$ & mRNA & $\begin{array}{l}\text { Gradual increase in mRNA expression from } \\
\text { neonates to older children was observed for P-gp, } \\
\text { MRP2, MRP3, MRP6, NTCP, OAT2, OATP1B1, } \\
\text { OATP1B3, OCT1, BCRP, BSEP, and MATE1. } \\
\text { MRP4 expression was high in neonates, but lower } \\
\text { in older children. }\end{array}$ & $\begin{array}{l}{[48]} \\
\text { Klaassen }\end{array}$ \\
\hline P-gp & $\begin{array}{l}\text { Human } \\
\text { Postmortem }\end{array}$ & $\begin{array}{l}\mathrm{N}=12 \\
1-6 \text { months }\end{array}$ & $\begin{array}{l}\text { mRNA } \\
\text { (Northern) } \\
\text { Protein (Western) }\end{array}$ & $\begin{array}{l}\text { P-gp expression is regulated developmentally. P- } \\
\text { gp mRNA and protein were present at } 1 \text { month } \\
\text { postnatal. }\end{array}$ & $\begin{array}{l}{[49]} \\
\text { Schuetz }\end{array}$ \\
\hline $\begin{array}{l}\text { P-gp } \\
\text { MRP2 }\end{array}$ & $\begin{array}{l}\text { Human } \\
\text { Living and } \\
\text { Postmortem }\end{array}$ & $\begin{array}{l}\mathrm{N}=65 \\
0.3-0.7 \text { yrs: } \mathrm{N}=6 \\
0.7-2 \text { yrs: } \mathrm{N}=13 \\
2-5 \text { yrs: } \mathrm{N}=13 \\
5-12 \text { yrs: } \mathrm{N}=33\end{array}$ & Protein (Western) & $\begin{array}{l}\text { For P-gp, relative protein expression was not } \\
\text { significantly different among the studied age } \\
\text { groups. For MRP } 2 \text {, protein levels were } \\
\text { significantly lower in infants under } 8 \text { months } \\
\text { compared to older children. }\end{array}$ & $\begin{array}{l}{[50]} \\
\text { Tang }\end{array}$ \\
\hline $\begin{array}{l}\text { P-gp } \\
\text { OATP1B1 } \\
\text { OATP1B3 }\end{array}$ & $\begin{array}{l}\text { Human } \\
\text { Living }\end{array}$ & $\begin{array}{l}N=64 \\
7-70 \text { yrs }\end{array}$ & $\begin{array}{l}\text { Protein (LC- } \\
\text { MS/MS) }\end{array}$ & $\begin{array}{l}\text { P-gp, OATP1B1 and OATP1B3 protein } \\
\text { expression was not associated with age in the } \\
\text { studied age range. }\end{array}$ & $\begin{array}{l}{[51]} \\
\text { Prasad }\end{array}$ \\
\hline $\begin{array}{l}\text { MRP2 } \\
\text { BSEP } \\
\text { NTCP }\end{array}$ & $\begin{array}{l}\text { Human } \\
\text { Living and } \\
\text { Postmortem }\end{array}$ & $\begin{array}{l}\mathrm{N}=15 \\
\text { Fetal: } 14-20 \text { weeks of } \\
\text { gestation }(\mathrm{N}=10) \\
\text { Adult }(\mathrm{N}=5)\end{array}$ & mRNA (RT-PCR) & $\begin{array}{l}\text { NTCP mRNA was } 1.8 \% \text { of adult expression in } \\
\text { fetal liver. BSEP and MRP } 2 \text { were } 30-50 \% \text { of adult } \\
\text { expression }\end{array}$ & $\begin{array}{l}{[52]} \\
\text { Chen }\end{array}$ \\
\hline
\end{tabular}


Table 1-1. (Continued)

\begin{tabular}{|c|c|c|c|c|c|}
\hline Protein & $\begin{array}{l}\text { Human/ } \\
\text { animal }\end{array}$ & $\begin{array}{c}\text { Age range and } \\
\text { number of samples }\end{array}$ & Methods used & Major results & $\begin{array}{l}\text { Reference } \\
\text { first } \\
\text { author }\end{array}$ \\
\hline $\begin{array}{l}\text { P-gp } \\
\text { MRP2 } \\
\text { MRP3 } \\
\text { MRP4 } \\
\text { BCRP } \\
\text { BSEP } \\
\text { NTCP } \\
\text { OATP1B1 } \\
\text { OATP1B3 }\end{array}$ & $\begin{array}{l}\text { Human } \\
\text { Postmortem }\end{array}$ & $\begin{array}{l}\mathrm{N}=20 \\
\text { Fetal: } 18-23 \text { weeks of } \\
\text { gestation }(\mathrm{N}=8) \\
\text { Adult }(\mathrm{N}=12)\end{array}$ & mRNA (RT-PCR) & $\begin{array}{l}\text { All investigated transporters except for MRP4 } \\
\text { were expressed, albeit at lower mRNA levels, in } \\
\text { fetal hepatocytes compared to hepatocytes from } \\
\text { adults. }\end{array}$ & $\begin{array}{l}{[53]} \\
\text { Sharma }\end{array}$ \\
\hline MRP2 & $\begin{array}{l}\text { Human } \\
\text { Living }\end{array}$ & $\begin{array}{l}\mathrm{N}=51 \\
7-63 \text { yrs }\end{array}$ & $\begin{array}{l}\text { Protein (LC- } \\
\text { MS/MS) }\end{array}$ & $\begin{array}{l}\text { MRP2 protein expression was not associated with } \\
\text { age in the studied age range. }\end{array}$ & $\begin{array}{l}{[54]} \\
\text { Deo }\end{array}$ \\
\hline BCRP & Human & $\begin{array}{l}\mathrm{N}=35 \\
5.5 \text { to } 28 \text { weeks of gestational } \\
\text { age }\end{array}$ & $\mathrm{IHC}$ & $\begin{array}{l}\text { BCRP was detected in all stages of intrauterine } \\
\text { development under study. }\end{array}$ & $\begin{array}{l}{[55]} \\
\text { Konieczna }\end{array}$ \\
\hline $\begin{array}{l}\text { BCRP } \\
\text { BSEP } \\
\text { OATP1B1 } \\
\text { OATP1B3 } \\
\text { NTCP } \\
\text { MRP3 }\end{array}$ & Human & $\begin{array}{l}\mathrm{N}=10 \\
\text { Neonates }(\mathrm{N}=5) \\
\text { Adults }(\mathrm{N}=5)\end{array}$ & Protein (Western) & $\begin{array}{l}\text { The relative protein expression was similar } \\
\text { between neonates and adults for BSEP, BCRP, } \\
\text { OATP1B1, OATP1B3, NTCP and MRP3. }\end{array}$ & $\begin{array}{l}{[56]} \\
\text { Yanni }\end{array}$ \\
\hline BCRP & $\begin{array}{l}\text { Human } \\
\text { Living }\end{array}$ & $\begin{array}{l}\mathrm{N}=65 \\
7-70 \mathrm{yrs}\end{array}$ & $\begin{array}{l}\text { Protein (LC- } \\
\text { MS/MS) }\end{array}$ & $\begin{array}{l}\text { BCRP protein expression was not associated with } \\
\text { age in the studied age range. }\end{array}$ & $\begin{array}{l}{[57]} \\
\text { Prasad }\end{array}$ \\
\hline
\end{tabular}


Table 1-1. (Continued)

\begin{tabular}{|c|c|c|c|c|c|}
\hline Protein & $\begin{array}{l}\text { Human/ } \\
\text { animal }\end{array}$ & $\begin{array}{c}\text { Age range and } \\
\text { number of samples }\end{array}$ & Methods used & Major results & $\begin{array}{l}\text { Reference } \\
\text { first } \\
\text { author }\end{array}$ \\
\hline Ntcp & Rat & $\begin{array}{l}\text { Fetal: } 18,20,21 \text { days of } \\
\text { gestation } \\
\text { Neonatal: day } 1 \\
\text { Suckling: week } 1,2,3,4\end{array}$ & $\begin{array}{l}\text { mRNA } \\
\text { (Northern) } \\
\text { Protein (Western) }\end{array}$ & $\begin{array}{l}\text { mRNA reached adult levels at day } 7 \text {, but transport } \\
\text { activity was only } 25 \% \text { of the adult value. } \\
\text { Immunoreactive protein expression was near adult } \\
\text { levels at birth, but molecular mass was } \\
\text { substantially lower until } 4 \text { weeks of age due to } \\
\text { incomplete glycosylation. }\end{array}$ & $\begin{array}{l}\text { [58] } \\
\text { Hardikar }\end{array}$ \\
\hline $\begin{array}{l}\text { OCT1 } \\
\text { OAT2 } \\
\text { OATP1B1 } \\
\text { OATP1B3 }\end{array}$ & Human & $\begin{array}{l}\text { Hepatocytes from pediatric } \\
\text { and adult donors }\end{array}$ & $\begin{array}{l}\text { mRNA } \\
\text { Transport } \\
\text { function }\end{array}$ & $\begin{array}{l}\text { No difference in gene expression for all four } \\
\text { transporters. Uptake activity of OATP1B1 and } \\
\text { OCT1 was significantly lower in pediatric relative } \\
\text { to adult hepatocytes. OATP1B3 was significantly } \\
\text { higher in pediatric hepatocytes. }\end{array}$ & $\begin{array}{l}{[59]} \\
\text { Hayashi }\end{array}$ \\
\hline $\begin{array}{l}\text { OATP1B1 } \\
\text { OATP1B3 }\end{array}$ & $\begin{array}{l}\text { Human } \\
\text { Living and } \\
\text { Postmortem }\end{array}$ & $\begin{array}{l}\mathrm{N}=78 \\
0-0.7 \text { yrs: } \mathrm{N}=35 \\
0.7-3 \text { yrs: } \mathrm{N}=8 \\
\text { 3-6 yrs: } \mathrm{N}=13 \\
6-12 \text { yrs: } \mathrm{N}=22\end{array}$ & Protein (Western) & $\begin{array}{l}\text { OATP1B1 has low expression from birth until } 6 \\
\text { years with increased expression thereafter. } \\
\text { OATP1B } 3 \text { exhibited high expression at birth, } \\
\text { which declined over the first months of life, and } \\
\text { then increased again in the pre-adolescent period. }\end{array}$ & $\begin{array}{l}{[60]} \\
\text { Thomson }\end{array}$ \\
\hline Mrp3 & Rat & $\begin{array}{l}\text { Embryonic days } 15.5,17,19, \\
20,22 \text { and newborn ( } 22 \text { days } \\
\text { gestational age) }\end{array}$ & mRNA (RT-PCR) & $\begin{array}{l}\text { Mrp3 expression progressively increased from } \\
\sim 10 \% \text { to over } 30 \% \text { from day } 15 \text { to day } 20 \text { of } \\
\text { gestation, and increased to near } 90 \% \text { of maternal } \\
\text { expression at day } 21 \text { and after birth. }\end{array}$ & $\begin{array}{l}{[61]} \\
\text { St-Pierre }\end{array}$ \\
\hline Mrp4 & Mouse & $\begin{array}{l}\text { Postnatal days }-2,0,1,3,5 \text {, } \\
10,15,20,30,45\end{array}$ & $\begin{array}{l}\text { mRNA (bDNA } \\
\text { assay) }\end{array}$ & $\begin{array}{l}\text { mRNA expression for Mrp4 was consistent from } 2 \\
\text { days before birth to } 45 \text { days of age, except for a } \\
\text { moderate increase on day } 1 \text { of age. }\end{array}$ & $\begin{array}{l}{[62]} \\
\text { Cui }\end{array}$ \\
\hline Mrp4 & Mouse & $\begin{array}{l}\text { Postnatal days }-2,0,5,10,15 \text {, } \\
23,30,35,40,45\end{array}$ & $\begin{array}{l}\text { mRNA (bDNA } \\
\text { assay) }\end{array}$ & $\begin{array}{l}\text { Mrp } 4 \text { mRNA expression was maximal at birth and } \\
\text { decreased } \sim 70 \% \text { by } 2 \text { weeks of age, but was } \\
\text { relatively constant thereafter. }\end{array}$ & $\begin{array}{l}{[63]} \\
\text { Maher }\end{array}$ \\
\hline
\end{tabular}


Table 1-1. (Continued)

\begin{tabular}{|c|c|c|c|c|c|}
\hline Protein & $\begin{array}{c}\text { Human/ } \\
\text { animal }\end{array}$ & $\begin{array}{c}\text { Age range and } \\
\text { number of samples }\end{array}$ & Methods used & Major results & $\begin{array}{c}\text { Reference } \\
\text { first } \\
\text { author }\end{array}$ \\
\hline Mrp6 & Rat & $\begin{array}{l}\text { Embryonic days } 16 \text { and } 20 ; \\
\text { Postnatal days } 0,5,12,20,29 \\
\text { and adult }\end{array}$ & mRNA (RT-PCR) & $\begin{array}{l}\text { Mrp6 mRNA expression was detectable at low } \\
\text { levels by embryonic day } 16 \text {, increased to } 40 \% \text { of } \\
\text { adult on postnatal day } 0 \text {, and reached adult levels } \\
\text { by day } 29 \text {. }\end{array}$ & $\begin{array}{l}{[64]} \\
\text { Gao }\end{array}$ \\
\hline Mate1 & Mouse & Embryonic day 7.5 and adult & mRNA (RT-PCR) & $\begin{array}{l}\text { Mate } 1 \text { mRNA was barely detectable in embryos } \\
\text { and was } 200 \text {-fold less than that expressed in adult } \\
\text { liver. }\end{array}$ & $\begin{array}{l}{[65]} \\
\text { Lee }\end{array}$ \\
\hline Ost $\alpha / \beta$ & Mouse & $\begin{array}{l}\text { Postnatal days }-2,0,1,3,5 \\
10,15,20,25,30,45,60\end{array}$ & $\begin{array}{l}\text { mRNA (bDNA } \\
\text { assay) }\end{array}$ & $\begin{array}{l}\text { Ost } \alpha \text { mRNA was expressed at low levels } \\
\text { throughout development. Ost } \beta \text { mRNA expression } \\
\text { increased rapidly after birth with peak expression } \\
\text { at day } 1 \text { ( } 4.5 \text {-fold increase from prenatal), and } \\
\text { decreased to adult levels between days } 5 \text { and } 10 \text {. }\end{array}$ & $\begin{array}{l}{[67]} \\
\text { Cui }\end{array}$ \\
\hline
\end{tabular}

Reprinted with permission Brouwer, K.L., et al., Human Ontogeny of Drug Transporters: Review and Recommendations of the Pediatric Transporter Working Group. Clin Pharmacol Ther, 2015. 98(3):p. 266-87.[68] 


\section{MDR1 (P-gp)}

Hepatic P-gp already was detectable in the wall of bile canaliculi in early fetal life at 14 weeks by immunohistochemistry and at the mRNA level.[44] Although expression was low initially, it seemed to increase throughout fetal development and was considered moderate at the protein level by fetal week 19.[45, 46] mRNA expression for P-gp increases throughout childhood development. In a study with 61 liver specimens, mRNA expression levels were 20- to 30-fold lower in the fetal and neonatal age group compared to adults. mRNA expression, however, rapidly increased in the early months of life: in infants (1-12 months), mRNA was only 5-fold lower compared to adults, and in children and adolescents it was indistinguishable from adult expression. [47] These observations are supported by less extensive studies from others [48], and also revealed a similarly high inter-individual variability in expression in children compared to adults. [47, 49] The limited results on P-gp protein expression,however, do not corroborate the reported agedependent P-gp mRNA expression. P-gp protein was detectable in samples as early as 1 month[49], and relative protein expression was not significantly different in 65 liver specimens from age groups $0.3-0.7,0.7-2,2-5$, and 5-12 years.[50] This observation may not be surprising in light of the observed lack of correlation between mRNA and protein levels for P-gp in adult liver.[69] P-gp protein expression quantified by LC-MS/MS was not associated with age in 64 liver specimens in the age range of 7-70 years.[51] Thus, further studies are urgently needed to clarify whether the age-dependent differences in mRNA expression translate into differences at the protein and ultimately the functional level for P-gp in the liver.

\section{MRP2}

Similar to P-gp, MRP2 has been detected by immunohistochemistry in the bile canalicular membranes of 14-week old fetuses, with a tendency for higher expression levels in older fetal liver[45] and adults.[52,53] The differences in age-dependent expression seem to be similar to P-gp with 30-fold lower mRNA expression in fetal liver, but substantially more pronounced mRNA expression in neonates and infants (1-12 months) with 200-fold and 100-fold lower expression compared to adults, respectively.[47, 48] These substantial differences at the transcriptional level seem to translate into developmental differences in MRP2 protein expression: MRP2 protein levels determined by Western blot were significantly lower in liver specimens from children younger than 8 months $(\mathrm{n}=24)$ compared to older children up to 12 years $(\mathrm{n}=59)$.[50] Later in childhood development, however, MRP2 protein expression assessed by mass spectrometry was independent of age in 51 liver specimens in the age range of 7-63 years.[54]

\section{BCRP}

BCRP was detectable by immunohistochemistry in fetal liver specimens from 5.5 to 28 weeks[55], and mRNA expression increased from 18-22 week fetal samples to adults.[53] A comparison of relative protein expression between 5 neonates and 5 adult 
livers by Western blot analysis indicated no detectable difference[56], although mRNA expression seemed to increase between neonates and older children.[48] In 56 livers from age 7 to 65 years, BCRP protein expression was correlated neither with age nor with mRNA expression.[57] These results together suggest that hepatic BCRP is expressed early during human development and does not undergo relevant developmental changes after term birth.

\section{BSEP}

At gestational age 14-20 weeks, BSEP was detectable by immunohistochemistry [52], and mRNA expression increased from neonates to older children [48] and adults.[53] Functional studies in isolated sandwich-cultured fetal and adult hepatocytes suggest that the biliary excretion index for taurocholate is substantially higher in adults compared to fetal hepatocytes. This higher functional activity for the BSEP substrate taurocholate could be explained by a higher expression level of BSEP in adult cells, assuming that there is a correlation between BSEP mRNA and protein expression.[53]

\section{NTCP}

NTCP was detectable by immunohistochemistry in fetal liver specimens at 14-20 weeks of gestation [52], and mRNA expression was reduced substantially to $4 \%$ of adult values in fetal livers of 18-22 weeks of gestational age.[53] At the protein level postpartum, NTCP expression in neonates was comparable to that in adults.[56] Thus, there also seems to be no developmental maturation of NTCP expression after birth in

humans. Rodent data suggest, however, that acquisition of functional transporter activity lags behind the developmental trajectories of mRNA and immunoreactive protein, and is not present until glycosylation is mature.[58]

\section{OCT1}

There is only very limited human data on the ontogeny of hepatic OCT1. In human hepatocytes from adult and pediatric livers, there was no significant difference in the mRNA expression of OCT1, but OCT1-mediated transport seemed lower in pediatric compared to adult hepatocytes.[59]

\section{OATP}

mRNA for the OATP isoforms OATP1B1, OATP1B2, and OATP2B1 was detectable in fetal hepatocytes by gestational week 18-23, and was significantly higher in adults compared to fetal livers for OATP1B1 and OATP2B1.[53] In a limited number of neonatal and adult liver specimens ( $\mathrm{n}=5$ each), no relevant difference was observed in OATP1B1 or OATP1B3 expression as determined by Western blot analysis.[56] mRNA expression in 45 liver specimens, however, was found to be highly age-dependent. For OATP1B1, mRNA expression was 20 -fold lower in fetal liver, 500 -fold lower in 
neonates, and 90-fold lower in infants compared to adults.[47] For OATP1B3, expression was 30-fold lower in fetuses, 600-fold lower in neonates, and 100-fold lower in infants (1-12months) than in adults.[47] These data are supported by Western blot analyses based on relative protein quantification in 78 liver samples that suggest a low expression from birth to age 6 years with increased expression thereafter for OATP1B1, and high expression for OATP1B3 at birth which declines over the first month of life, and then rises again by age 6 years.[60] In 64 livers from age 7 to 70 years, neither OATP1B1, OATP1B2, nor OATP2B1 relative protein expression assessed by mass spectrometry was correlated with age.[51]

\section{Other Liver Transport Proteins}

For MRP3, MRP4, MRP6, MATE1, OAT2, OAT7, and OST $\alpha / \beta$, there is no or only very limited data available on the human ontogeny of these transporters. Thus, observations from rodent species will be provided in the following section, although there is so far no indication that rodent protein and especially mRNA expression profiles are in any way predictive of human transporter ontogeny.

MRP3. In humans, MRP3 mRNA expression was significantly lower in fetal hepatocytes by gestational week 18-23 compared to adults.[53] Similarly, Mrp3 in fetal rat liver progressively increased from about $10 \%$ to over $30 \%$ of the maternal mRNA levels from day 15 of gestation to day 20, and increased to near $90 \%$ of the maternal level at day 21 and after birth.[61] This is consistent with increased mRNA expression observed from neonates to older children and adults in a small set of human specimens (perinatal $n=6$, children $n=8$, adult $n=6$ ). $[48]$

MRP4. In humans, mRNA expression for MRP4 did not show any significant differences in fetal hepatocytes by gestational week 18-23 compared to adults [53], or when comparing neonates to older children and adults. [48] These observations are supported by mRNA expression in mice.[62, 63]

MRP6. Similar to MRP3, MRP6 mRNA expression increased in humans from neonates to older children and adults in a small set of subjects.[48] In mouse liver, Mrp6 expression was not detectable until 10 days of age, at which time the mRNA levels were the highest. The expression of Mrp6 decreased to about $60 \%$ by day 15 and remained relatively constant thereafter.[64]

MATE1. mRNA expression for MATE1 increased in humans from neonates to older children and adults in a small set of subjects.[48] Mate1 mRNA expression was absent on embryonic day 7.5 in mice.[65]

$\boldsymbol{O A T 2}$. Similar to MRP3 and MRP6, OAT2 mRNA expression increased from neonates to older children and adults in a small set of human subjects.[48]

$\boldsymbol{O A T 7}$. No information could be found on the ontogeny of OAT7 in humans or rodents. 
OST $\boldsymbol{\alpha} / \boldsymbol{\beta}$. mRNA expression was detectable for OST $\alpha$ and OST $\beta$ in pediatric liver with an age around 1 year.[66] Although Ost $\alpha$ mRNA is expressed at low levels in liver throughout development from day -2 to day 45 in mice, Ost $\beta$ mRNA markedly increased to 4.5-fold of prenatal levels with a peak around 1 day after birth.[67]

\section{Summary}

Overall, there are limited data available on the ontogeny of hepatic transport proteins. The emerging picture, however, suggests that there may be substantial differences between transporters in the time course of development and expression. Some transport proteins such as P-gp, BCRP, and NTCP are expressed early in childhood development, while others such as OATP1B1, BSEP and MRP2 seem to exhibit delayed maturation and reduced expression levels compared to adults during at least the first months of life. In general, differences seem to be absent between older children and adults. This conclusion is supported by the notion that localization of the canalicular transporters (BSEP, P-gp, MRP2) in pediatric liver (6-17 months) had reached a similar level and pattern as adult liver indicating that the pediatric liver around 1 year of age has obtained a mature canalicular structure.[52]

\section{Developmental Pharmacogenetics}

The physiologic processes involved in drug disposition are influenced not only by normal age-associated development but also by genetic variation. Single nucleotide polymorphisms (SNPs) in the genes encoding the enzymes and transporters involved in drug disposition account for a substantial fraction of the inter-individual variation of drug response. Several of the drug metabolizing enzymes have known SNPs that impact drug disposition.

CYP2D6 is highly polymorphic resulting in metabolizing phenotypes of poor, intermediate, rapid, and ultra-rapid metabolizers. These phenotypes have a marked impact on drug disposition. The poor metabolizer phenotype is the product of two loss of function alleles which results in inefficient removal of drug from the body.[20] Poor metabolizers given the probe substrate dextromethorphan have had exposures to the parent dextromethorphan that were up to 150 times greater as compared to their extensive metabolizer counterparts. [3] Similar findings were also seen with another CYP2D6 substrate, chlorpheniramine. Poor metabolizers had significantly higher exposures (4-5 times) to chlorpheniramine compared to extensive metabolizers. [3] While CYP2D6 expression may not approach adult levels until late infancy or later, it has been shown that genotype and phenotype correlate by 2 weeks of age.[26]

While the example of dosing chloramphenicol to infants the subsequent tragedy of Grey Baby Syndrome illustrated the importance of ontogeny in drug therapy; the administration of codeine to a breastfeeding mother highlights multiple aspects of drug therapy not the least of which is polymorphic gene expression. A breastfeeding mother 
had been given acetaminophen with codeine in the immediate postpartum period for analgesia.[70] The infant became increasingly lethargic and died by 13 days of age.[70] Upon investigation it was determined that the mother was an ultra-rapid metabolizer at CYP2D6, converting codeine to morphine at greater than normal rate, and passing larger than expected amounts of morphine to the infant in breastmilk. [70] The immaturity of the neonatal drug metabolizing enzymes as previously discussed made it impossible for the infant to eliminate the excessive amount of narcotic.

When discussing pharmacogenetics CYP2D6 is most often at the forefront as it has several defined phenotypes that can be identified fairly easily with known probes; however, it is not the only polymorphic drug metabolizing enzyme. The CYP2C family member 2C19 is also polymorphic. CYP2C19 is responsible for the metabolism of drugs such as phenytoin, omeprazole, indomethacin, and propranolol. There are over 30 variant alleles identified for CYP2C19 with the most common conferring normal function (CYP2C19*1), loss of function (CYP2C19*2 and CYP2C19*3), and increased function (CYP2C19*17).[71] Patients homozygous for loss of function allele have been found to have 5-6 times greater exposure to omeprazole and 3 times higher exposure to esomeprazole as compared to patients possessing at least one functional CYP2C19 allele.[72] The increased exposure to omeprazole in these poor metabolizers also correlates to higher cure rates of $H$. pylori infection in this group of patients. [72] When examining the implications of CYP2C19 genotype on dosing of citalopram, escitalopram, and sertraline, the Clinical Pharmacogenetics Implementation Consortium recommends using a starting dose that is half of that stated in the drug label for patients that are homozygous for loss of function alleles and switching to a different selective serotonin reuptake inhibitor for patients with at least one increased function allele.[71]

The CYP2C family also consists of CYP2C9 which is also polymorphic. CYP2C9 is responsible for the metabolism of diclofenac, warfarin, phenytoin, tolbutamide, and rosuvastatin. Patients with the CYP2C $9 * 3$ allele show decreased metabolism due to reduced $\mathrm{V}_{\max }$ and increased $\mathrm{k}_{\mathrm{m}}$ requiring lower doses of substrates such as warfarin.[73, 74] The importance of CYP2C9 polymorphisms may be unclear for warfarin and phenytoin which currently have well established therapeutic monitoring systems in place to attain and maintain therapeutic levels, although for patients with decreased function of CYP2C9 there was increased risk of bleeding during the start of therapy.[73] During post-marketing studies rosuvastatin labelling was updated to include information about decreased starting doses in Asian patients based on the increased likelihood that these patients possess the CYP2C $9 * 3$ allele.[75]

While the CYP2D and CYP2C families are responsible for the metabolism of many medications, CYP3A is responsible for the metabolism of almost half of medications.[27] CYP3A also demonstrates polymorphic expression which has implications on drug disposition. The CYP3A $4 * 22$ allele was found to have both decreased expression as well as function which would predict higher exposures of substrates in individuals possessing this allele.[27] The CYP3A5 isoform has been the focus of variability in CYP3A function. This isoform has an allele known for decreased function, CYP3A5*3 which is important in the overall ability to metabolize medications 
through CYP3A as CYP3A4 and CYP3A5 share over 80\% homology.[27] In vitro studies found that midazolam clearance in liver microsomes homozygous for CYP3 A $5 * 3$ was half that from samples with only one CYP $3 \mathrm{~A} 5 * 3$ allele.[76, 77] Similar findings were found when looking at tacrolimus dosing in heart transplant patients; those homozygous for $\mathrm{CYP} 3 \mathrm{~A} 5 * 3$ required about half the dose as those with one functional allele.[78]

Phase II metabolizing enzymes can also exhibit genetic polymorphism. UGT has been extensively studied in this regard. UGT1 A1*28 has been associated with prolonged hyperbilirubinemia due to a decreased ability to conjugate bilirubin to glucuronic acid.[76] Patients possessing this allele have approximately 30\% lower glucuronidation capacity as compared to wild-type.[79] This polymorphism can lead to increased exposure to medications as well as endogenous substrates. Caucasian patients homozygous for UGT1A1*28 typically have been diagnosed with Gilbert Syndrome which is characterized by mild unconjugated hyperbilirubinemia, although other mutations in UGT1A1 can also be associated with Gilbert Syndrome particularly in other patient populations such as Japanese patients.[33,79] Up to $20 \%$ of the inter-individual variability seen in the clearance of UGT1A6 substrates, such as serotonin and acetaminophen, has been attributed to a polymorphism known as UGT1A6*2.[80] This particular variant results in an increased intrinsic clearance value leading to decreased exposure to substrates of UGT1A6.[80] Patients homozygous for the UGT2B7*2 variant were found to have increased production of morphine-6-glucuronide, an active metabolite of morphine.[81, 82] In this case an active medication is turned into an active metabolite which can prolong exposure; for medications that would be inactivated by glucuronidation by UGT2B7 there would be a decrease in exposure due to the increased clearance of the medication.

While it is relatively simple to predict the response a patient with a specific polymorphism in a drug metabolizing enzyme or other gene involved in drug disposition may illicit; the variation does not exist in isolation. Often medications are metabolized by multiple enzymes particularly phase I then phase II enzymes. When the metabolism pathway is known, these interactions can also be predicted. Complicating these predictions are many patient specific factors. When genetic variability and ontogeny meet there is often uncertainty in the predictions. Leeder et al.[3] has provided a potential framework for investigating the intersection of ontogeny and genetic variability. Understanding the routes of metabolism for the substrate of interest and the relative importance of each is key in determining if the addition of genetic analysis is necessary in clinical trials of that substrate. [3] Other key factors include understanding the functional consequences of the allelic variation in the major routes of metabolism and understanding the role of ontogeny in the major drug metabolizing enzyme. As the functional consequences of the ontogeny of drug metabolizing enzymes as well their allelic variation become better understood, this framework can be utilized to determine the best pharmacotherapy for infants and young children. 


\section{CHAPTER 2. HYPOTHESIS AND SPECIFIC AIMS}

Determining appropriate pharmacotherapy for infants and children has historically been precarious. As using children in clinical trials throughout the drug development and post-marketing process involves ethical and practical challenges, pharmacotherapy decisions in children are often extrapolated from adult data. In order to give accurate predictions in appropriate pharmacotherapy the physiological development of children must be taken into account. This includes the development of all processes involved in drug disposition as well as the pathophysiology of the disease or condition to be treated. I have focused my work on drug disposition to that of hepatic transport. An often overlooked aspect of drug disposition is the ability of a drug to gain entry into the drug removal organs (ie. liver and kidneys). If a drug is not lipophilic making passive diffusion across the biomembranes possible, active transport is the only way for drugs to enter body organs. As starting framework for discussing the ontogeny of drug transport, the framework used for the ontogeny of drug metabolizing enzymes was used. The developmental pathway of drug metabolizing enzymes have been described by three distinct models: high expression at birth with a decline occurring over the first weeks to months after birth, low to no expression at birth increasing over months to years after birth, and somewhat stable expression from birth to adulthood.[7] Preliminary mRNA work indicated that the transporters OATP1B1 and OATP1B3 may show developmental changes. Using this data I hypothesized that OATP1B3 would exhibit a developmental expression pattern with low expression early in life with increasing expression thereafter. I hypothesized that the expression pattern of OATP1B1 would be fairly constant with no discernible pattern. While understanding the ontogeny of OATP1B1 and OATP1B3 is important and will aid in improving pharmacotherapy, investigating the impact of polymorphisms in these transporters is also important. Finally, the functional consequence of the hypothesized lack of OATP1B transporter expression was investigated using an animal model. I hypothesized that the lack of OATP1B transporter expression would lead to altered pharmacokinetic properties of a probe substrate.

\section{Specific Aim 1}

Understanding the actual development of drug transporter expression is an important aspect of overall drug disposition. Many drugs rely upon active transport across biomembranes in order to reach sites of action, metabolism, or excretion. OATP1B1 and OATP1B3 transport drugs into the liver where they may be metabolized by the CYP enzymes or excreted into bile. Based on preliminary work on mRNA expression of OATP1B1 and OATP1B3, it is hypothesized that expression of OATP1B3 will be significantly lower at birth and increase throughout childhood. OATP1B1 is expected to remain relatively constant in expression throughout childhood. 


\section{Specific Aim 2}

Development of the drug disposition processes do not occur in isolation. Intertwined with development are the consequences of genetic variation. Both OATP1B1 and OATP1B3 have several known polymorphisms. OATP1B1 has two functionally relevant SNPs, $521 \mathrm{~T} \rightarrow \mathrm{C}$ and $388 \mathrm{~A} \rightarrow \mathrm{G}$, that appear to decrease transporter uptake and increase uptake respectively. [83] Functionally relevant SNPs of OATP1B3 include $334 \mathrm{~T} \rightarrow \mathrm{G}$ and $699 \mathrm{G} \rightarrow \mathrm{A}$ which decrease uptake substrates.[84] The interaction of protein expression and genetic variation will be examined.

\section{Specific Aim 3}

Understanding the functional consequences of the hypothesized lack of protein expression and genetic variation will improve pharmacotherapy regimens. Using a knockout mouse model the consequences of the loss of Oatp1b will be investigated using fexofenadine as a probe substrate. I hypothesize that the knockout mice with no Oatp1b expression will have higher exposures to fexofenadine due decreased clearance as well as decreased volume of distribution. 


\section{CHAPTER 3. EXPRESSION PATTERNS OF OATP1B1 AND OATP1B3 PROTEIN IN HUMAN, PEDIATRIC LIVER ${ }^{2}$}

Pharmacotherapy in young children is a very challenging proposition due to the intricate pattern of their physiologic development. This developmental pattern includes changes in every body system from the time of birth through adulthood. Many of these changes have an impact on drug disposition. $[10,12]$ In the last two decades, much work has been focused on elucidating the ontogeny of drug metabolizing enzymes including Phase I enzymes such as the cytochrome P450 (CYP) enzyme subfamilies CYP3A, CYP2D, and CYP1A, as well as Phase II enzymes such as sulfotransferases, glutathione S-transferases, and UDP glucuronosyltransferases.[7] One component of drug disposition that has so far received limited attention in terms of developmental expression is the area of drug transport which has been highlighted and summarized in the recently published recommendations by the NIH Pediatric Transporter Working Group.[68]

Organic Anion Transporting Polypeptide (OATP) is a family of transmembrane transport proteins responsible for the uptake of substances into the cells of a variety of organs. OATP1B1 (encoded by the SLCO1B1 gene) and OATP1B3 (SLCO1B3) are members of the OATP family located primarily on the basolateral surface of hepatocytes. These two transporters share approximately $80 \%$ sequence identity, resulting in an overlapping substrate profile.[85] Endogenous substrates for OATP1B1 and OATP1B3 include bilirubin, bile salts, thyroid hormones, and steroid sex hormones and their conjugates, while exogenous substrates include HMG-CoA reductase inhibitors, angiotensin II receptor antagonists, rifampicin, and methotrexate.[42, 85] The important role of OATP1B1 for systemic pharmacokinetics and treatment outcome has recently been highlighted for chemotherapy in pediatric patients with acute myeloid leukemia.[86] In this study, patients homozygous for a genetic variant of $S L C O 1 B 1$ had significantly more favorable survival outcome, likely because of reduced clearance and thus increased exposure to chemotherapeutic agents that are substrates for OATP1B1.

While it has been reported that the rodent ortholog of OATP1B1 and OATP1B3, Oatp1b2, exhibits a differential expression pattern based on the age of the rodent [87], there is a paucity of similar information on the human transporters, OATP1B1 and OATP1B3. Thus, the purpose of this manuscript was to examine the ontogenic patterns of OATP1B1 and OATP1B3 protein expression in pediatric livers.

${ }^{2}$ Reprinted with permission from the American Society of Pharmacology and Experimental Therapeutics. All Rights Reserved. Thomson, M.M., et al., Expression Patterns of Organic Anion Transporting Polypeptides $1 B 1$ and $1 B 3$ Protein in Human Pediatric Liver. Drug Metab Dispos, 2016. 44(7): p. 999-1004. 


\section{Methods}

\section{Pediatric Liver Specimens}

Post-mortem liver specimens $(\mathrm{n}=48)$ from individuals aged $0.038-12$ years were obtained from the Brain \& Tissue Bank for Developmental Disorders, University of Baltimore and University of Miami (National Institute of Child Health \& Human Development contract N01-HD-8-3284).[31] Liver samples from living organ donors $(\mathrm{n}=32)$, aged $0.25-12$ years, were obtained from the Liver Tissue Procurement and Distribution System (Pittsburgh, PA, National Institutes of Health Contract N01-DK-92310). Basic demographic information including age, gender, race, and post-mortem interval as appropriate, was available for most samples used in the study, and is summarized in Table 3-1. Besides major diseases and cause of death, no other sample identifiers were available. Samples from individuals with disease conditions that potentially could involve liver damage were not included in the study. Tissues were stored at $-70^{\circ} \mathrm{C}$ until analysis. The study was approved by the Institutional Review Board of the University of Tennessee Health Science Center.

\section{Relative Protein Quantification}

Membrane proteins from the post-mortem samples were isolated using the ProteoExtract ${ }^{\circledR}$ Native Membrane Protein Extraction kit per manufacturer protocol (Calbiochem, La Jolla, CA). Membrane proteins from the living-donor samples were isolated using ultracentrifugation. Briefly, approximately $2 \mathrm{~g}$ of frozen liver tissue was quickly thawed and homogenized in $10 \mathrm{~mL}$ of homogenization buffer consisting of $0.1 \mathrm{M}$ Tris $\mathrm{pH}$ 7.4, 0.1 M potassium chloride, $0.02 \mathrm{mM}$ butylated hydroxytoluene, and $1 \mathrm{mM}$ EDTA. The homogenate was centrifuged at $12,000 \mathrm{~g}$ for $15 \mathrm{~min}$ at $4{ }^{\circ} \mathrm{C}$. The supernatant was discarded and the remaining pellet consisting of membrane proteins was resuspended in $5 \mathrm{~mL}$ of membrane storage buffer consisting of $20 \%$ glycerol, $1 \mathrm{mM}$ dithiothreitol, $0.02 \mathrm{mM}$ butylated hydroxytoluene, and 0.1 potassium phosphate $\mathrm{pH} 7.25$. Aliquots of the membrane protein were prepared and stored at $-70^{\circ} \mathrm{C}$ until further processing.

Total protein concentration was determined using the Bio-Rad Protein Assay (Bio-Rad, Hercules, CA) with bovine serum albumin as the standard.[88] Protein was separated using SDS-PAGE gel electrophoresis after loading $15 \mu \mathrm{g}$ total protein in each well. After separation protein was transferred to an Invitrolon ${ }^{\mathrm{TM}}$ polyvinylidene difluoride membrane (Invitrogen, Grand Island, NY) overnight at $30 \mathrm{~V}$ on ice. Membranes were incubated with Tris-buffered saline - 0.5\% Tween ${ }^{\circledR} 20$ and 5\% non-fat dried milk (TBS-T-M) for 3 hours. OATP1B1 and OATP1B3 were detected using a murine, monoclonal anti-OATP1B antibody, mMDQ (Novus Biologicals, Littleton, CO), incubated at $1: 33$ dilution overnight at $4{ }^{\circ} \mathrm{C}$ with fresh TBS-T-M. mMDQ had been raised against a synthetic peptide antigen that is common to both OATP1B1 and OATP1B3. It has widely been used and characterized in detail with regard to its ability to detect both, OATP1B1 and OATP1B3.[89, 90] Subsequently, the membrane was washed three times 
Table 3-1. Demographic information of study individuals

\begin{tabular}{ccc}
\hline Category & N & Range \\
\hline Postnatal Age Range & 80 & 14 days $-12 \mathrm{yr}$ \\
Mean (SD) & & $3.53(3.86) \mathrm{yr}$ \\
Gender & & \\
Males & 43 & \\
Females & 27 & \\
Unknown & 10 & \\
Race & & \\
Caucasian & 43 & \\
African-American & 20 & \\
Other & 5 & \\
Unknown & 12 \\
Source & \\
Living Donor & 32 \\
Post-Mortem & 48 \\
\hline
\end{tabular}


in Tris-buffered saline $-0.5 \%$ Tween $\AA 20$ (TBS-T). The membrane was then incubated in fresh TBS-T-M with a horseradish peroxidase-conjugated horse anti-mouse IgG (Cell Signaling Technology, Danvers, MA) secondary antibody at 1:2,500 dilution for 2 hours. After washing the membrane three times with TBS-T, enhanced chemiluminescence ECL PLUS (GE Healthcare, Piscataway, NJ) was used for visualization of the proteins with exposure to Kodak BioMax XAR autoradiography film (Sigma Aldrich, St. Louis, MO). The films were digitized using a CanoScanLide30 scanner (Canon, Melville, NY). Digitized images were then analyzed in Image J (NIH, Bethesda, MD).

Membranes were stripped using Restore Western Blot Stripping Buffer (Thermo Scientific, Rockford, IL) and washed two times with PBS-0.1\% Tween ${ }^{\circledR} 20$ (PBS-T). Membranes were then incubated in PBS-T with 5\% non-fat, dried milk for 1 hour. GAPDH protein was detected using a murine anti-GAPDH antibody (Sigma-Aldrich, St Louis, MO) incubated at 1:2500 for 2 hours with fresh PBS-T-M. The remaining steps of detecting GAPDH protein were the same as those for OATP1B1 and OATP1B3.

All OATP1B protein expression values were normalized to GAPDH expression within each sample. Each Western blot experiment included a protein ladder consisting of 9 recombinant proteins of known molecular weight (MagicMark XP Western Protein Standard, Life Technologies, Carlsbad, CA), as well as two commercially available positive controls. For OATP1B3, the positive control was the lysate of OATP1B3 overexpressing HEK293 cells (Novus Biologics, Littleton, CO). For OATP1B1, the positive control was an adult human liver membrane lysate (Abcam, Cambridge, MA). Comparison of the ratios between OATP1B1 or OATP1B3 and GAPDH for these positive controls across blots was used to control for consistency between blots. A representative Western blot including these controls and several pediatric liver samples is displayed in Figure 3-1.

\section{Statistical Analysis}

All statistical analyses were performed using SPSS v.23 (IBM, Armonk, NY). Relative protein expression among groups was compared by one-way analysis of variance with Bonferroni correction for post hoc comparisons after logarithmic transformation. Associations between select continuous variables were investigated by Pearson product moment correlation. All p-values $\leq 0.05$ were considered significant.

\section{Results}

The ontogeny of OATP1B transporters was assessed with 80 pediatric liver specimens, 32 from living donors (biopsy) and 48 obtained post-mortem. The ages of sample donors ranged from 9 days to 12 years. General characteristics of the sample donors can be found in Table 3-1. For statistical analysis samples were divided into four groups based on age: Group A comprised samples from donors aged $<3$ months, Group B 3 months to $<2$ years, Group C 2 to $<6$ years, and Group D 6-12 years. Group cutoffs 


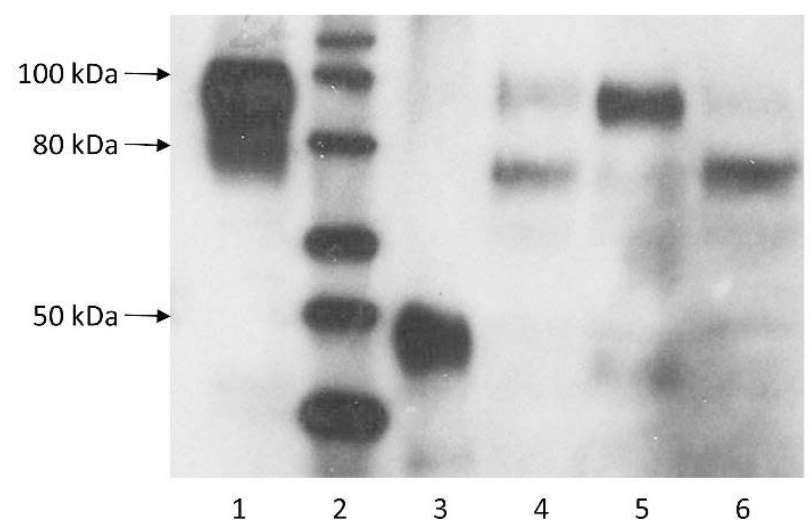

Figure 3-1. Representative Western blot analysis of OATP1B1 and OATP1B3

Lane 1: Positive control for OATP1B3; Lane 2: Molecular ladder; Lane 3: Positive control for OATP1B1; Lanes 4-6: Pediatric liver specimens. Bands representing highly glycosylated OATP1B3, core-glycosylated OATP1B3, and OATP1B1 can be seen at approximately 100,80 , and $50 \mathrm{kDa}$ respectively. 
were determined in order to provide fairly equal group sizes for statistical power. As there was no difference in OATP1B expression detected between post-mortem and living donor samples, results are presented for the combined sample set. Similarly, no expression differences were detected based on gender, race, or the post-mortem sampling interval.

Western blot analysis with the OATP1B mMDQ antibody revealed one band representing OATP1B1 and two bands representing OATP1B3 as indicated in Figure 3-1. Using the same primary mMDQ antibody and OATP1B3 overexpressing HEK 293 cells as in our study as well as human liver membrane preparations, Cui et al.[89] observed the same two bands for OATP1B3 and attributed them to a highly glycosylated and a core-glycosylated form of OATP1B3, which was confirmed by deglycosylation studies.[91, 92] The concurrent detection of highly glycosylated and core-glycosylated OATP1B3 is not surprising as OATP1B3 has been reported to be extensively glycosylated and similar observations have been reported by others.[93] Although one might expect that post-translational modifications such as glycosylation play an important role for the intracellular localization and/or activity of OATP1B3, information on its function have so far been scarce, and thus we report in the following highly glycosylated, core-glycosylated and total (highly glycosylated and core-glycosylated) OATP1B3, as summarized in Table 3-2, Figure 3-2, and Figure 3-3.

For OATP1B3, relative expression of highly glycosylated protein in age group A was approximately seven times higher than in age group $B(p=0.002)$ and four times higher than in age group $\mathrm{C}(\mathrm{p}=0.036)$. Expression of highly glycosylated OATP1B3 protein in age group A was on average more than twice as high $(235 \%)$ as that in age group D, whereas age groups B and C had only $33 \%$ and $50 \%$ of the expression in age group D, but only the difference between groups B and D reached statistical significance $(p=0.050)$. Expression of core-glycosylated OATP1B3 protein in age group A was $505 \%$ of that in group $D(p=0.013)$, and was also seven times higher than in group $B(p=0.002)$ and 9 times higher than in group $\mathrm{C}(\mathrm{p}=0.001)$. Groups $\mathrm{B}$ and $\mathrm{C}$ had geometric mean expression levels for core-glycosylated OATP1B3 of $70 \%$ and $56 \%$ relative to group D, but those differences did not reach statistical significance. Total OATP1B3 protein expression relative to group D was $357 \%$ in group A, $64 \%$ in group B, and $59 \%$ in group $\mathrm{C}$, with significant differences between $\mathrm{A}$ and all other groups.

For OATP1B1, average expression in groups $\mathrm{A}, \mathrm{B}$ and $\mathrm{C}$ was $38 \%, 32 \%$, and $20 \%$ of group $\mathrm{D}$, but did not reach statistical significance $(\mathrm{p}=0.12)$, likely due to large inter-individual expression differences in each group, which are in line with previous reports.[94]

Figure 3-3 presents the individual expression versus age for highly glycosylated, core-glycosylated and total OATP1B3, as well as OATP1B1. Despite high variability, a clear developmental pattern emerges for OATP1B3 with highest expression at the youngest ages early after birth, followed by a low, but steady expression level until the prepubescent period when OATP1B3 protein expression starts to increase again. In contrast, OATP1B1 expression was independent of age within the studied age range. 
Table 3-2. Mean normalized OATP1B protein amounts

\begin{tabular}{|c|c|c|c|c|}
\hline Category & Age group A & Age group $B$ & Age group C & Age group D \\
\hline Postnatal age range & $<3$ months & 3 months $-<2$ yr & $2-<6 \mathrm{yr}$ & $6-12 \mathrm{yr}$ \\
\hline $\mathrm{N}$ & 20 & 21 & 17 & 22 \\
\hline Mean age (yr) & 0.128 & 0.715 & 3.73 & 9.14 \\
\hline Standard deviation (yr) & 0.067 & 0.412 & 1.13 & 1.67 \\
\hline \multicolumn{5}{|c|}{ Highly Glycosylated OATP1B3 } \\
\hline Geometric Mean & $1.49 * * \mathrm{~B}, * \mathrm{C}$ & $0.210 * \mathrm{D}$ & 0.320 & 0.637 \\
\hline $25^{\text {th }}$ to $75^{\text {th }}$ percentile & $0.801-2.79$ & $0.028-1.05$ & $0.267-0.763$ & $0.223-3.31$ \\
\hline Relative to Group D & $235 \%$ & $33 \%$ & $50 \%$ & $100 \%$ \\
\hline \multicolumn{5}{|c|}{ Core-Glycosylated OATP1B3 } \\
\hline Geometric Mean & $3.59 * * \mathrm{~B}, * * \mathrm{C}, * \mathrm{D}$ & 0.495 & 0.399 & 0.710 \\
\hline $25^{\text {th }}$ to $75^{\text {th }}$ percentile & $2.41-5.11$ & $0.240-2.17$ & $0.319-1.11$ & $0.471-2.08$ \\
\hline Relative to Group D & $505 \%$ & $70 \%$ & $56 \%$ & $100 \%$ \\
\hline \multicolumn{5}{|l|}{ Total OATP1B3 } \\
\hline Geometric Mean & $5.31 * * \mathrm{~B}, * * \mathrm{C}, * \mathrm{D}$ & 0.956 & 0.873 & 1.49 \\
\hline $25^{\text {th }}$ to $75^{\text {th }}$ percentile & $3.33-7.86$ & $0.412-3.37$ & $0.720-2.21$ & $0.671-4.95$ \\
\hline Relative to Group D & $357 \%$ & $64 \%$ & $59 \%$ & $100 \%$ \\
\hline \multicolumn{5}{|l|}{ OAPT1B1 } \\
\hline Geometric Mean & 0.0535 & 0.0445 & 0.0277 & 0.139 \\
\hline $25^{\text {th }}$ to $75^{\text {th }}$ percentile & $0.0045-0.296$ & $0.0107-0.196$ & $0.0155-0.0947$ & $0.0275-0.871$ \\
\hline Relative to Group D & $38 \%$ & $32 \%$ & $20 \%$ & $100 \%$ \\
\hline
\end{tabular}

Statistically significant differences are marked with asterisks $(* \mathrm{P} \leq 0.05, * * \mathrm{P} \leq 0.01)$. Superscript letters denote the comparison group. 
A

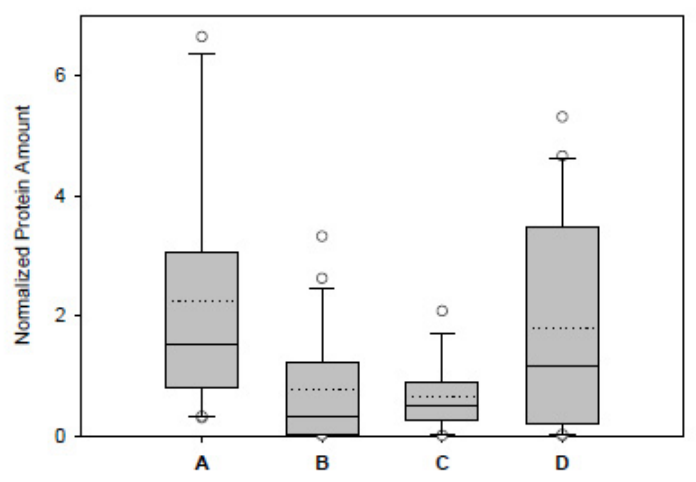

C

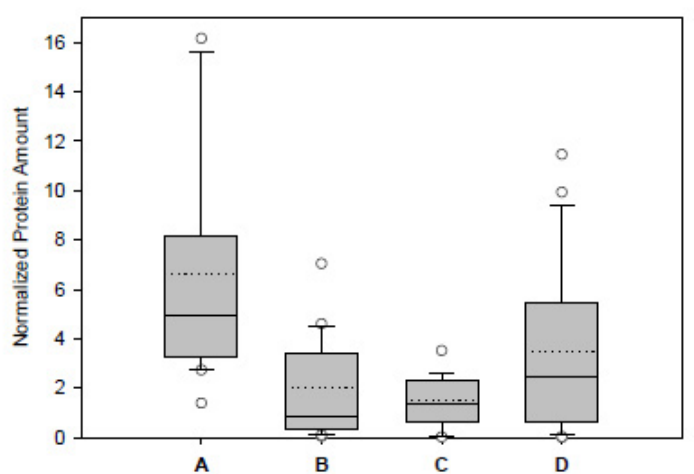

B

Core-Glycosylated OATP1B3

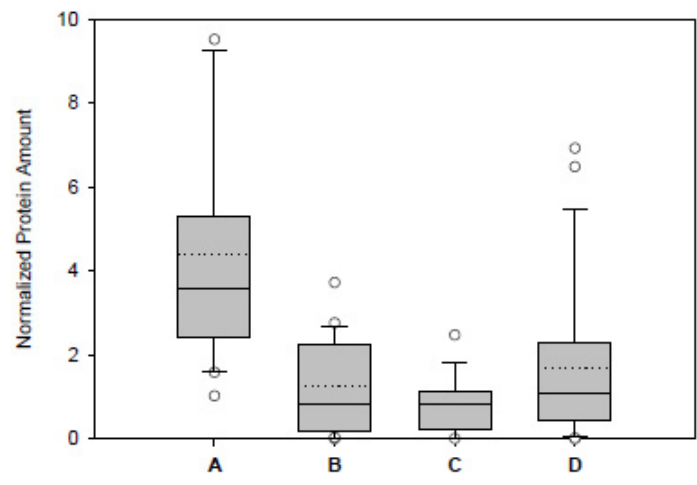

D

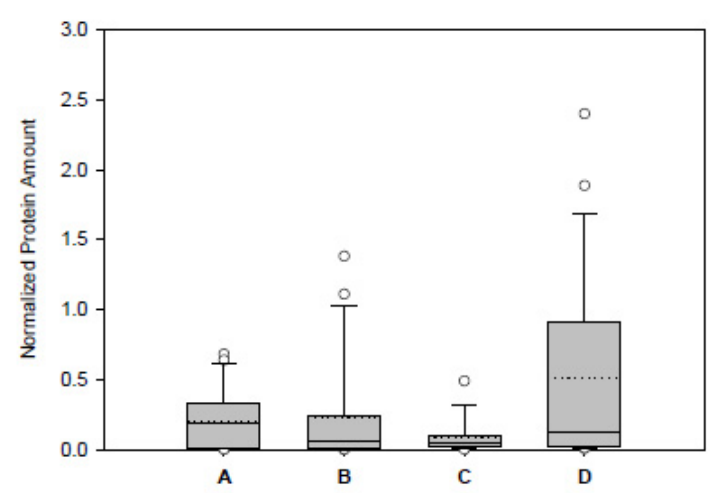

Figure 3-2. Box and whisker plots of OATP expression normalized to GAPDH expression by age group

Relative OATP1B protein expression (normalized to GAPDH) in pediatric liver for different age groups (Group A: $<3$ months, Group B: 3 months to $<2$ years, Group C: 2 to $<6$ years, Group D: 6 to 12 years): Panel A: Highly glycosylated OATP1B3, Panel B:

Core-glycosylated OATP1B3, Panel C: Total (highly glycosylated and core-glycosylated) OATP1B3, Panel D: OATP1B1. Statistically significant differences are marked with * $(p \leq 0.05)$ and $* *(p<0.01)$. Boxes represent the interquartile range, whiskers the $10^{\text {th }}$ and $90^{\text {th }}$ percentile. The solid horizontal line in the box denotes the median, the dotted line the mean of the data. 

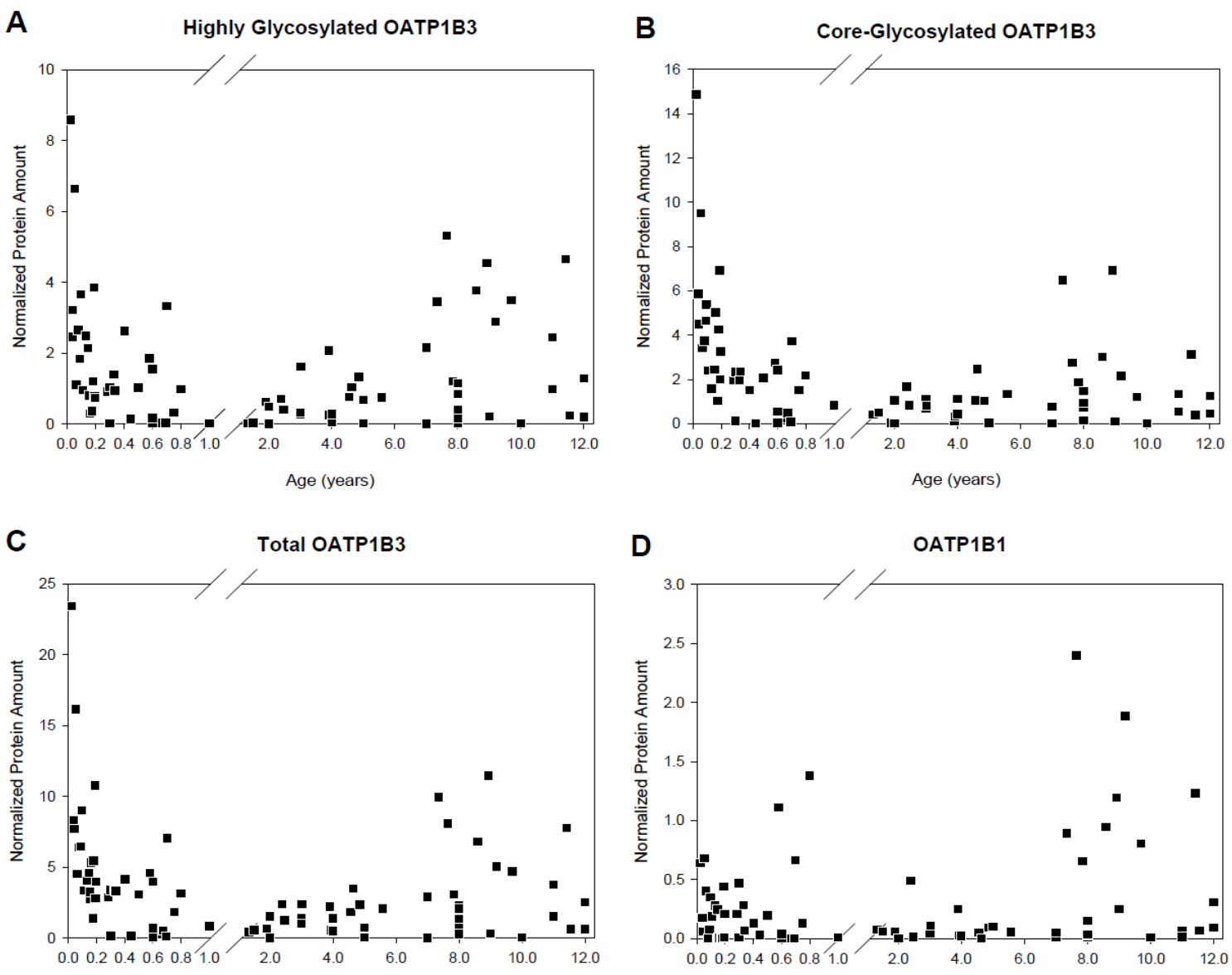

Figure 3-3. Scatter plot of OATP protein expression normalized to GAPDH protein expression

Relative OATP1B protein expression (normalized to GAPDH) in pediatric liver versus postnatal age. The $\mathrm{x}$-axis is discontinuous with ages less than 1 year shown as a fraction. Panel A: Highly glycosylated OATP1B3, Panel B: Core-glycosylated OATP1B3, Panel C: Total (highly glycosylated and core-glycosylated) OATP1B3, Panel D: OATP1B1. 


\section{Discussion}

Ontogeny patterns of drug metabolizing enzymes fit into one of three categories, and as drug metabolizing enzymes and transporters are co-regulated, one might expect a similar behavior for transport proteins. [95] The first category is characterized by high expression during gestation with low to no expression after 1 year of age. Examples of this pattern of expression include the Phase I metabolizing enzymes CYP3A7 and FMO1, as well as, Phase II metabolizing enzymes SULT1A3/4 and SULT1E1.[7, 31] The second ontogeny pattern is characterized by relatively stable expression of the protein. Drug metabolizing enzymes that exemplify this pattern include CYP3A5 and SULT1A1 [7]. The current study failed to show a statistically significant correlation between OATP1B1 protein expression and age, indicating that expression of the OATP1B1 transport protein likely fits into this second pattern of ontogeny. Finally, the third ontogeny pattern is characterized by no to low expression during gestation with expression increasing postnatally.[7] This third category appears to be the vastest with many examples including CYP1A2, CYP2C19, CYP2E1, CYP3A4, FMO3, and SULT2A1.[7, 23, 31] This third category also appears to be the most diverse in terms of the rate at which expression levels increase with some of the drug metabolizing enzymes achieving adult levels in the neonatal period and others not reaching that level of expression until after one year of age [22]. OATP1B1 might potentially also fit into this category as there was a trend towards lower expression at earlier age, although this did not reach statistical significance, potentially due to the observed high inter-individual variability.

While the data for OATP1B1 can be ascribed to one of these described categories of ontogeny, the ontogeny pattern of the OATP1B3 protein is intriguing and unexpected. As can be seen in Figure 3-3 expression for OATP1B3 starts out high at birth with a fairly rapid decrease in expression during the first few months of life. This may be explained in part by looking at the normal physiology of a neonate. There are many endogenous substrates that are elevated in the neonate as compared to the adult including bilirubin and bile acids. The rate of bilirubin production is approximately two times greater in neonates than in adults and drops to roughly adult values within 2 weeks after birth.[16, 17] The period in which the bilirubin production is high, but starts to decrease, overlaps the same age range in which OATP1B3 expression is elevated in the current study. Bile acid production is known to start increasing during the end of gestation in the fetus.[96] Since bilirubin and many bile salts are substrates for OATP1B3, it is possible that the increased presence of circulating bilirubin and bile salts induces the expression of OATP1B3.

The increased expression of OATP1B3 could be modulated by one of the nuclear receptors, in particular the farnesoid X receptor (FXR). Bile acids are the endogenous substrate for FXR and modulate FXR expression in order to maintain bile acid homeostasis.[97-99] When bile acids do accumulate, the FXR pathway seems to upregulate OATP1B3 expression and down-regulate of OATP1B1 expression, although the latter seems to be limited to highly pathological bile salt concentrations.[98] In this study OATP1B 3 protein expression was elevated by approximately $200 \%$ in individuals aged less than 3 months compared to those 6-12 years old, which is consistent with the FXR 
bile acid activation. OATP1B1 protein expression was not statistically lower in the samples from the youngest donors, although average expression tended to be lower than in the 6-12 years old individuals. Whether the bile acid insult has not been large enough to result into an FXR-mediated down-regulation of OATP1B1 or whether the tendency to lower average expression in the youngest age group already indicates such a downregulation remains unclear. In rodent models it has been suggested that the nuclear receptors constitutive androstane receptor (CAR) and pregnane $\mathrm{X}$ receptor (PXR) are also activated by bile acids and bilirubin, but that CAR in particular may not be expressed in the neonate showing the third ontogeny pattern previously described.[100, 101] These regulatory pathways provide another possible explanation for the apparent activation of OATP1B3 and lack thereof for OATP1B1 in the neonate.

The OATP1B3 expression pattern has a second increase during the pre-adolescent period, which may also be explained by substrate-mediated induction. Endogenous substrates for this transporter include sex steroids, including estrone-3-sulfate, estradiol $17-\beta$-glucuronide, and dihydroepiandrosterone 3-sulfate.[102] Endogenous levels of these substrates are expected to start increasing as a child approaches puberty, which tends to fall into age group D in our study in which increased OATP1B3 expression was observed.[103]

Comparison between the highly glycosylated and core-glycosylated forms of OATP1B3 indicated a weak correlation between the fraction that is highly glycosylated and age (Pearson's correlation coefficient $0.377, \mathrm{p}=0.001$ ), with average fractions of $31.2,32.7,43.3$ and $50.4 \%$ in age groups A, B, C and D, respectively. Differences of A vs. D and B vs. D were statistically significant $(p<0.05)$. Posttranslational modification by glycosylation has been suggested to affect intracellular localization and function of some transporters [58, 104], including localization to the basolateral membrane and transport function of OATP1B3 $[93,105]$. As the ratio of glycosylated to nonglycosylated protein changes, our data suggest that in addition to protein expression, ageassociated differences in posttranslational modifications, such as glycosylation, may have an effect on the developmental pattern of OATP1B3 function. Future studies, however, will need to delineate the impact of differences in glycosylation on the functional activity of OATP1B3.

Two publications have recently addressed certain aspects of the age-associated expression of OATP1B1 and OATP1B3. Prasad, Evers [51] examined the protein expression of both transporters in 64 liver samples from donors ages 7 to 55 years. The investigators did not detect any age-associated expression, but only 6 of the investigated 64 individuals were below the age-cutoff of twelve years used in this study. In addition, the investigators used an LC-MS/MS techniques which removes all post-translational modifications such as glycosylation, and thus quantifies total rather than glycosylated OATP1B. Thus, our results are not inconsistent with the results reported by Prasad et al.

Mooij et al.[106] investigated the mRNA expression of OATP1B1 and 1B3 in 45 liver specimens from fetal to adult age. Compared with adult liver, OATP1B1 mRNA expression was 20 -fold lower in fetal liver samples, 500-fold lower in neonates, and 90- 
fold lower in infants. Expression of hepatic OATP1B3 was 30-fold lower in fetuses, 600fold lower in neonates, and 100-fold lower in infants than in adults. Given the fact that there is only a weak if any correlation between mRNA and protein expression for OATP1B1 and 1B3[94], these findings are also not inconsistent with our results.

In summary, this study has shown that OATP1B3 protein expression shows an unusual pattern of development as compared to other drug disposition proteins. Protein expression starts at a very high expression level throughout the neonatal phase, thereafter declining into the early childhood years. Then protein expression starts to increase again during the pre-adolescent period. The protein expression for OATP1B1 showed a pattern consistent with ontogeny category 2 with no association found between protein expression across age. Further understanding the ontogeny of drug disposition pathways including transport proteins will contribute to the scientific basis for rationale approaches to improve pharmacotherapy in young children, including the currently widely used physiologically based modeling and simulation approaches.[107, 108] 


\section{CHAPTER 4. GENENTIC VARIABILITY OF OATP1B1 AND OATP1B3}

Complicating the ontogeny patterns of transporters or drug metabolizing enzymes is the genetic variability of the transporter or enzyme. Each genetic variant of a drug metabolizing enzyme or transporter has a functional consequence. The genetic variability of CYP2D6 has been extensively studied leading to the discovery of more than 75 different variants.[3] These variants result in phenotypes with increased or decreased activity. The variants have altered protein expression due to changes in sequence, deletions, and splicing defects.[109] The transporter MDR1 also has multiple genetic variants that impact function. Of the most commonly studied SNPs in MDR three of them $(1236 \mathrm{C} \rightarrow \mathrm{T}, 2677 \mathrm{G} \rightarrow \mathrm{T} / \mathrm{A}$, and $3435 \mathrm{C} \rightarrow \mathrm{T})$ are in linkage disequilibrium.[110] The resulting decreased function of these variants not fully been elucidated. Potential sources of the reduced function include less stable mRNA, altered protein folding, and impaired membrane placement.[110]

Many times data on drug metabolism containing genetic information from the adult population is extrapolated to children and infants without incorporating the role of growth and development.[3] Investigations into the relationship between ontogeny and genotype have so far yielded limited results. The genotype-phenotype relationship cannot be fully apparent until the proteins in question are expected to be fully expressed which varies by each individual gene.[3] The relationship among genotype, phenotype and ontogeny has slowly been investigated within the CYP family of drug metabolizing enzymes. One of the most notable polymorphic drug metabolizing enzymes, CYP2D6 has been shown to have genotype-phenotype agreement after the first two weeks of life.[13] However, for CYP2C19 the situation is much more complicated. While the number of functional CYP2C19 alleles are a predictor of exposure to substrates; this is only true for adults, adolescents, and older children.[13] Predicting exposure of CYP2C19 substrates in infants is much more complicated because ontogeny patterns overshadow the genotype.[13] Looking at the interplay of genotype and ontogeny is possible for many of the CYP enzymes as the genetic information has been well documented and the ontogeny has been investigated to some degree.

Investigation of genetic variability of drug transporters has lagged behind that of the drug metabolizing enzymes but is expanding. Information regarding genetic variation in most of the drug transporter families now exists. Variation in the ABC transporter family has found genetic variants with reduced expression (MDR1, MRP3, MRP4, MRP2, BCRP), increased expression (BCRP), and reduced activity (BCRP, MRP1, MRP4).[111] The SLC family of transporters contain the members OATP1B1 and OATP1B3. Both OATP1B1 and OATP1B3 have been found to be polymorphic genes with several single nucleotide polymorphisms (SNP) that appear to alter activity of the transporter. OATP1B1 has two functionally relevant SNPs that are commonly studied, $521 \mathrm{~T} \rightarrow \mathrm{C}$ which decreases uptake by the transporter and $388 \mathrm{~A} \rightarrow \mathrm{G}$ which appears to have the opposite effect.[83] The $388 \mathrm{~A} \rightarrow \mathrm{G}$ change results in an amino acid change from asparagine, a polar hydrophilic amino acid, to aspartic acid, an acidc amino acid.[112] The $521 \mathrm{~T} \rightarrow \mathrm{C}$ change results in an amino acid change from valine to alanine[112] which 
results in altered cell membrane expression and reduced maximal transport activity.[113] OATP1B1 $521 \mathrm{~T} \rightarrow \mathrm{C}$ change has been studied extensively with statins as the probe substrates. The $521 \mathrm{C}$ allele decreases transport of atorvastatin, cerivastatin, and pravastatin in in vitro studies.[113] Systemic exposure (AUC) to pravastatin was increased two-fold in patient studies.[113] The increased systemic exposure is due to decreased hepatic uptake activity resulting in increased concentrations in the plasma and reduced opportunity to be excreted from the body. The decrease in OATP1B1 521C transport ability has been confirmed with other substrates as well. There is an increase in systemic exposure to the protease inhibitor lopinavir when 521C is present.[114] Similarly, there is an increase in systemic exposure as well as maximum concentration of the anti-diabetic medication, nateglinide.[115]

Examination of OATP1B1 $388 \mathrm{~A} \rightarrow \mathrm{G}$ has not been as straight forward. Studies have shown that plasma concentrations of pravastatin are reduced with the $388 \mathrm{G}$ allele, indicating increased hepatic uptake by OATP1B1.[113] Increased hepatic uptake decreases plasma concentrations as once in the liver substrates are metabolized or excreted into bile. The anti-diabetic medication repaglinide has shown decreased exposure when patients have $388 \mathrm{G}$ indicating increased uptake.[116] Contradicting the results seen with pravastatin, studies the cerivastatin have shown increased plasma concentrations.[113]Current reports tend to show increased transporter uptake activity when $388 \mathrm{G}$ is involved, but caution should be used for untested substrates with this SNP.

The most commonly studied, functionally relevant, SNPs for OATP1B3 include $334 \mathrm{~T} \rightarrow \mathrm{G}$ and $699 \mathrm{G} \rightarrow \mathrm{A}$, where $334 \mathrm{~T}$ and $699 \mathrm{G}$ are the lesser frequency allele, appear to increase hepatic uptake of substrates.[84] The 334T $\rightarrow$ G SNP results in the amino acid change serine, a hydrophilic amino acid, for the hydrophobic alanine.[117] The 699G $\rightarrow \mathrm{A}$ SNP has a similar change switching the hydrophilic methionine for the hydrophobic isoleucine.[117] These SNPs are usually examined together as most studies find them to be in linkage disequilibrium.[118] Patients given mycophenolic acid have increased dosenormalized systemic exposure to the medication if they have $334 \mathrm{G}$ or $699 \mathrm{~A}$ due to decreased hepatic uptake.[119] Cholecystokinin (CCK8) has shown decreased uptake into cells transfected with either 334G or 699A. [93] The decrease in uptake of CCK 8 by the hepatocytes expressing 699A has been attributed to a decrease in the maximal transport activity.[93] Similar results of decreased uptake into cells transfected with 334G or 699A was also seen with rosuvastatin.[93] Dose-normalized trough concentrations of digoxin have been found to be reduced in patients with $334 \mathrm{~T}$ or $699 \mathrm{G}$ alleles but these findings were not statistically significant in 29 patients.[120]

The purpose of this study was to explore the presence of the SNPs in pediatric liver samples as a pilot project. The SNPs OATP1B1 $388 \mathrm{~A} \rightarrow \mathrm{G}$ and $521 \mathrm{~T} \rightarrow \mathrm{C}$ were chosen as they appear to be the most common and relevant in terms of OATP1B1 activity. OATP1B1 $521 \mathrm{~T} \rightarrow \mathrm{C}$ has an allele frequency reported between $0.02-0.14$ depending upon ethnicity.[102] The OATP1B3 SNPs 334T $\rightarrow \mathrm{G}$ and 699G $\rightarrow$ A were chosen as they are the most commonly discussed SNPs for OATP1B3. They were also chosen to further investigate the linkage disequilibrium between the two. The genetic 
variation found amongst the samples will be explored with the ontogeny data to determine if genotype influences protein expression of OATP1B1 andOATP1B3.

\section{Methods}

\section{Pediatric Liver Specimens}

Post-mortem liver specimens $(n=67)$ from individuals aged $0.025-12$ years were obtained from the Brain \& Tissue Bank for Developmental Disorders, University of Baltimore and University of Miami (National Institute of Child Health \& Human Development contract N01-HD-8-3284) [31]. Besides major diseases and cause of death, no other sample identifiers were available. Samples from individuals with disease conditions that potentially could involve liver damage were not included in the study. Tissues were stored at $-70^{\circ} \mathrm{C}$ until analysis. The study was approved by the Institutional Review Board of the University of Tennessee Health Science Center. These samples are a subset of those used for the ontogeny investigation in Chapter 3.

\section{SNP Determination}

Genomic DNA was isolated from $25 \mathrm{mg}$ of post-mortem liver samples. Concentration was determined by the ultraviolet absorbance at 260/280 nm. Using allele specific primers in which the SNP of interest is the difference between two primers the genotype was determined for each sample. Both allele primers are added to a single PCR reaction. Only the primer with the corresponding SNP anneals to the denatured DNA. TaqMan ${ }^{\circledR}$ Drug Metabolism Genotyping Assay ${ }^{\mathrm{TM}}$ probes were acquired for OATP1B1 $388 \mathrm{~A} \rightarrow \mathrm{G}$, OATP1B1 $521 \mathrm{~T} \rightarrow \mathrm{C}$, OATP1B3 334T $\rightarrow \mathrm{G}$, and OATP1B3 699G $\rightarrow \mathrm{A}$ (Applied Biosystems, Foster City, CA) (Table 4-1) where the first allele is the reference allele and the second allele is the variant allele. PCR reactions were carried out per manufacturer's protocol. In brief, the $25 \mu 1$ reaction mixture consisted of $20 \mathrm{ng}$ DNA, $12.5 \mu 12$ X TaqMan ${ }^{\circledR}$ Drug Metabolism PCR Master Mix, $1.25 \mu 1$ 20X Drug Metabolism Genotyping Assay Mix. The PCR reaction was performed on the ABI Prism ${ }^{\circledR}$ Sequence Detection System 7000 (Applied Biosystems, Foster City, CA), with the following steps: $50^{\circ} \mathrm{C}$ x 2 minutes, $95^{\circ} \mathrm{C}$ x 10 minutes, then 50 cycles of $92^{\circ} \mathrm{C}$ x 15 seconds and $60^{\circ} \mathrm{C} \mathrm{x}$ 90 seconds. Allelic discrimination was performed using the Sequence Detection Software provided.

\section{Statistical Analysis}

All Statistical analyses were performed using SAS version 9.3 (Cary, NC). Allele frequency was examined for Hardy-Weinberg Equilibrium using Pearson chi square. Relative protein expression among SNP groups was compared by one-way analysis of variance with Bonferroni correction for post hoc comparisons after logarithmic 
Table 4-1. PCR primers used for allelic discrimination assay

\begin{tabular}{|c|c|c|c|}
\hline Gene & SNP & $\begin{array}{c}\text { SNP } \\
\text { reference } \\
\text { ID } \\
\end{array}$ & Sequence \\
\hline OATP1B1 & 388 & Rs2306283 & CAGGTATTCTAAAGAAACTAATATC[A/G]ATTCATCAGAAAATTCAACATCGAC \\
\hline OATP1B1 & 521 & Rs4149056 & TCTGGGTCATACATGTGGATATATG[C/T]GTTCATGGGTAATATGCTTCGTGGA \\
\hline OATP1B3 & 334 & Rs4149117 & TATGGGAACTGGAAGTATTTTGACA[G/T]CTTTACCACATTTCTTCATGGGATA \\
\hline OATP1B3 & 699 & Rs7311358 & CACTGGGATCTCTGTTTGCTAAAAT【A/G]TACGTGGATATTGGATATGTAGATC \\
\hline
\end{tabular}

The bracketed nucleotide is the location of the SNP. One primer contains the first nucleotide in the bracket; the second primer contains the other nucleotide. 
transformation. Associations between select continuous variables were investigated by Pearson product moment correlation. All $\mathrm{p}$-values $\leq 0.05$ were considered significant.

\section{Results}

67 post-mortem liver samples were used for SNP determination. All four SNPs investigated, OATP1B1 $388 \mathrm{~A} \rightarrow \mathrm{G}$, OATP1B1 $521 \mathrm{~T} \rightarrow \mathrm{C}$, OATP1B3 334T $\rightarrow \mathrm{G}$, and OATP1B3 699G $\rightarrow$ A, were found to be in Hardy-Weinberg equilibrium $(p>0.05)$. Allele frequencies for OATP1B1 $388 \mathrm{~A} \rightarrow \mathrm{G}$ and OATP1B1 $521 \mathrm{~T} \rightarrow \mathrm{C}$ can be found in Table 4-2; while the frequencies for OATP1B3 334T $\rightarrow$ G and OATP1B3 699G $\rightarrow$ A are in Table 4-3. Previous reports of allele frequencies for each SNP currently examined were compared to the observed values. Allele frequencies differ with different ethnicity and geographical origin and samples from Caucasians and African-Americans were analyzed separately for this reason.[112] For purposes of this analysis it was assumed those classified as Caucasian were of European American ethnicity and analyzed separately from samples from African-Americans. Observed values did not statistically differ from the expected values in terms of allele frequency for Caucasians or AfricanAmericans.[112, 117] OATP1B3 334T $\rightarrow \mathrm{G}$ and OATP1B3 699G $\rightarrow$ A were found to be in complete linkage disequilibrium $(\mathrm{p}=0.0000)$. OATP1B1 $388 \mathrm{~A} \rightarrow \mathrm{G}$ was found to be in linkage disequilibrium with both OATP1B3 334T $\rightarrow \mathrm{G}$ and OATP1B3 699G $\rightarrow$ A $(\mathrm{p}<0.05)$.

Associations between SNP and protein expression were explored using analysis of variance. As can be seen in Figure 4-1, Figure 4-2, Figure 4-3, and Figure 4-4 there was no statistical significance seen between OATP1B genotype and protein expression for each of the four SNPs investigated. This was true for OATP1B1 $388 \mathrm{~A} \rightarrow \mathrm{G}$, OATP1B1 $521 \mathrm{~T} \rightarrow \mathrm{C}$, OATP1B3 $344 \mathrm{~T} \rightarrow \mathrm{G}$, and OATP1B3 699G $\rightarrow \mathrm{A}(\mathrm{p}>0.05)$. For OATP1B3 correlation between genotype and protein expression for both glycosylated and non-glycosylated forms of the transporter was explored; no statistical significance was found for either form of the protein.

Associations between SNP, protein expression, age were also explored using analysis of variance. As can be seen in Figure 4-5, Figure 4-6, Figure 4-7, Figure 4-8, Figure 4-9, and Figure 4-10 there was no statistical significance seen between OATP1B genotype, protein expression, and age. For each of the genotypes investigated, there were no discernible patterns observed with age and protein expression. This was true for OATP1B1 $388 \mathrm{~A} \rightarrow \mathrm{G}$, OATP1B1 $521 \mathrm{~T} \rightarrow \mathrm{C}$, OATP1B3 $344 \mathrm{~T} \rightarrow \mathrm{G}$, and OATP1B3 $699 \mathrm{G} \rightarrow \mathrm{A}(\mathrm{p}>0.05)$. For OATP1B3 correlation between genotype, protein expression, and age for both glycosylated and non-glycosylated forms of the transporter was explored; no statistical significance was found for either form of the protein. 
Table 4-2. Allelic frequencies for OATP1B1 SNPs $388 \mathrm{~A} \rightarrow \mathrm{G}$ and $521 \mathrm{~T} \rightarrow \mathrm{C}$

\begin{tabular}{lccc}
\hline \multicolumn{1}{c}{ SNP } & N & $\begin{array}{c}\text { Reference allele } \\
(\mathbf{p})\end{array}$ & Variant allele (q) \\
\hline SNP 388 & & & \\
Overall & 67 & 0.530 & 0.470 \\
Observed Caucasian & 41 & 0.6 & 0.4 \\
$\begin{array}{l}\text { Observed African- } \\
\text { American }\end{array}$ & 23 & 0.370 & 0.630 \\
Reported Caucasian & & & \\
$\begin{array}{l}\text { Reported African- } \\
\text { American }\end{array}$ & & 0.7 & 0.3 \\
SNP 521 & & 0.28 & 0.72 \\
Overall & & & \\
Observed Caucasian & 67 & 0.940 & \\
Observed African- & 23 & 0.902 & 0.060 \\
American & & 1 & 0.098 \\
Reported Caucasian & & & \\
Reported African- & & 0.87 & 0.13 \\
American & & 0.98 & 0.02 \\
\hline
\end{tabular}

$\mathrm{A}$ and $\mathrm{G}$ are the reference and variant alleles respectively for $388 \mathrm{~A} \rightarrow \mathrm{G}$ and $\mathrm{T}$ and $\mathrm{C}$ are the reference and variant alleles respectively for $521 \mathrm{~T} \rightarrow \mathrm{C}$. Previously reported values are included for reference.[102, 112] 
Table 4-3. Allelic frequencies for OATP1B3 SNPs 334T $\rightarrow G$ and $699 G \rightarrow A$

\begin{tabular}{lccc}
\hline \multicolumn{1}{c}{ SNP } & N & Reference allele (p) & Variant allele (q) \\
\hline SNP 334 & 67 & 0.261 & 0.739 \\
Overall & 41 & 0.134 & 0.866 \\
Observed Caucasian & 23 & 0.5 & 0.5 \\
Observed African- & & & \\
American & & 0.19 & 0.81 \\
Reported Caucasian & & 0.41 & 0.59 \\
Reported African- & & \\
American & & & \\
SNP 699 & 67 & 0.261 & 0.739 \\
Overall & 41 & 0.134 & 0.866 \\
Observed Caucasian & 0.5 & 0.5 \\
Observed African- & & \\
American & 23 & 0.19 & \\
Reported Caucasian & 0.41 & 0.81 \\
Reported African- & & & 0.59 \\
American & & & \\
\hline
\end{tabular}

$\mathrm{T}$ and $\mathrm{G}$ are the reference and variant alleles respectively for $334 \mathrm{~T} \rightarrow \mathrm{G}$. $\mathrm{G}$ and $\mathrm{A}$ are the reference and variant alleles respectively for and $699 \mathrm{G} \rightarrow$ A. Previously reported values are included for reference.[102, 117] 


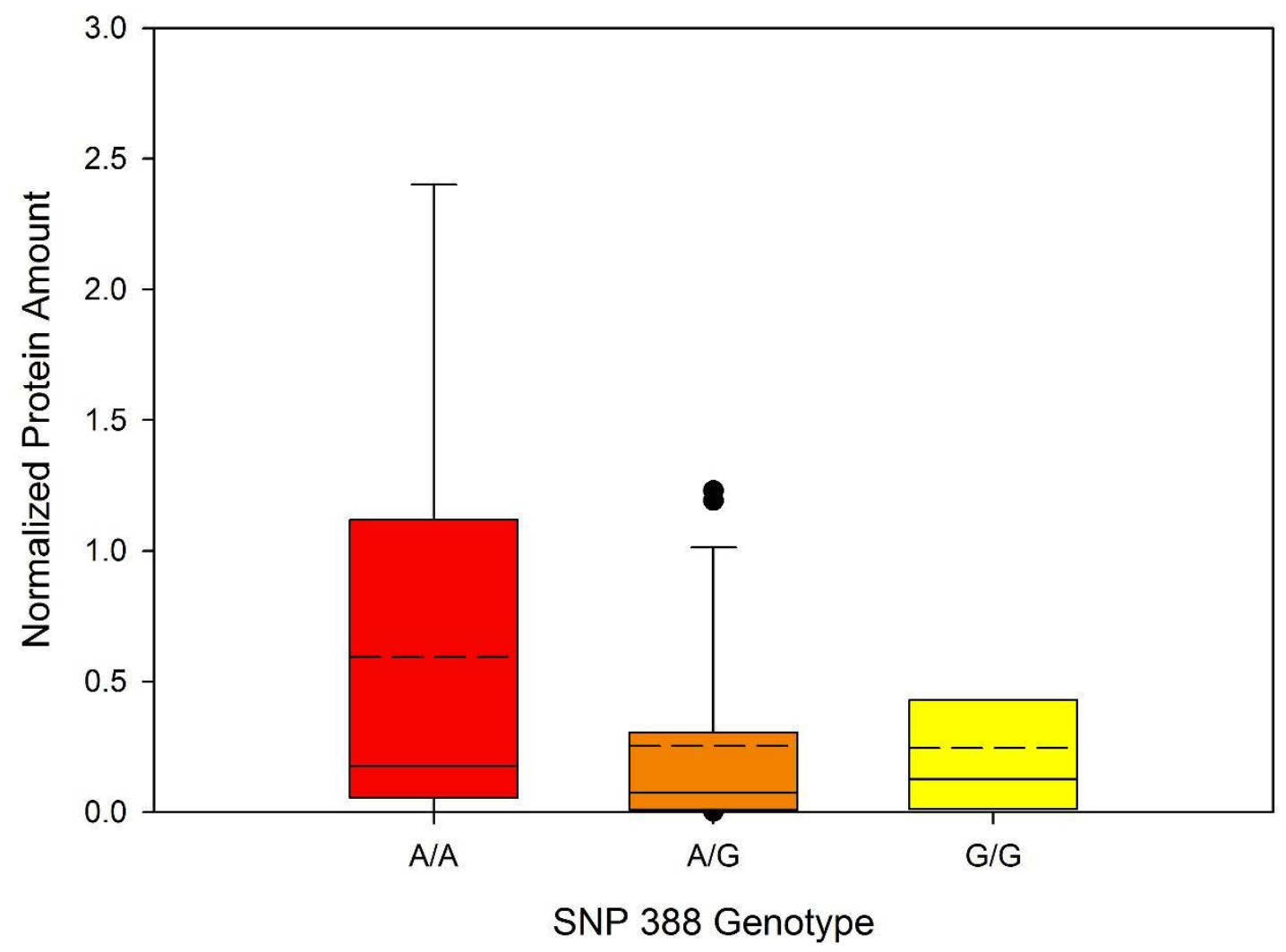

Figure 4-1. Normalized OATP1B1 protein and SNP 388 genotype

Box and whisker plot examining normalized OATP1B1 $388 \mathrm{~A} \rightarrow$ G genotype. A/A represents samples that were homozygous for the reference allele. $G / G$ represents samples that were homozygous for the variant allele. Boxes represent the interquartile range, whiskers the $10^{\text {th }}$ and $90^{\text {th }}$ percentile. The solid horizontal line in the box denotes the median, the dotted line the mean of the data. 


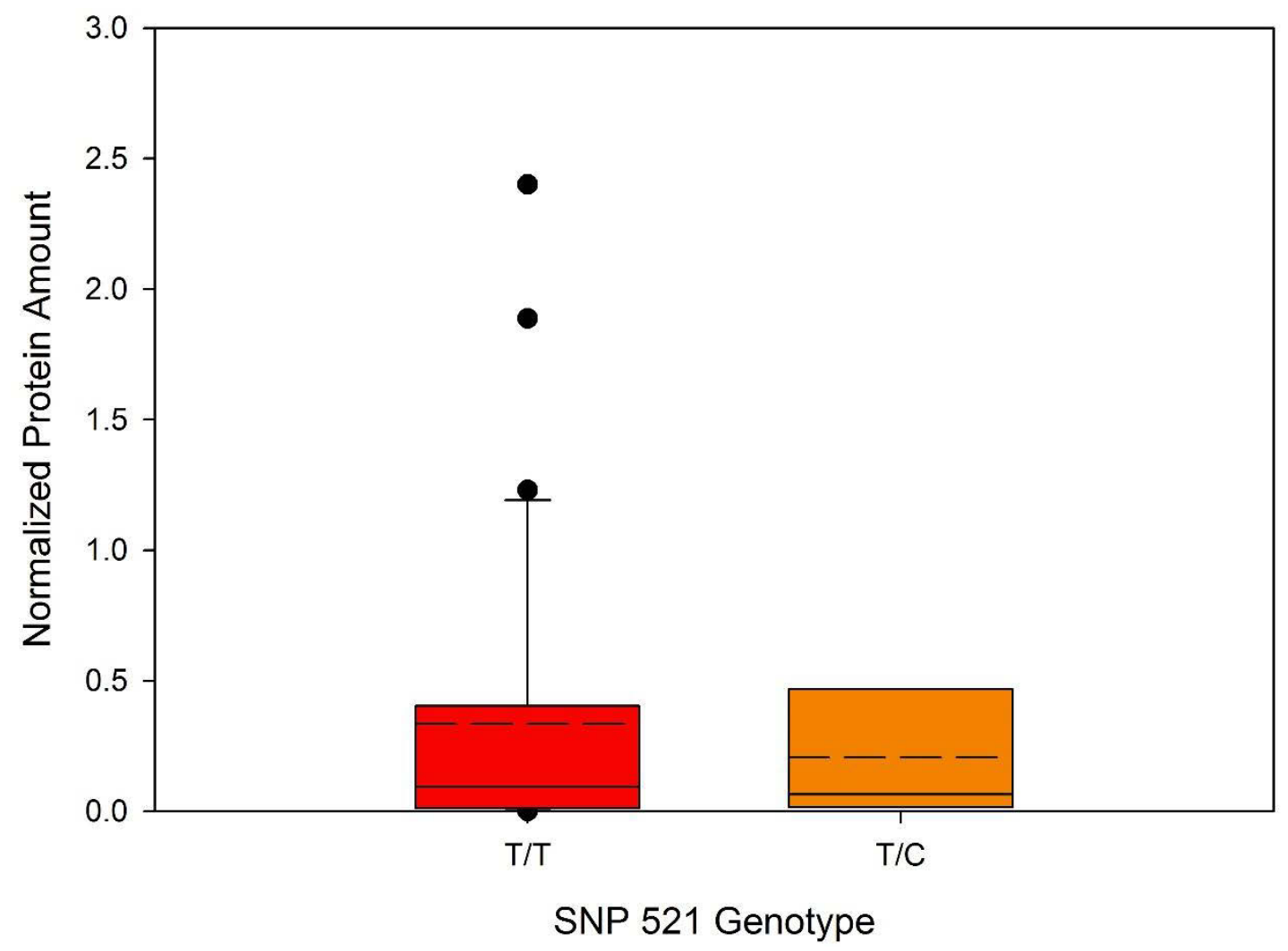

Figure 4-2. Normalized OATP1B1 protein compared to SNP 521 genotype

Box and whisker plot examining normalized OATP1B1 $521 \mathrm{~T} \rightarrow \mathrm{C}$ genotype. T/T represents samples that were homozygous for the reference allele. There were no samples that were homozygous for the variant allele $\mathrm{C} / \mathrm{C}$. Boxes represent the interquartile range, whiskers the $10^{\text {th }}$ and $90^{\text {th }}$ percentile. The solid horizontal line in the box denotes the median, the dotted line the mean of the data. 


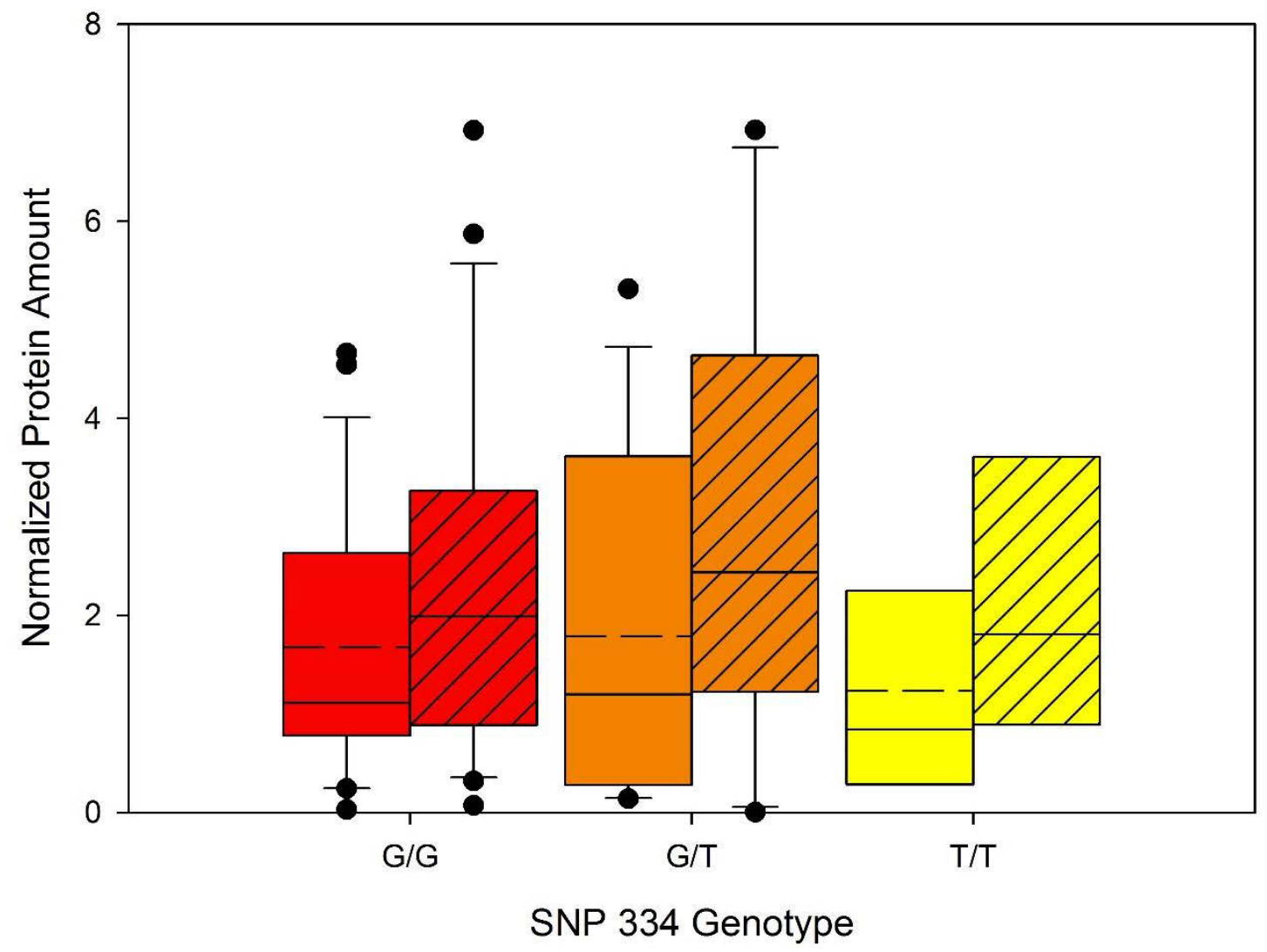

Figure 4-3. Normalized OATP1B3 glycosylated and non-glycosylated protein compared to SNP 334 genotype

Box and whisker plot examining normalized OATP1B3 334G $\rightarrow$ T genotype. G/G represents samples that were homozygous for the reference allele. $\mathrm{T} / \mathrm{T}$ represents samples that were homozygous for the variant allele. The shaded boxes represent the nonglycosylated protein. Boxes represent the interquartile range, whiskers the $10^{\text {th }}$ and $90^{\text {th }}$ percentile. The solid horizontal line in the box denotes the median, the dotted line the mean of the data. 


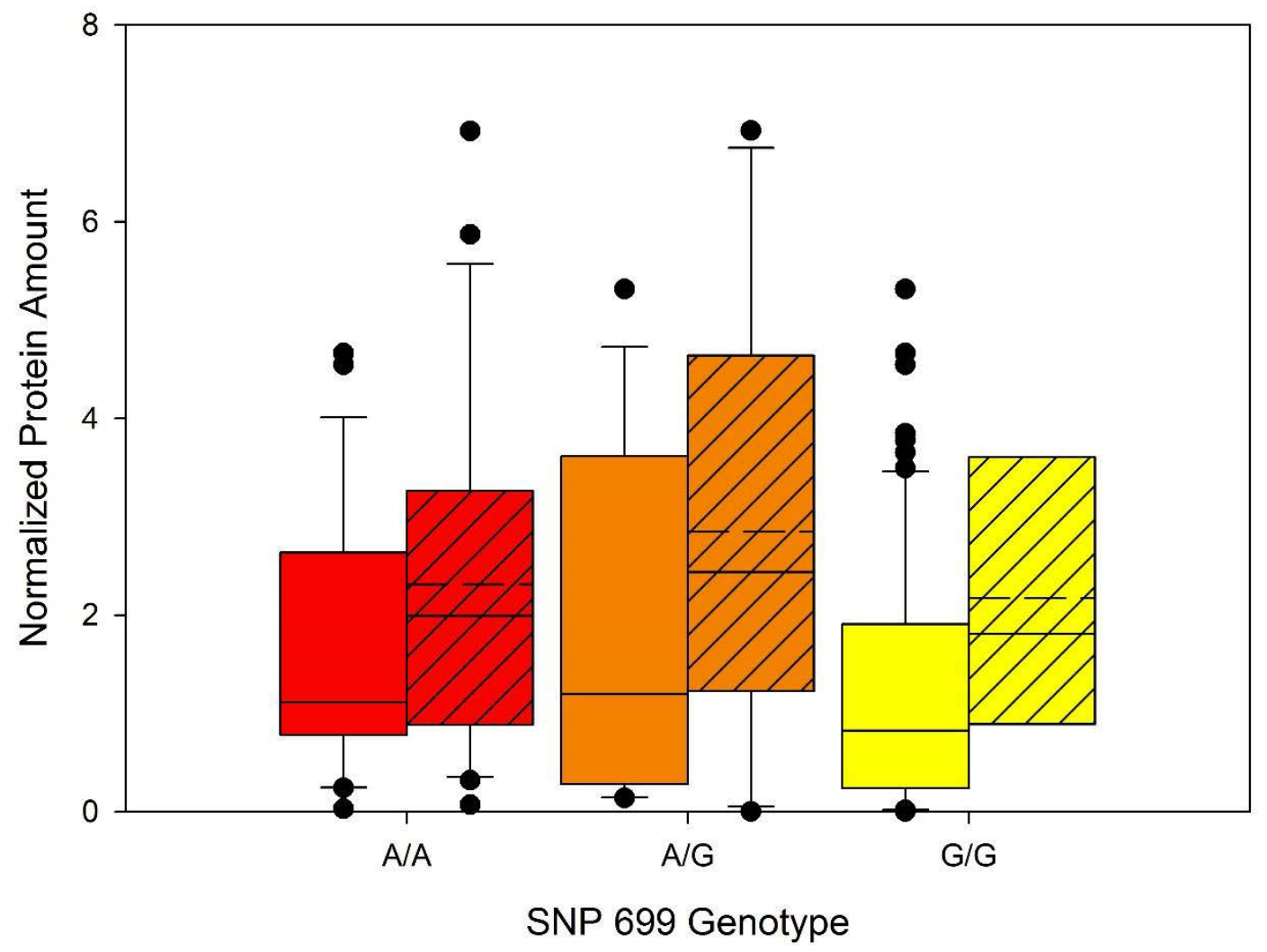

Figure 4-4. Normalized OATP1B3 glycosylated and non-glycosylated protein compared to SNP 699 genotype

Box and whisker plot examining normalized OATP1B3 699A $\rightarrow$ G genotype. A/A represents samples that were homozygous for the reference allele. G/G represents samples that were homozygous for the variant allele. The shaded boxes represent the nonglycosylated protein. Boxes represent the interquartile range, whiskers the $10^{\text {th }}$ and $90^{\text {th }}$ percentile. The solid horizontal line in the box denotes the median, the dotted line the mean of the data. 


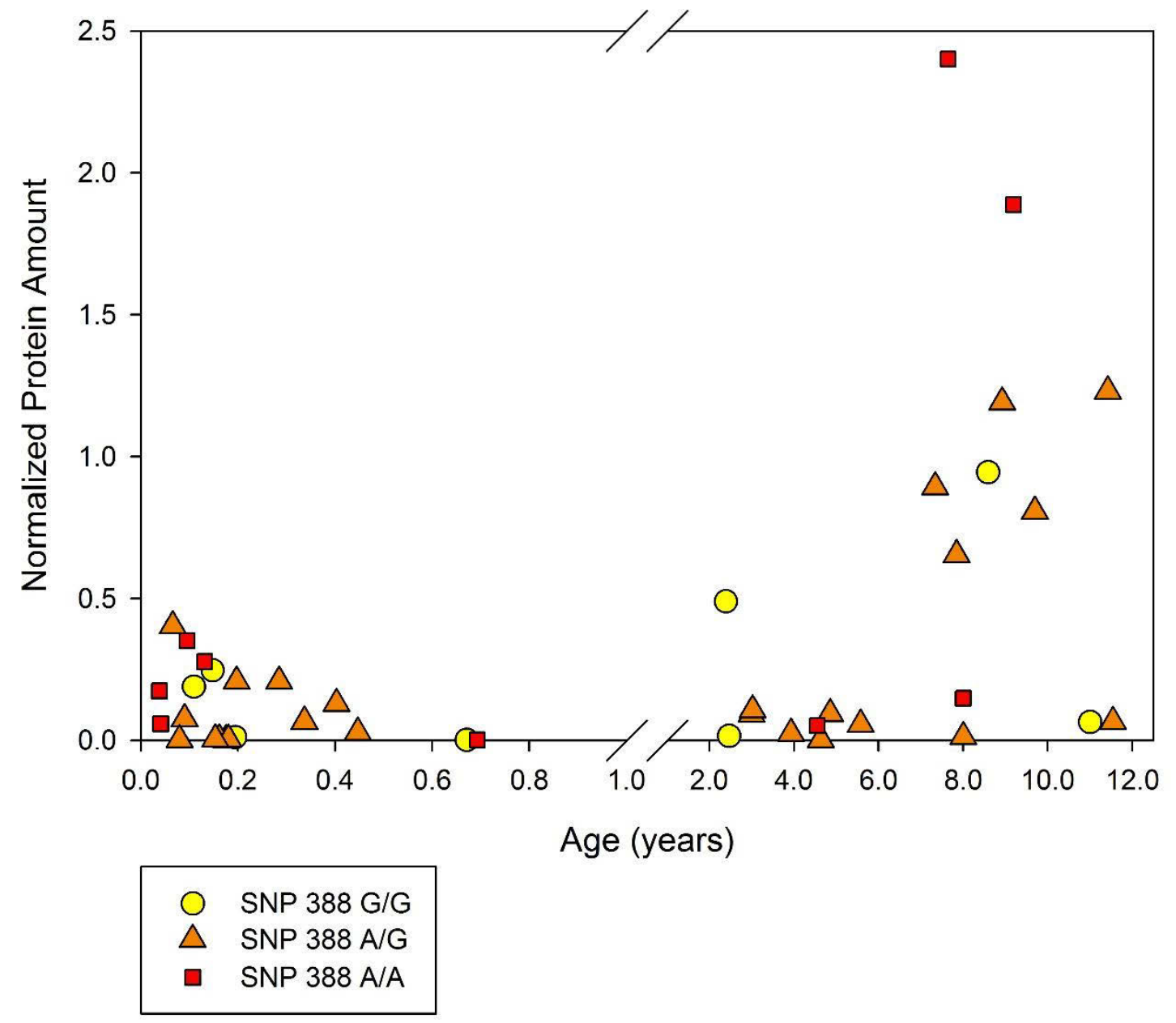

Figure 4-5. Scatterplot of normalized OATP1B1 protein expression compared to age by SNP388

Relative OATP1B1 protein expression (normalized to GAPDH) in pediatric liver versus postnatal age. The $\mathrm{x}$-axis is discontinuous with ages less than 1 year shown as a fraction. The 388 genotype of each sample is represented by the symbol (O) for homozygous variant allele $\mathrm{G} / \mathrm{G}(\Delta)$ for heterozygous $\mathrm{G} / \mathrm{A}$ and $(\square)$ homozygous reference allele $\mathrm{A} / \mathrm{A}$. 


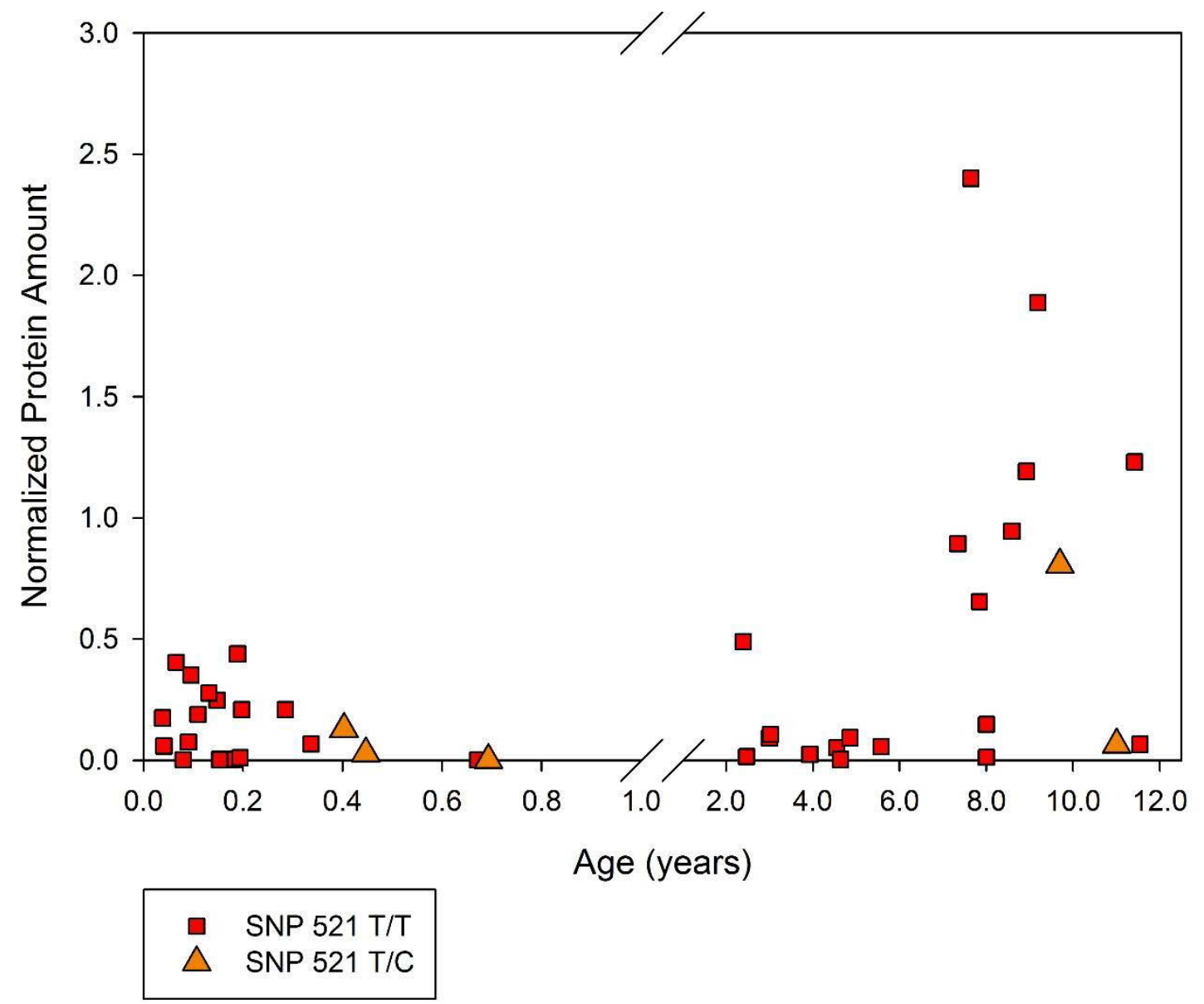

Figure 4-6. Scatterplot of normalized OATP1B1 protein expression compared to age by SNP 521

Relative OATP1B1 protein expression (normalized to GAPDH) in pediatric liver versus postnatal age. The $\mathrm{x}$-axis is discontinuous with ages less than 1 year shown as a fraction. The 521 genotype of each sample is represented by the symbol $(\Delta)$ for heterozygous T/C and ( $\square$ ) homozygous reference allele $T / T$. There were no samples representing the homozygous variant genotype $\mathrm{C} / \mathrm{C}$. 


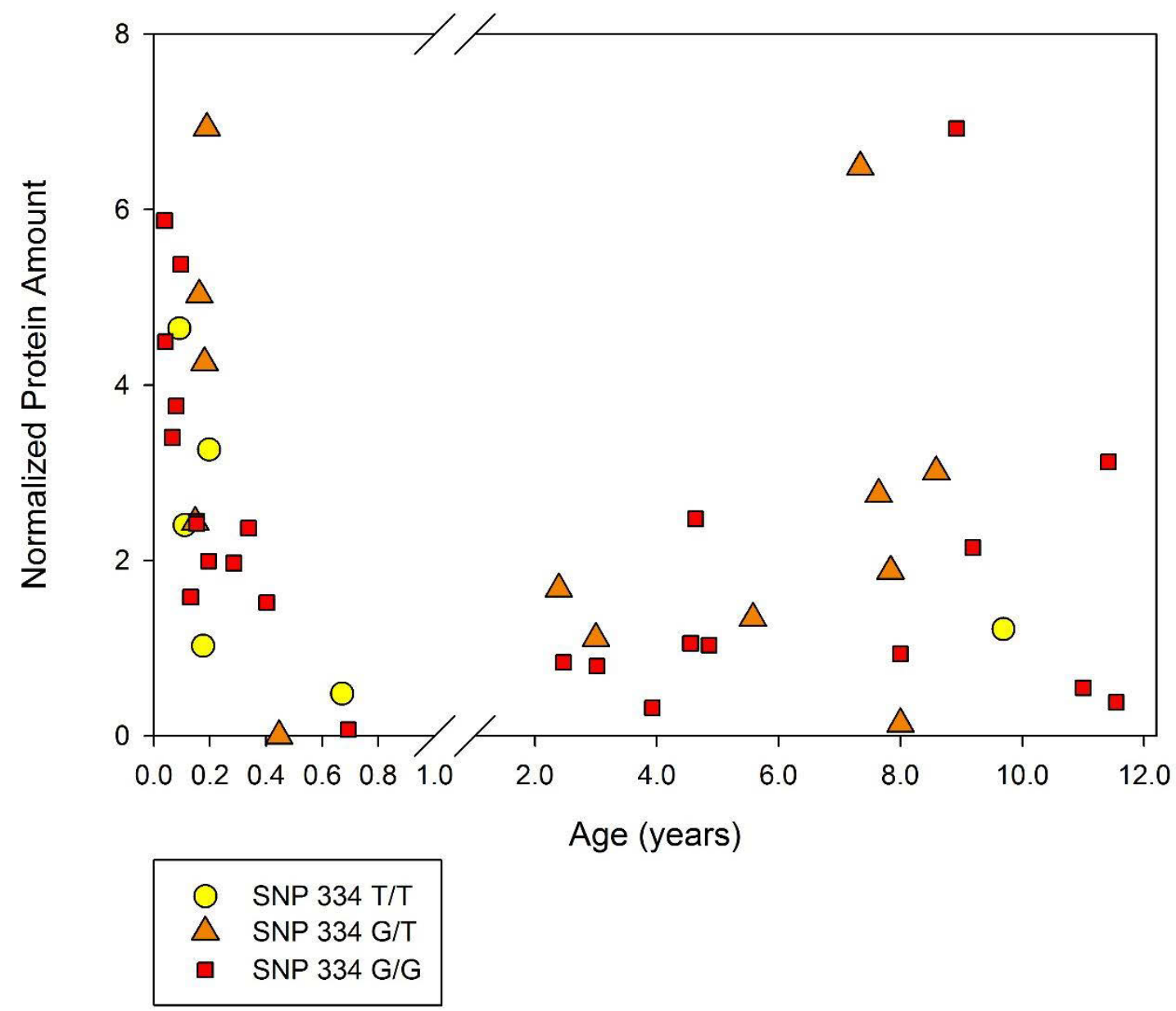

Figure 4-7. Scatterplot of normalized OATP1B3 non-glycosylated protein compared to age by SNP 334

Relative OATP1B3 non-glycosylated protein expression (normalized to GAPDH) in pediatric liver versus postnatal age. The $\mathrm{x}$-axis is discontinuous with ages less than 1 year shown as a fraction. The 334Genotype of each sample is represented by the symbol ( $(0)$ for homozygous variant allele $\mathrm{G} / \mathrm{G}(\Delta)$ for heterozygous $\mathrm{T} / \mathrm{G}$ and $(\square)$ homozygous reference allele $\mathrm{T} / \mathrm{T}$. 


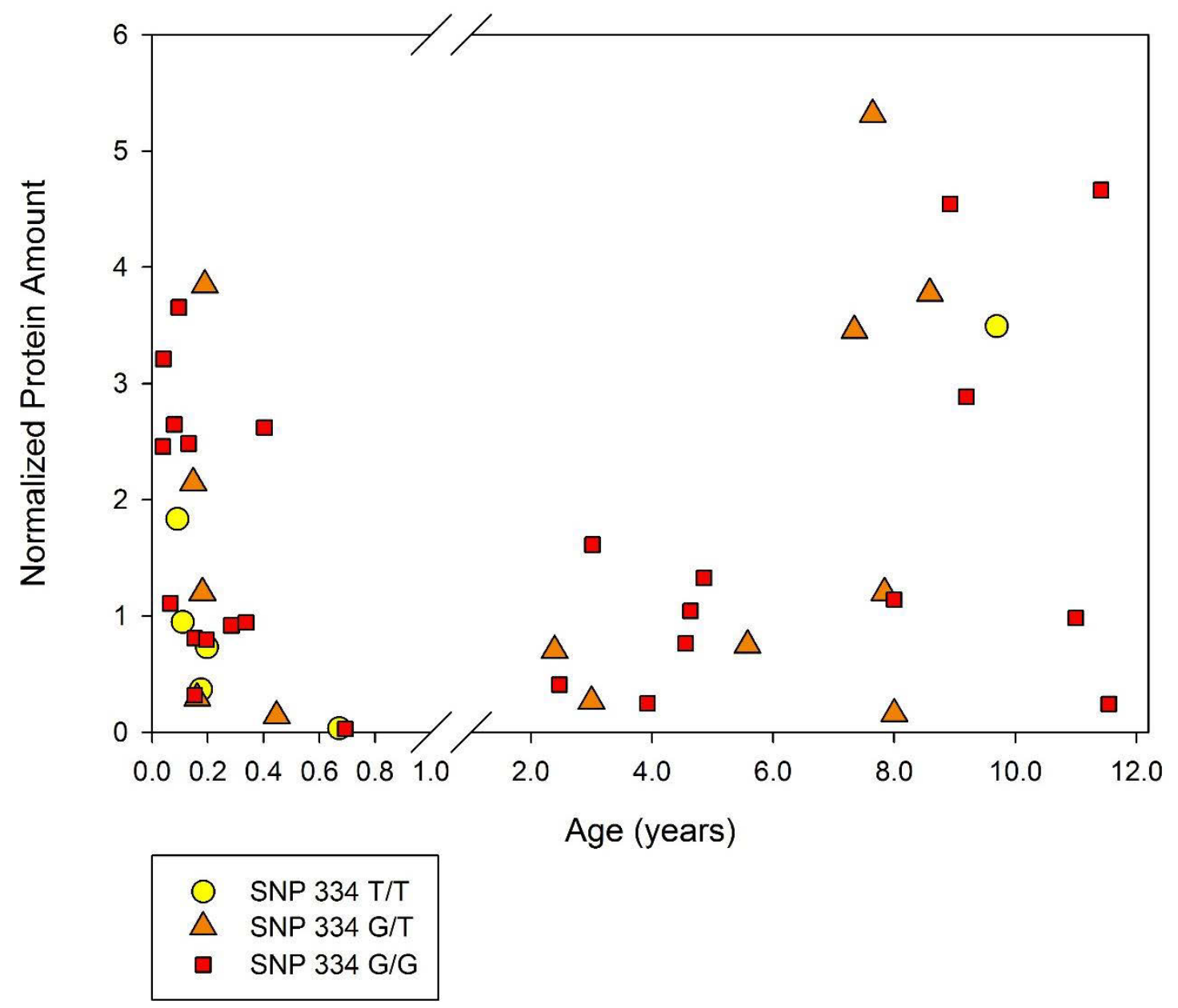

Figure 4-8. Scatterplot of normalized OATP1B3 glycosylated protein compared to age by SNP 334

Relative OATP1B3 glycosylated protein expression (normalized to GAPDH) in pediatric liver versus postnatal age. The $\mathrm{x}$-axis is discontinuous with ages less than 1 year shown as a fraction. The 334Genotype of each sample is represented by the symbol ( 0 ) for homozygous variant allele $\mathrm{G} / \mathrm{G}(\Delta)$ for heterozygous $\mathrm{T} / \mathrm{G}$ and $(\square)$ homozygous reference allele $\mathrm{T} / \mathrm{T}$. 


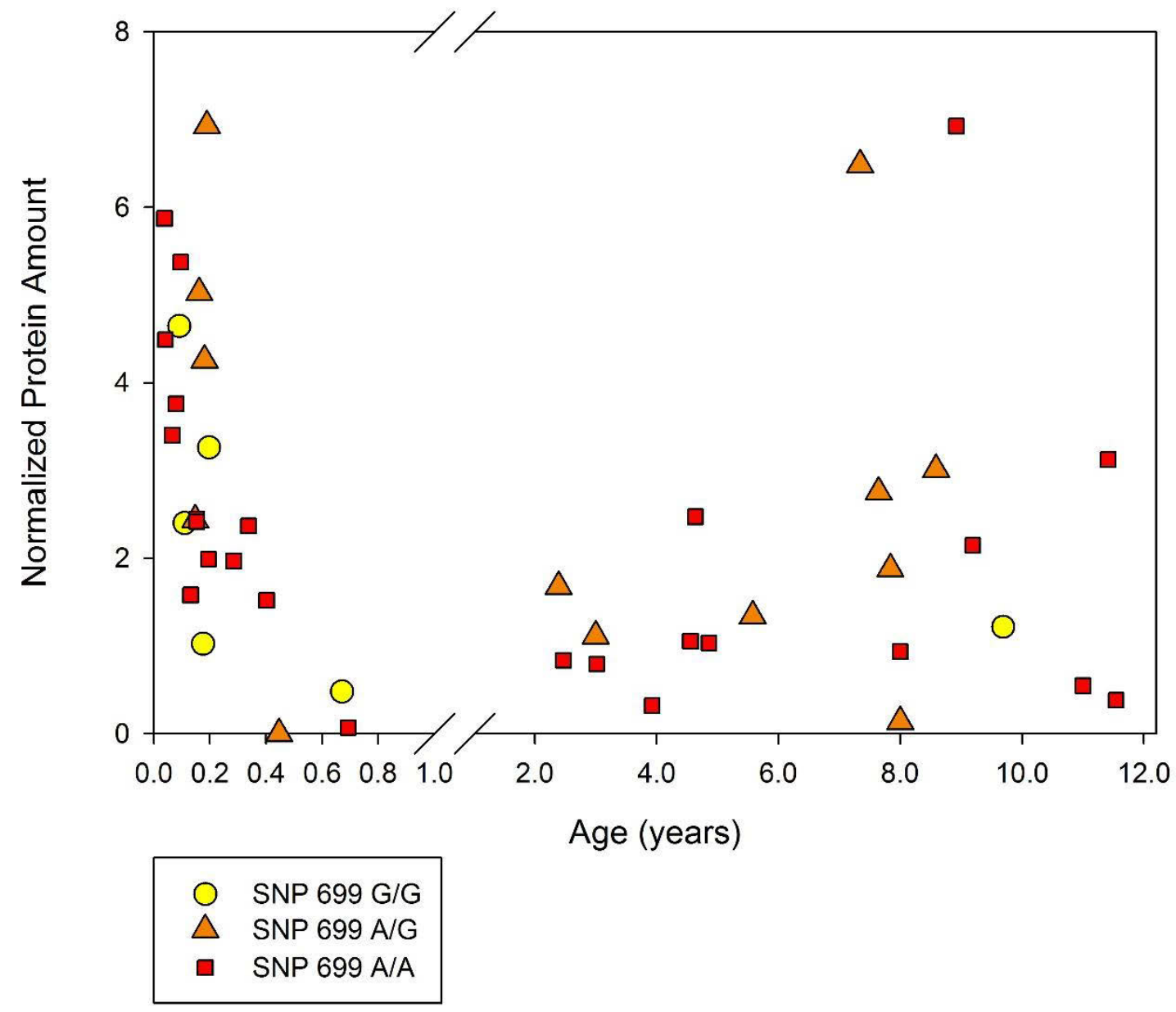

Figure 4-9. Normalized OATP1B3 non-glycosylated protein compared to age by SNP 699

Relative OATP1B3 non-glycosylated protein expression (normalized to GAPDH) in pediatric liver versus postnatal age. The $\mathrm{X}$-axis is discontinuous with ages less than 1 year shown as a fraction. The 699Genotype of each sample is represented by the symbol (O) for homozygous variant allele $\mathrm{A} / \mathrm{A}(\Delta)$ for heterozygous G/A and $(\square)$ homozygous reference allele $\mathrm{G} / \mathrm{G}$. 


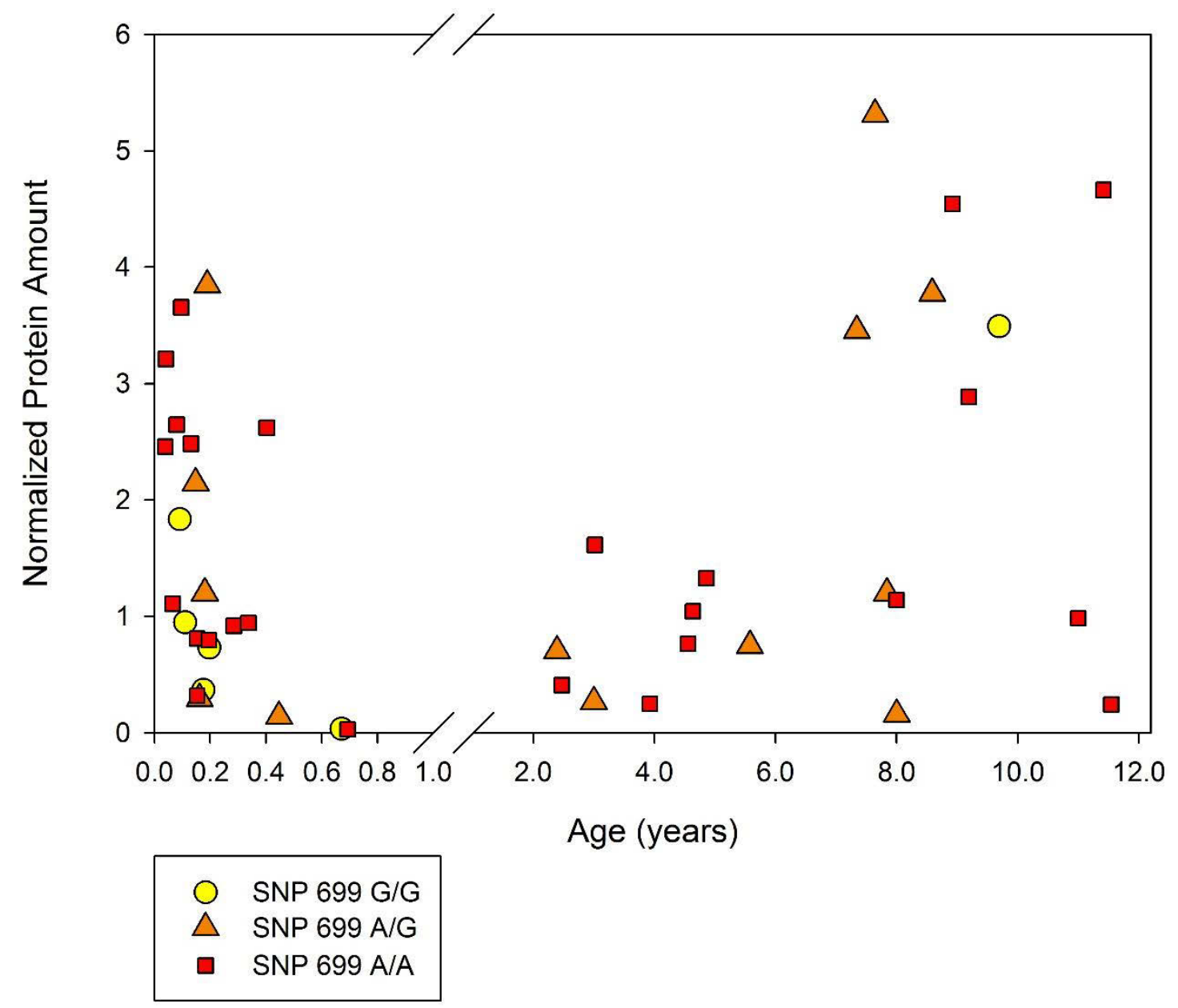

Figure 4-10. Normalized OATP1B3 glycosylated protein compared to age by SNP 699

Relative OATP1B3 glycosylated protein expression (normalized to GAPDH) in pediatric liver versus postnatal age. The $\mathrm{x}$-axis is discontinuous with ages less than 1 year shown as a fraction. The 699Genotype of each sample is represented by the symbol ( 0 ) for homozygous variant allele $\mathrm{A} / \mathrm{A}(\Delta)$ for heterozygous $\mathrm{G} / \mathrm{A}$ and $(\square)$ homozygous reference allele $\mathrm{G} / \mathrm{G}$. 


\section{Discussion}

The present study investigated the association between genotype and protein expression. All of the SNPs (OATP1B1 $388 \mathrm{~A} \rightarrow \mathrm{G}$, OATP1B1 $521 \mathrm{~T} \rightarrow \mathrm{C}$, OATP1B3 $334 \mathrm{~T} \rightarrow \mathrm{G}$, and OATP1B3 $699 \mathrm{G} \rightarrow \mathrm{A}$ ) examined in the present study have been shown to alter drug disposition. Possession of the $521 \mathrm{~T} \rightarrow \mathrm{C}$ SNP double pravastatin concentrations.[121] The degree of drug-drug interaction between atorvastatin and rifampicin is determined by the $521 \mathrm{~T} \rightarrow \mathrm{C}$ SNP with possession of the $\mathrm{C}$ allele increasing atorvastatin concentrations.[122] The $521 \mathrm{~T} \rightarrow \mathrm{C}$ SNP decreases activity of OATP1B1 resulting in increased concentrations of the endogenous substrates estrone sulfate, triiodothyronine sulfate, thyroxine sulfate, and bilirubin.[123] The pharmacokinetics of the immunosuppressant mycophenolate mofetil are influenced by the SNPs in OATP1B3.[84] When patients express OATP1B3 the 334G and 699A variant alleles the systemic exposure to the glucuronidated metabolite gradually increased with increasing number of $\mathrm{G}$ and A alleles, respectively, due to increased transport of parent mycophenolate mofetil into the liver.[84] Patients with the 334T (699G) reference alleles had higher systemic exposure to mycophenolate mofetil.[84, 119]

Associations of SNPs in the OATP1B genes have been investigated in regards to possible links to disease. In particular, a role for OATP1B1 has been described for the severity of neonatal hyperbilirubinemia.[124-126] Several groups examining risk factors for severe hyperbilirubinemia found that infants who possessed the OATP1B1 $388 \mathrm{~A} \rightarrow \mathrm{G}$ were more likely to suffer from severe hyperbilirubinemia than those infants who possessed the two copies of the reference allele.[124-126] Investigations using samples from older patients found that the OATP1B1 $388 \mathrm{~A} \rightarrow \mathrm{G}$ SNP was not the sole factor increasing the risk for hyperbilirubinemia; but, that change along with a SNP in either UGT 1A1 or glucose-6-phosphate dehydrogenase increased the risk of an individual having the disorder.[126, 127]

The present study investigated the association between genotype and protein expression. In that process it was confirmed that OATP1B3 334T $\rightarrow$ G and OATP1B3 $699 \mathrm{G} \rightarrow \mathrm{A}$ are in complete linkage disequilibrium.[118, 119, 128] Analysis of protein expression data and genotype failed to find an association between them. Of the samples with protein expression data from Chapter 3, only a subset also had genetic data which reduced the sample substantially. With the current sample size, the homozygous variant genotype was not expected to show in the OATP1B1 $521 \mathrm{~T} \rightarrow \mathrm{C}$ group. Possible reasons for the reduced activity seen with the studied SNPs include decreased protein expression, altered biomembrane placement, and reduced transporter kinetics. While the relationship between OATP1B genotype and protein expression was unknown, it would have been reasonable for several of the genotypes studied to have had reduced protein expression. Several MDR1 genetic variants have shown to have reduced expression resulting in higher plasma concentrations. [111] This is also true of other polymorphic transporters such as MRP2, MRP3, MRP4, and OAT4.[111]

Examination of the relationship among genotype, protein expression and age was also attempted. This analysis also failed to show a significant relationship amongst 
genotype, protein expression, or age. This relationship was explored as the influence of ontogeny over genotype is uncertain. If due to normal physiological development a gene (transporter) is not expressed at a certain point in time the actual genotype should not matter as the subject would be a phenotypic no expresser for that gene at that time. A common example in the discussion of the influence of ontogeny on genotype is CYP2D6. This enzyme is polymorphic with distinct phenotypes ranging from no metabolism to extremely increased metabolism due to gene duplication.[111] Ontogeny of CYP2D6 has shown that during the first week of life protein expression is only $5 \%$ of adult values which increase to over 30\% in the first month.[25] Studies have shown that by the first and typically by the first 2 weeks of life the phenotype and genotype match.[26] While this is a fairly short time period, this discrepancy rooted in normal ontogeny between genotype and phenotype illustrates that care must be taken in determining pharmacotherapy for neonates and young children. The relationship for CYP2D6 has been elucidated as the enzyme is responsible for metabolizing $12 \%-20 \%$ of medications.[25, 111] Work with pantoprazole has shown a that genotype and phenotype of CYP2C19 do not correspond until approximately 4 months of life.[13] As more neonates are given more medications at an earlier age information regarding the genotype ontogeny relationship will be observed.

Genetic alterations in OATP1B transporters have an impact on the pharmacokinetics of many drugs investigated to date. While the significance on alterations in drug disposition was known for the four SNPs investigated it was not known if the alterations were due to solely to changes in transporter kinetics or if alterations in transporter protein expression were also a factor. Although the current study was unable to detect an association between protein expression and genotype of any of the four SNPs investigated in OATP1B1 or OATP1B3, this study did confirm allele frequencies for each of the SNPs and the complete linkage disequilibrium that exists for $\mathrm{OATP} 1 \mathrm{~B} 3334 \mathrm{~T} \rightarrow \mathrm{G}$ and $699 \mathrm{G} \rightarrow \mathrm{A}$. The finding of complete linkage disequilibrium for the two SNPs in OATP1B3 was not unexpected as it had been reported elsewhere.[119, $128,129]$

A finding that had not been reported previously was that the SNPs in OATP1B3 were in linkage disequilibrium with OATP1B1 $388 \mathrm{~A} \rightarrow \mathrm{G}$. This association could influence the severity of hyperbilirubinemia cases by limiting the uptake of bilirubin by either OATP1B transporter into the liver which in the short-term is a protective strategy but over time can damage non-hepatic tissues. As mentioned previously, studies investigating risk factors for severe hyperbilirubinemia have focused on OATP1B1 and not OATP1B3 either alone or in combination with OATP1B1. It may be that OATP1B3 is up-regulated while OATP1B1 is down-regulated in times of pathological conditions as a means of protecting the liver as OATP1B1 appears to have higher affinities for shared substrates; but the linkage disequilibrium found between OATP1B1 $388 \mathrm{~A} \rightarrow \mathrm{G}$ and $\mathrm{OATP} 1 \mathrm{~B} 3334 \mathrm{~T} \rightarrow \mathrm{G}$ and $699 \mathrm{G} \rightarrow \mathrm{A}$ indicate that looking at the role of just one of the OATP1B transporters may be short-sighted in terms of understanding the role these transporters may play in hepatic pathological conditions. 
While no associations between protein expression and SNPs OATP1B1 388 $\mathrm{A} \rightarrow \mathrm{G}$ and $521 \mathrm{~T} \rightarrow \mathrm{C}$ and OATP1B3 334T $\rightarrow \mathrm{G}$ and $699 \mathrm{G} \rightarrow \mathrm{A}$ were found; several interesting genetic findings were discovered. The allelic frequencies of the four SNPs were confirmed. The complete linkage disequilibrium of the OATP1B3 SNPs was also confirmed. The interesting finding was that the SNPs in OATP1B3 and OATP1B1 388 $\mathrm{A} \rightarrow \mathrm{G}$ also showed linkage disequilibrium which was not expected. The OATP1B transporters share $80 \%$ homology and this last finding indicates that the relationship between these two transporters needs to be investigated further. Understanding the ontogeny of drug disposition pathways as well as the impact of genetic polymorphisms on those pathways will help improve pharmacotherapy in young children. 


\section{CHAPTER 5. FEXOFENADINE DISPOSITION IN OATP1B2 KNOCKOUT MICE}

Drug transport is a vital part of drug disposition. Not only is drug transport important as a way for an organ to pump drug out in a protective manner; transport into organs is also important for substances which do not readily diffuse across membranes. The liver is a major detoxifying organ which has multiple transporters which allows for both the influx and efflux of substances in what is believed to be a coordinated effort with phase I and phase II metabolic enzymes.[130] The Organic Anion Transporting Polypeptide (OATP) family is responsible for the uptake of many endogenous and xenobiotic substances including bile salts, bilirubin, HMG-coA reductase inhibitors, and rifampicin. $[42,85,131]$ OATP1B transporters are located exclusively on the basolateral surface of the liver.[85]

In humans the OATP1B family is represented by OATP1B1 and OATP1B3. [132, 133] These two transporters share approximately $80 \%$ homology and extensive substrate overlap.[85] As previously discussed in previous chapters, the expression of the OATP1B1 and OATP1B3 may have consequences for the disposition of substances that must transverse the liver for removal from the body. In Chapter 3 it was shown that OATP1B3 protein expression is associated with age such that infants have very high expression of OATP1B3 protein that diminishes during the first year of life with a subsequent increase in the pre-adolescent stage. Chapter 3 also demonstrated the relationship between age and protein expression of OATP1B1 did not show a discernible pattern. While the expression profile gives insight into what is happening at a molecular level it does not answer what happens at a functional level. To that end a knock-out mouse model was used.

In humans OATP1B1, OATP1B3, and OATP2B1 are the only OATP transporters found in the liver.[68] The mouse has significantly more Oatp transporters located in the liver including Oatp1a1, Oatp1a4, Oatp1a5, Oatp1a6, Oatp1b2, and Oatp2b1.[134] Humans only have 1 OATP1A family member, OATP1A2, which is located in the intestines, while mice have multiple Oatpla members that are expressed in multiple organs. $[48,68]$ Of particular interest based on the protein expression study in Chapter 3 is Oatp1b2 which is the murine ortholog of OATP1B1 and OATP1B3.[133] This is the only Oatp $1 \mathrm{~b}$ transporter found in the mouse and shares approximately $65 \%$ homology to the two human members.[133] In vitro methods have shown that Oatp1b2 shares substrate specificity to the human orthologs.[134] The disruption of Oatp1b2 in mice has resulted in mice that appear normal but unable to transport endogenous substrates in a normal manner into the liver.[134] These knock-out mice have elevated levels of total bilirubin which is a substrate of Oatp1b2.[48] The use of fexofenadine as a probe substrate will help elucidate the role that Oatp1b2 plays in the disposition of fexofenadine and provides insight for potential extrapolation into humans.

Fexofenadine is a non-sedating histamine $\mathrm{H} 1$ receptor antagonist used in the treatment of seasonal allergies.[135] After a radiolabeled dose $>80 \%$ of fexofenadine is 
excreted unchanged into bile in humans.[135] Mice also show large biliary excretion with $>60 \%$ of dose unchanged in the bile.[136] At physiological $\mathrm{pH}$ fexofenadine is a zwitterion making active transport an important route of entry into organs. [135] In dosing studies using Mdr1a/1 $\mathrm{b}^{-/-}$knockout mice fexofenadine had higher plasma concentrations and systemic exposure following an oral dose as compared to wild-type controls.[136] Intravenous dosing failed to show the same results suggesting that the difference in fexofenadine disposition in regards to $\mathrm{Mdrla} / 1 \mathrm{~b}$ is related to the lack of efflux into intestine versus efflux from liver as this difference only occurred in oral dosing.[136] Fexofenadine has been demonstrated to be transported by OATP1B.[137-139] HEK293 cells transfected with OATP1B3 demonstrated uptake of fexofenadine as well as the inhibition of that uptake by cyclosporine, ketoconazole, and erythromycin.[137, 138] An in vivo study showed that subjects with the OATP1B1 521T $\rightarrow$ C SNP had statistically significant higher systemic exposure (AUC) in a dose dependent manner with those homozygous for the variant allele had the highest systemic exposure, heterozygous for the alleles were intermediate, and those homozygous for the reference allele had the lowest exposure.[140] Studies have shown fexofenadine to have a large therapeutic window with low risk of toxicity making this a good candidate as a probe substrate.[141]

The fact that fexofenadine is not metabolized with a positive safety profile makes this a good candidate for a probe to investigate the lack of Oatp1b2 protein has on drug disposition. To that end an Oatp1b2 $2^{-}$knockout mouse model was obtained to examine the functional consequence of the lack of Oatp1b2 protein. The ability of murine Oatp1b2 to transport fexofenadine was first explored using cell-culture based uptake assay. It was hypothesized that the lack of Oatp1b2 protein would result in higher systemic exposure to fexofenadine.

\section{Methods}

\section{Cell-Culture Based Uptake Assay}

It had been reported that mouse Oatp1b2 may not transport fexofenadine[133] so prior to starting the in vivo mouse study an exploratory cell-culture based uptake assay confirming fexofenadine uptake by murine Oatp1b2 was performed. HEK293 cells transfected with murine Oatp1b2 were obtained from the laboratory of Dr. Alex Sparreboom (St. Jude Children's Research Hospital, Memphis, TN) and incubated at $37^{\circ} \mathrm{C}$ and $5 \% \mathrm{CO}_{2}$ in DMEM with $10 \% \mathrm{FBS}$. Media was removed and replaced with 2 $\mathrm{mL}$ DMEM with $1 \mu \mathrm{M}$ fexofenadine (Sigma, St. Louis, MO) per well. Plates containing triplicates of control (vector only transfected) and murine Oatp1b2 transfected HEK293 cells were incubated for $15 \mathrm{~min}$ at $37^{\circ} \mathrm{C}$ and $5 \% \mathrm{CO}_{2}$. Plates were placed on ice and wells were washed twice with $2 \mathrm{~mL}$ ice cold PBS. A third washing with PBS was transferred to a centrifuge tube making sure to remove cells from the bottom of the wells. The cells were spun down at $1200 \mathrm{rpm}$ for $5 \mathrm{~min}$. After the removal of the supernatant $200 \mu \mathrm{L}$ $0.2 \mathrm{~N} \mathrm{NaOH}$ was added to each tube and allowed to sit overnight at room temperature. The lysed cells were neutralized with $40 \mu \mathrm{L} 1 \mathrm{~N} \mathrm{HCl}$. The cell lysate were stored at $-80^{\circ} \mathrm{C}$ 
until further quantification of fexofenadine content in the cell lysate. Total protein concentration was determined using the Bio-Rad Protein Assay (Bio-Rad, Hercules, CA) with bovine serum albumin as the standard for each sample.[88] Total protein concentration was used to normalize fexofenadine transport for each sample in order to make comparisons across samples.

\section{Pharmacokinetic Study in Mice}

Adult wild-type mice (DBA/LacJ background) (n=8) and knock-out (Oatp1b2 (-/)) mice $(n=5)$ were obtained from the laboratory of Dr. Alex Sparreboom (St. Jude Children's Research Hospital, Memphis, TN). Mice were housed in a temperature controlled environment with a 12 hour light/dark cycle. They were fed a standard diet and water ad libitum. The animal protocol was approved by the St. Jude Children's Research Hospital Animal Use and Care Committee. On the day of the PK study mice were given $10 \mathrm{mg} / \mathrm{kg}$ fexofenadine [136] (Sigma Aldrich, St. Louis, MO) intravenously via tail vein injection. Blood samples were obtained from bilateral buccal bleeding, retro-orbital bleeding, and terminal cardiac puncture by collection into heparinized capillary tubes. These samples were taken at 5, 15,30,60, and 90 minutes after the fexofenadine intravenous dosing into the tail vein. Blood samples were placed on ice and within 10 minutes centrifuged at $2500 \mathrm{rpm}$ for 5 minutes to separate plasma. The collected plasma was stored at $-80^{\circ} \mathrm{C}$ until analysis.

\section{Plasma Sample Preparation}

Fexofenadine (Sigma Aldrich, St. Louis, MO) and internal standard (diphenhydramine hydrochloride (Sigma Aldrich, St. Louis, MO)) were extracted from $10 \mu \mathrm{L}$ of plasma mixed with $490 \mu \mathrm{L}$ of internal standard at a concentration of $150 \mathrm{ng} / \mathrm{ml}$. Oasis HLB columns (Waters, Milford, MA) were preconditioned with $1 \mathrm{~mL}$ acetonitrile followed by $1 \mathrm{~mL}$ of water. After samples were loaded onto the columns, the columns were washed with $1 \mathrm{~mL}$ water followed by $1 \mathrm{ml} \mathrm{15 \%}$ acetonitrile. Samples were eluted from the column using $1 \mathrm{~mL}$ acetonitrile. Samples were evaporated to dryness using a TurboVap LV (Caliper Life Sciences, Waltham, MA) set a $65^{\circ} \mathrm{C}$ and under a gentle stream of nitrogen gas. Once the acetonitrile was evaporated samples were reconstituted using $50 \mu \mathrm{L}$ diluent (50:50 Methanol and acetate buffer $\mathrm{pH}$ 5.56).

Calibration standards were prepared using blank mouse plasma and a prepared fexofenadine standard at a concentration of $100 \mu \mathrm{g} / \mathrm{ml}$. Using serial dilution 10 standards were prepared from $3.9 \mathrm{ng} / \mathrm{mL}-8000 \mathrm{ng} / \mathrm{mL}$-. Four quality control samples were prepared in the range of $11.7 \mathrm{ng}$ to $6000 \mathrm{ng} / \mathrm{mL}$ and run after every 10 mice samples. As the quality control samples were of known concentration the standard curve could be

confirmed. Fexofenadine and diphenhydramine were extracted in the same manner as described for the animal samples. 


\section{HPLC}

Fexofenadine and diphenhydramine concentrations were determined using a Shimadzu (Columbia, MD) HPLC system which consisted of a system controller (model SLC 10AVP), pump (model LC-10AD), autosampler (model SIL-20A), and fluorescence detector (RF-10AXL). Samples were loaded onto a Synergi Fusion-RP column (Phenomenex, Torrance, CA) particle size $4 \mu \mathrm{m}$, length $150 \mathrm{~mm}$, and internal diameter $4.6 \mathrm{~mm}$. Mobile phase consisted of $63 \%$ acetate buffer (per 1 L: $7.7 \mathrm{~g}$ ammonium acetate, $1 \mathrm{ml}$ triethylamine, $\mathrm{pH} 5.56$ ) and $37 \%$ acetonitrile set a flow rate of $0.75 \mathrm{ml} / \mathrm{min}$. The fluorescence detector excitation/emission was set at 220/290 nm. The run time for each sample was $15 \mathrm{~min}$. A standard calibration curve was constructed by plotting the ratio of the peak area of fexofenadine and the peak area of diphenhydramine against their concentration. The ratio of peak area of fexofenadine and diphenhydramine was calculated for each sample. Fexofenadine concentration was calculated by linear regression of the standard curve. The lower limit of quantification was $3.9 \mathrm{ng} / \mathrm{mL}$. Accuracy was $16 \%$ and precision was $7 \%$. Data acquired for each sample was analyzed using LCSolution software version 1.21 (Shimadzu, Columbia, MD).

\section{Data Analysis}

Individual concentration-time profiles were generated using SigmaPlot version 10.0 (Systat Software, Inc., San Jose, CA). Terminal slopes were calculated by Equation 5-1.

$$
C_{t}=C_{o} e^{-k t} \quad(\mathbf{E q} \cdot \mathbf{5 - 1})
$$

Clearance was determined by Equation 5-2

$$
C L=\frac{D}{A U C} \quad(\mathbf{E q} \cdot \mathbf{5 - 2})
$$

Non-compartmental analysis was performed with Phoenix version 6.3 (Pharsight, Mountain View, CA). Differences between groups were verified by one-way ANOVA or Kruskal-Wallis test as appropriate using SAS version 9.3 (Cary, NC). All p-values $<0.05$ were considered significant.

\section{Results}

\section{Cell-Culture Based Uptake Assay}

To verify transport of fexofenadine by murine Oatp1b2 a cell-culture based uptake assay was performed using HEK293 cells transfected with mOatp1b2. Protein concentration for mOatp1b2 transfected cells was $17.8 \mu \mathrm{g} / \mathrm{mL} \pm 12.1$ compared to 16.4 $\mu \mathrm{g} / \mathrm{mL} \pm 15.4(\mathrm{p}=0.63)$ for the vector transfected control cells. Fexofenadine 
concentrations were normalized to protein concentrations. Vector transfected control cells had an average uptake of fexofenadine of $0.0423 \mathrm{ng} / \mu \mathrm{g}$ protein \pm 0.0531 compared to $4.56 \mathrm{ng} / \mu \mathrm{g}$ protein $\pm 2.41(\mathrm{p}=0.0002)$ refer to Figure 5-1.

\section{Pharmacokinetic Study in Mice}

Plasma concentrations of fexofenadine were determined for wild-type $(n=6)$ and the Oatp1b2 (-/-) mice $(n=8)$. Concentrations for all 5 time points could be determined for 4 of the wild-type mice while 4 time points $(5,15,30,60$ minutes $)$ could be determined for the other 2 wild-type mice. Concentrations for all 5 time points could be determined for 6 of the Oatp1b2 (-/-) mice while 3 time points $(5,15,30$ minutes) could be determined for the other 2 Oatp1b2 (-/-) mice. Individual and group concentration-time profiles can be seen in Figure 5-2 and Figure 5-3 respectively. A list of pharmacokinetic parameters can be seen in Table 5-1. Half-life for wild-type mice was $34.3 \mathrm{~min} \pm 27.8$ compared to $54.6 \mathrm{~min} \pm 28.7(\mathrm{p}>0.1)$ for the Oatp1b2 (-/-) mice. AUC for wild-type mice was approximately half the value of the Oatp1b2 (-/-) mice at $102 \mu \mathrm{g} * \mathrm{~min} / \mathrm{mL} \pm 67.9$ versus $215 \mu \mathrm{g} * \mathrm{~min} / \mathrm{mL} \pm 91.5(\mathrm{p}<0.05)$. Clearance was nearly double in wild-type mice at $134.6 \mathrm{~mL} / \mathrm{min} \pm 74.0$ compared to $60.4 \mathrm{~mL} / \mathrm{min} \pm 41.2$ in Oatp1b2 (-/-) mice (p<0.05). $\mathrm{V}_{\mathrm{ss}}$ was also significantly different $(\mathrm{p}<0.05)$ at $5542.4 \mathrm{~mL} / \mathrm{kg} \pm 4062.2$ in wild-type mice versus $1994.7 \mathrm{~mL} / \mathrm{kg} \pm 948.2$ in Oatp1b2 (-/-) mice.

\section{Discussion}

Fexofenadine is a zwitterion at physiological $\mathrm{pH}$ making it difficult for it to cross biological membranes.[135] Over $80 \%$ of the radiolabeled dose given to human subjects is recovered unchanged in the bile, so metabolism effects are minimal.[135] For these reasons fexofenadine is a reasonable candidate as a probe to study drug transport. Cell uptake assays have shown that fexofenadine is indeed a substrate for human OATP1B1, OATP1B3, and rat Oatp1b2.[102, 137, 142] While these transporters are orthologs and share $>65 \%$ homology, there are some differences in substrate affinity. The two human isoforms, OATP1B1 and OATP1B3, which share $>80 \%$ homology both transport bilirubin, methotrexate, rifampin, and rosuvastatin; but OATP1B3 is thought to be the only homolog to transport CCK-8, amantin, and digoxin. $[42,102]$ With these differences in transport between the human homologs it was decided to confirm that mouse Oatp1b2 transports fexofenadine in vitro.

As can be seen in Figure 5-1 the mOatp1b2 transfected cells transported fexofenadine while the vector transfected control cells did not transport fexofenadine to any appreciable extent. With the ability of mOatp $1 \mathrm{~b} 2$ to transport fexofenadine confirmed, the effect of Oatp1b2 on the disposition of fexofenadine was investigated in Oatp1b2 (-/-) mice. As can be seen from both Figure 5-2 and Figure 5-3 the loss of Oatp1b2 impacted the disposition of fexofenadine. The Oatp1b2 (-/-) mice had double the systemic exposure and half the clearance of fexofenadine. The increased systemic exposure was anticipated since fexofenadine uptake into the liver was expected to be 


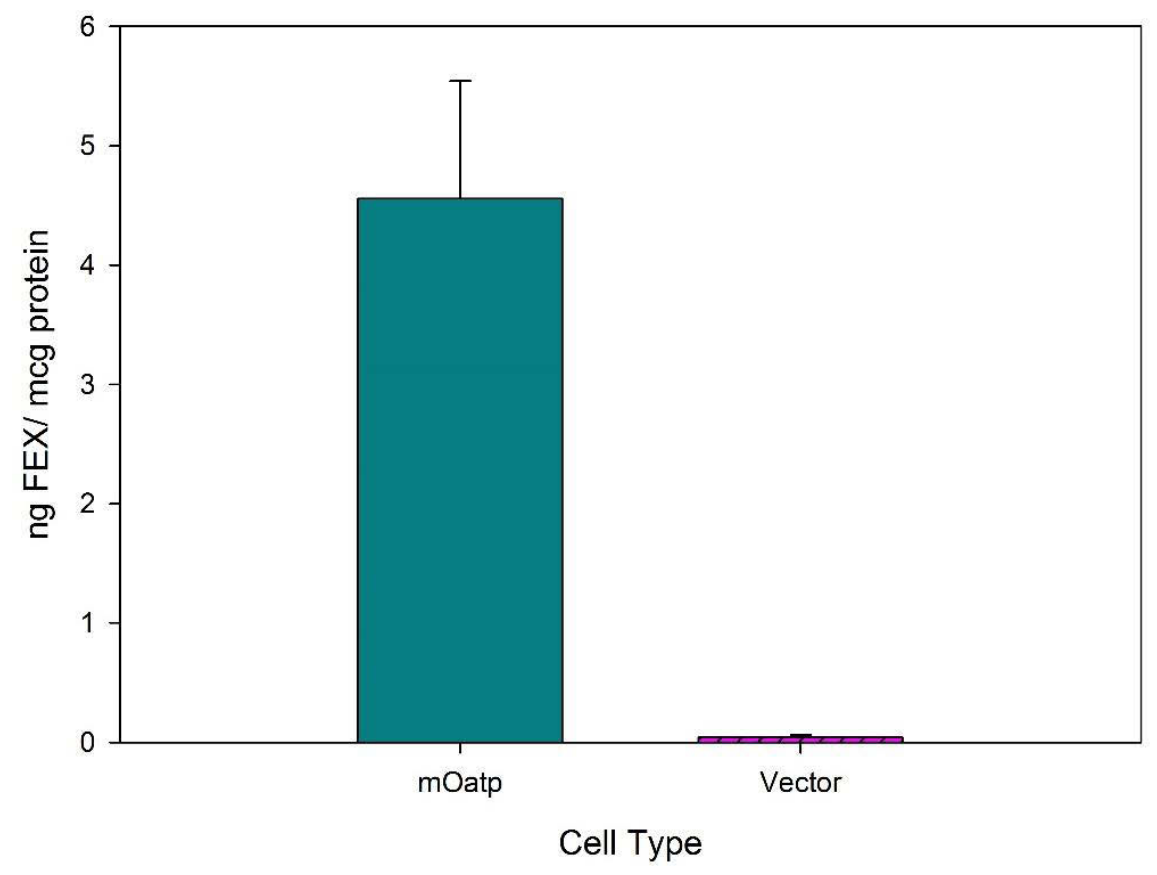

Figure 5-1. Fexofenadine uptake assay performed in mOatp1b2 and vector transfected HEK 293 cells

Fexofenadine concentrations were normalized to protein concentrations in the respective cells. The difference in uptake was significantly different $(\mathrm{p}<0.001)$. 


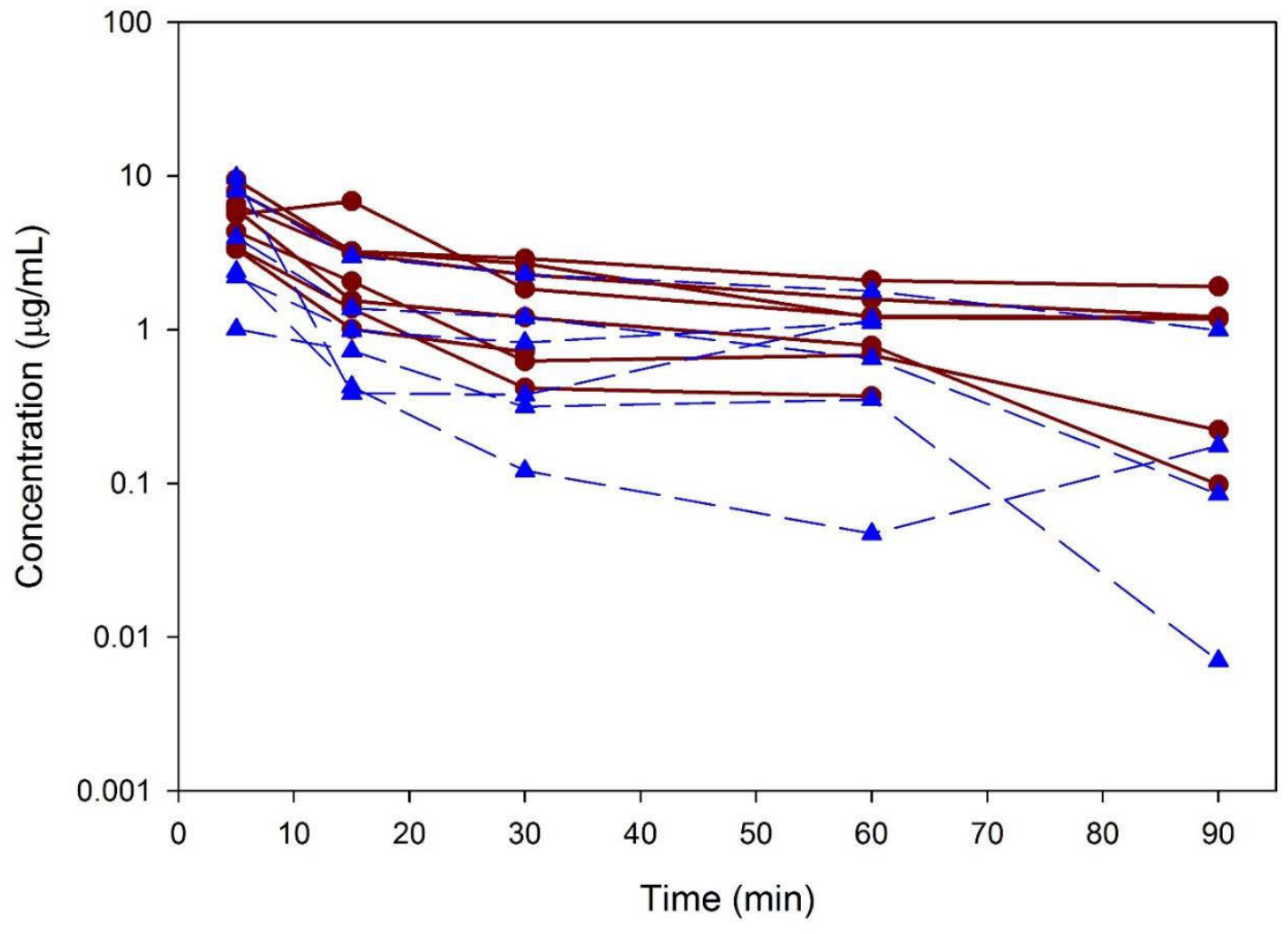

Figure 5-2. Individual concentration-time profiles for Oatp1b2 (-/-) mice represented by $\circ$ symbols and wild-type mice represented by $\Delta$ symbols 


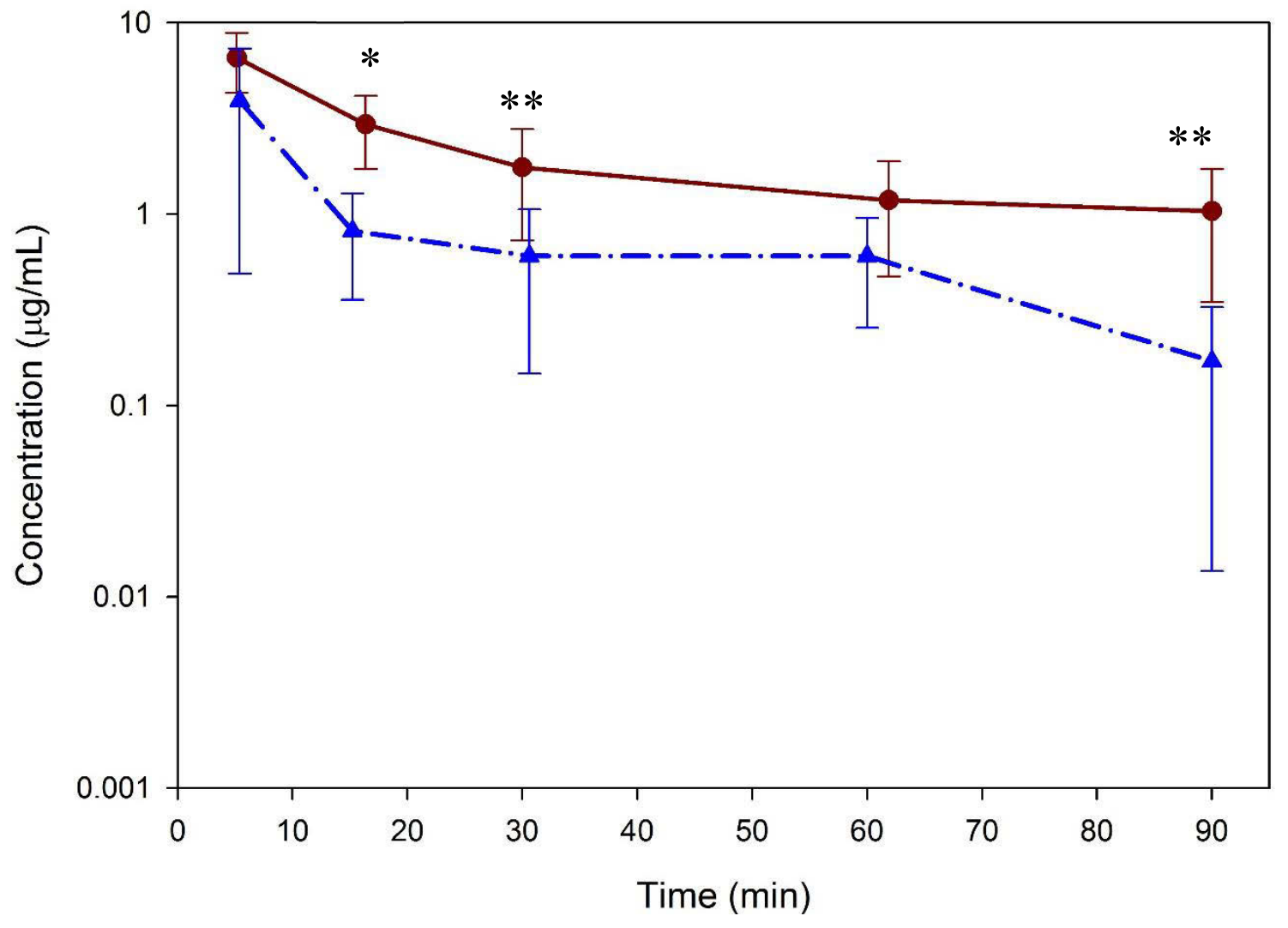

Figure 5-3. Average concentration-time profiles for Oatp1b2 (-/-) mice, represented by $\Delta$ symbols, and wild-type mice, represented by $\circ$ symbols

Time points denoted with an $*$ were significantly different between the groups at $\mathrm{p}<0.005$ or $* *$ at $\mathrm{p}<0.05$. 
Table 5-1. Pharmacokinetic parameters of fexofenadine after IV bolus into wildtype and Oatp1b2 (-/-) mice

\begin{tabular}{ccc}
\hline Parameter & Wild-type & Oatp1b2 (-/-) \\
\hline $\mathrm{T}_{1 / 2}(\mathrm{~min})$ & $34.3 \pm 27.8$ & $54.6 \pm 28.7$ \\
$\mathrm{CL}(\mathrm{mL} / \mathrm{min})^{*}$ & $135 \pm 74.0$ & $60.4 \pm 41.2$ \\
$\mathrm{~V}_{\mathrm{ss}}(\mathrm{mL} / \mathrm{kg})^{*}$ & $5.54 \pm 4.06$ & $2.00 \pm 0.948$ \\
$\mathrm{C}_{\max }(\mu \mathrm{g} / \mathrm{mL})$ & $3.90 \pm 3.41$ & $6.38 \pm 2.15$ \\
$\mathrm{AUC}(\mu \mathrm{g} * \mathrm{~min} / \mathrm{mL})^{*}$ & $102 \pm 67.9$ & $215 \pm 91.5$ \\
$\mathrm{C}_{0}(\mathrm{ng} / \mathrm{mL})$ & $12.9 \pm 19.0$ & $11.6 \pm 5.78$ \\
\hline
\end{tabular}

Parameters marked with * were statistically significant at $\mathrm{p}<0.05$. 
decreased due to the loss of Oatp1b2. The loss of Oatp1b2 transport into the liver reduced access of fexofenadine to excretion into the bile hence reducing clearance. As fexofenadine distribution was limited to the plasma in the Oatp1b2 (-/-) mice since transport into tissues was impaired, the volume of distribution for the Oatp1b2 (-/-) mice being $36 \%$ of that seen in the wild-type mice was not surprising. In this study exposure to fexofenadine in the Oatp1b2 (-/-) mice was 2.1-fold higher compared to wild-type mice. This finding is in agreement with van de Steeg et al (2010)[132] which had found exposure to be 3.3-fold higher in Oatpla/1b (-/-) mice.

The additional increase in exposure that was seen in the double knockout mouse underscores the difficulty in studying the OATP/Oatp transporters. There are few if any straightforward orthologs in transporters between humans and rodents, humans have two OATP1B (OATP1B1 and OATP1B3) transporters whereas mice have only Oatp1b2.[48, 143] In addition to the lack of true orthologs between the species there is also differences in tissue distribution with rats and mice having Oatp1b2 as well as Oatp1a1, Oatp1a4, Oatp1a5, and Oatpla6 located within the basolateral membrane of hepatocytes while humans do not have any OATP1A transporters located within hepatocytes.[48, 132, 143] In humans OATP1A2 is located within the brush border of the intestine and becomes important when discussing oral absorption.[85] There is also some substrate overlap between Oatplb and Oatpla, including fexofenadine, which can complicate the extrapolation into humans.[144-146] In the van de Steeg et al. study when fexofenadine was given orally, exposure was even higher than when it was given by IV bolus suggesting that intestinal and hepatic uptake by Oatpla in the mouse, and intestinal uptake in humans, is also important in the disposition of fexofenadine.[132] For these reasons fexofenadine was given as IV bolus in our pharmacokinetic study in order to mitigate the effects that intestinal Oatpla may have on fexofenadine absorption.

While the absence of Oatp1b2 transporters in the liver did not stop the hepatic uptake of fexofenadine due to substrate overlap with other hepatic transporters as previously discussed, the absence clearly had a profound effect on the volume of distribution and clearance of fexofenadine. These changes were also anticipated. Volume of distribution in the Oatp $1 \mathrm{~b} 2(-/-)$ mice was $63 \%$ of that seen in wild-type mice as a clear consequence of reduced transport into the liver. Studies in mice have shown that fexofenadine distributes into the liver, small intestine, and kidneys with the highest concentrations in the liver.[132] In Oatpla/1b (-/-) mice concentrations in liver tissue decreased to $33 \%$ of that seen in wild-type mice with a subsequent increase in kidney concentrations of $140 \%$ and plasma concentrations of 330\%.[132] These finding that the liver is a major organ for the distribution of fexofenadine and the lack of transport into the liver would be decreased in the Oatp1b2 (-/-) mice in the present study. Clearance was $55 \%$ of that seen in the wild-type mice as a consequence reduced transport into the liver hence a reduced pool of fexofenadine to be eliminated into the bile. These alterations in clearance and volume of distribution have also been seen with other substrates given to Oatp1b2 (-/-) mice. When rifampin was given as an IV bolus to Oatp1b2 (-/-) mice a $67 \%$ decrease in volume and a $43 \%$ decrease in clearance were seen as well as a 1.7 fold increase in exposure.[134] In the same study when pravastatin was administered as a continuous IV infusion clearance was found to be $46 \%$ lower in the 
Oatp1b2 (-/-) mice. [134] Another study looking at the ability of Oatp1b2 (-/-) mice to handle conjugated and unconjugated bile acids found that both volume and clearance of unconjugated cholate were decreased 50\% compared to wild-type mice.[147] The findings presented here with a different probe are in agreement with those previously reported suggesting that there may be a quantifiable impact of the loss of Oatp1b2 on disposition of its substrates.

It is believed that understanding the role Oatp1b2 plays in mice will help elucidate the roles that OATP1B1 and OATP1B3 play. In humans, drug-drug interactions, pathological conditions, such as cholestasis, and genetic variation can alter OATP1B transport activity. Uptake studies showed that erythromycin is a substrate of Oatp1b2 when its uptake in both isolated hepatocytes and in vivo rat studies was diminished in the presence of rifampin, an inhibitor of Oatp1b2 transport.[148] Uptake of erythromycin was also diminished in the presence of rifampin in cells transfected with OATP1B3 and Oatp1b2.[129] Erythromycin is often used a probe to investigate uptake and inhibition of CYP 3A4.[129] The interaction that exists between fexofenadine and erythromycin seems to be explainable only by an interaction with OATP1B3 since fexofenadine is not metabolized thus an interaction with CYP3A4 is unlikely.[149]

The approach of using a known inhibitor for a transporter (or metabolic enzyme) is very common in determining new substrates especially when a viable in vivo knockout model is difficult to obtain, but has limitations due to alternate interactions with other transporters. The availability of the Oatp1b2 (-/-) mouse can help explain in an in vivo model unexpected clinically seen drug-drug interactions that may or may not have been demonstrated in in vitro models. In most in vitro models the inhibition uptake of estradiol-17ß-glucuronide is studied. Through these models the interaction of rifampin, rifamycin and cyclosporine with OATP1B transporters has been investigated.[24, 150, 151] An in vivo experiment in Oatp1b2 (-/-) mice showed that when rifampin was given to these mice exposure to rifampin was increased 1.7 fold as compared to wild-type mice.[134]

In present study we demonstrated that fexofenadine is transported by Oatp $1 \mathrm{~b} 2$ using the Oatp1b2 (-/-) mouse model. In these mice exposure to fexofenadine was greater than 1.5 fold higher compared to wild-type mice. Fexofenadine is minimally metabolized so the number of drug-drug interactions is expected to be fairly minimal as well. The fact that there are drug-drug interactions with fexofenadine as a medication that does not undergo metabolism underscores the importance of examining the effect that transport plays on drug disposition. The human orthologs to Oatp1b2, OATP1B1 and OATP1B3, have been shown to transport some commonly used medications such as fexofenadine, pravastatin, atorvastatin, rosuvastatin, and repaglinide, emphasizing the need to understand the role that transporters serve in drug disposition and drug-drug interactions. $[152,153]$

The loss of Oatp1b2 function had a significant impact on the disposition of the probe substrate fexofenadine. When these results are examined in combination with the results from Chapter 3, the potential impact of the loss of OATP1B1 and OATP1B3 
expression on pharmacotherapy can be seen. In Chapter 3 it was shown that OATP1B3 protein expression was high at birth declining rapidly in the first few months of life with a subsequent increase in the prepubescent period. The protein expression of OATP1B1 did not exhibit a discernible pattern with regards to age of donor sample. Extrapolating the data from the Oatp1b2 (-/-) mice into young children who had the lowest OATP1B3 protein expression that these young children should have reduced clearance of fexofenadine. As the results for the Oatp1b2 (-/-) mice presented here are in agreement with studies using different Oatp1b2 probes, it suggests that drug disposition for OATP1B3 substrates, not just fexofenadine, will be altered (reduced clearance, increased systemic exposure) in young children. The anticipated reduced clearance and increased systemic exposure increases the potential for toxicity and medication misadventures. 


\section{CHAPTER 6. SUMMARY}

Throughout history children have often been treated as little adults in terms of administering medications. It has only been in the face of tragic events that investigation of the differences of drug disposition between children and adults was triggered. The administration of colic treatment, sulfonamide, and chloramphenicol, just to name a few widespread instances, led to serious injury or death of many children these medications were meant to treat.[1, 2, 4] The suffering that resulted from these events led to new laws and regulations meant to protect children undergoing pharmacotherapy. Another key outcome is an understanding that children are not merely miniature adults but tiny humans that have a unique development of physiologic systems that may function differently than adult counterparts for varying periods of childhood. While this view has led to increased recognition that medications need to be evaluated in children; there is a discrepancy between perception and practice with over half the drugs used in pediatrics still being used without the benefit of proper clinical testing.[154] The risk of adverse drug reactions is high due to the lack of formal testing complicated by the normal ontogeny processes that may be further altered in sick children due to disease pathology.

Examination of adverse drug events (ADE) in children less than 2 years of age has shown hospitalizations of 4.3\%.[155] The incidence of ADE in children already hospitalized was $16.6 \%$ with the rate being even higher in the neonatal intensive care unit.[155] These numbers only reflect ADEs that were severe enough to warrant hospitalizations. ADEs in pediatric patients, in particular, may be under-reported as they are unable to effectively communicate symptoms they may be experiencing, thus requiring the caregiver to notice the symptom and assign the cause to an administered medication instead of another cause, underlying pathology, or normal development. Infants are undergoing constant physiological changes that make deciphering symptoms difficult to interpret as there are no firm boundaries as to when each phase of development is complete.

Understanding the normal development of the systems involved in drug disposition is an important aspect of optimizing pharmacotherapy for infants and children. Much attention has focused on the ontogeny of drug metabolizing enzymes which has led to the observation of three expression patterns (1) high expression during gestation and/or infancy with decreasing expression within the first weeks or months after birth, (2) relatively stable expression with no clear pattern observed, and (3) low expression at birth with increasing during infancy and early childhood.[7] In the current study this framework was used to investigate the ontogeny of drug transporters, specifically uptake transporters of the liver. It was hypothesized that the protein expression of the hepatic uptake transporter, OATP1B3, would be low at birth which would alter drug disposition while OATP1B1 would show more consistent expression. To answer that question the protein expression of OATP1B3 and OATP1B1 was determined. An exploratory study was conducted examining a potential relationship amongst genotype, protein expression and age. Finally, an in vivo study was performed 
using mice deficient in Oatp1b2 to determine the consequence the lack of Oatp $1 \mathrm{~b} 2$ expression had on the disposition of the probe, fexofenadine.

The expression pattern of the hepatic uptake transporter OATP1B3 like all other ontogeny processes has individualized boundaries as to when expression levels shift. The work in chapter 3 describes a fourth expression pattern that differs from the three patterns used to describe drug metabolizing enzymes. OATP1B3 protein expression was found to be high at birth with a relatively rapid decrease in the first few months of life reminiscent of the expression pattern 1 of drug metabolizing enzymes. [7] What makes this work unique is that OATP1B3 protein expression begins to increase in the prepubescent period reminiscent of expression pattern 3.[7] The U-shaped expression pattern for OATP1B3 protein expression detailed in chapter 3 is intriguing if unexpected. Upon examining each trend of expression separately, possible explanation began to emerge. OATP1B3 is responsible for the uptake transport of many endogenous substrates. In the neonate period the transport of bilirubin is important as neonatal livers begin processing not only their bilirubin but also maternal bilirubin. In the prepubescent period a similar increase in endogenous sex steroids are also expected. As the pediatric liver samples came from donors aged 14 days to 12 years of age it was not possible to fully investigate the increase in protein expression seen in the prepubescent period but the inter-subject variability was clearly evident in this age group. It appears that the samples from female donors started to show an increase in protein expression at an earlier age compared to samples from male donors. Both these trends can be explained as reactions to normal physiologic changes in endogenous substrate concentrations that result in altering OATP1B3 protein expression. It is known that OATP1B3 expression is modulated during times of hepatic stress such as cholestasis which supports OATP1B3 expression modulation in response to substrate concentration fluctuations.[156]

Much of the focus has been on OATP1B3, but protein expression data was also evaluated for OATP1B1. There were no statistically significant differences seen in protein expression amongst the four age groups considered although protein expression was $29 \%, 45 \%$ and $15 \%$ lower in age groups $<3$ months, 3 months $<2$ years, and $2<6$ years respectively. This pattern correlates to the expression pattern 2 described for drug metabolizing enzymes which has relatively stable expression. [7] While this pattern is less intriguing than the U-shaped expression pattern discerned for OATP1B3, it is helpful in understanding the ontogeny of drug disposition processes such that appropriate dosing changes may be considered. In the case of OATP1B1 dosing changes based on ontogeny may not be necessary but consideration of genotype may be prudent.

The impact genotype has on protein expression was also examined. The two most functionally relevant SNPs for OATP1B1, $388 \mathrm{~A} \rightarrow \mathrm{G}$ and $521 \mathrm{~T} \rightarrow \mathrm{C}$, were examined, as were SNPS $334 \mathrm{~T} \rightarrow \mathrm{G}$ and $699 \mathrm{G} \rightarrow \mathrm{A}$ for OATP1B3. It has been reported that possession of an OATP1B1 521C, OATP1B1 388G, OATP1B3 334A, or OATP1B3 699G allele increases exposure to substrates resulting in increased risk of toxicity.[84, 121, 126] Reports suggested decreased activity of the transporter but the cause of the decreased activity had not been fully examined. With protein expression and genotype data available we were able to investigate whether the decreased activity was a result of 
decreased protein expression or altered transport kinetics. It appears that the affect OATP1B genotype exerts on drug disposition is through altered transport kinetics as a significant finding with protein expression could not be detected. Further investigation with a larger sample size into the relationship between OATP1B protein expression and genotype is warranted as the work in Chapter 4 only had genotype and protein expression data on 46 samples. The conclusions on OATP1B1 $521 \mathrm{~T} \rightarrow \mathrm{C}$ are particularly deficient in that there were no donor samples that were homozygous for the variant $\mathrm{C}$ allele.

There were several limitations to the work performed on the human samples. In order to investigate the role age plays on the protein expression of OATP1B1 and OATP1B3 the samples were divided into four groups. The size and age ranges of each group were determined in order to maximize statistical power for analysis. While the groupings were arbitrary in terms of age and did not correspond absolutely with age categories FDA uses, the groupings showed the relative expression patterns between the youngest, middle, and oldest sample donors. As there is variability associated with expression understanding the pattern is the key component of these findings and not specific age markers for expression. Related to the use of human samples was the lack of information on medication use by each sample donor that may alter OATP1B1 or OATP1B3 expression through induction or inhibition by nuclear receptors such as FXR, CAR, or PXR. Ideally the genetic study would have been able to have equal numbers of homozygous reference, homozygous variant, and heterozygous genotypes. Unfortunately, the nature of the primary focus of this dissertation, protein expression of OATP1B1 and OATP1B3 in children, did allow for prospectively planning the studies due to the limitations inherent in obtaining liver samples from pediatric subjects. The variability inherent in the evaluation of the Western blot was a limitation. While there are more sophisticated methods for determining protein expression, such as LC-MS/MS, these methods would have lost the information on glycosylation that the Western blot method was able to provide. As glycosylation is important for the proper placement of the OATP1B3 protein in the membrane, having this information is key in determining whether the protein measured is capable of proper function or if the protein is likely to remain in intracellular space.[105] The ontogeny patterns of glycosylation have not been determined which may have an impact on the proper placement and function of OATP1B3 protein. Finally, the migration patterns of the OATP1B1 and OATP1B3 on the Western blot were different than expected. Based on molecular weight the two proteins should have migrated at similar rates as they are similar in size.[85] As was seen in Chapter 3 this was not the case. Through the use of two separate positive controls (one for OATP1B1 and one for OATP1B3) it was shown that the proteins migrated anomalously. There is work showing that membrane proteins can migrate anomalously on SDS-PAGE gels in part due to interactions with the detergent SDS.[157, 158] One study showed that different genetic variants of the same protein exhibited different migration motility due to altered interaction with SDS.[157] For this reason the positive controls for each protein were utilized.

The in vivo consequences of OATP1B loss of function were investigated in an animal model. Oatp1b2 is a rodent ortholog of human OATP1B1 and OATP1B3 sharing greater than $65 \%$ homology with each of the human transporters.[133, 143] Fexofenadine 
was chosen as a probe for Oatp $1 \mathrm{~b} 2$ uptake as it is minimally metabolized making transport the main pathway for elimination from the body. After an IV bolus of fexofenadine the Oatp $1 \mathrm{~b} 2^{-/-}$mice had significantly higher exposure to fexofenadine as compared to wild-type mice. The Oatp $1 \mathrm{~b} 2^{-/-}$mice also had a significantly lower clearance and volume of distribution as would be predicted with decreased uptake into the liver.

The focus of this dissertation has been the development of the hepatic uptake transporters OATP1B1 and OATP1B3 during childhood and infancy. While many of the known substrates for OATP1B1 and OATP1B3 are not commonly used in the pediatric population, there are a few that can be used such as fexofenadine and methotrexate in addition to the endogenous substrates bilirubin and steroid sex hormones. [42, 85] Methotrexate has been shown to be a substrate of OATP1B3 in slcola/ $1 \mathrm{~b}^{-/-}$mice and confirmed in humanized transgenic slcola $/ 1 \mathrm{~b}^{-/}, 1 \mathrm{~B} 3^{\text {tg }}$ mice with the latter rescuing the transport of methotrexate into the liver resulting in decreased exposure to methotrexate.[159, 160] When extrapolated to human subjects these findings with methotrexate suggest that those individuals with reduced or no expression of OATP1B transporters will also have greater exposure to methotrexate and increased toxicities. As discussed previously the most at risk population due to normal physiologic development will be young children starting after the neonatal period until the pre-pubescent period when natural expression of these transporters is low (during the period after neonatal to pre-pubescent). With the results provided here, it may be possible to create physiologically-based pharmacokinetic models that can aid in determining appropriate initial pediatric dosing for this rapidly changing patient population. 


\section{LIST OF REFERENCES}

1. Hirschfeld, S. and A. Saint-Raymond, Pediatric regulatory initiatives. Handb Exp Pharmacol, 2011. 205: p. 245-68.

2. Steinbrook, R., Testing medications in children. N Engl J Med, 2002. 347(18): p. 1462-70.

3. Leeder, J.S., et al., Understanding the relative roles of pharmacogenetics and ontogeny in pediatric drug development and regulatory science. J Clin Pharmacol, 2010. 50(12): p. 1377-87.

4. Burns, L.E., J.E. Hodgman, and A.B. Cass, Fatal circulatory collapse in premature infants receiving chloramphenicol. N Engl J Med, 1959. 261: p. 131821.

5. Johnson, T.N., The development of drug metabolising enzymes and their influence on the susceptibility to adverse drug reactions in children. Toxicology, 2003. 192(1): p. 37-48.

6. McCarver, D.G. and R.N. Hines, The ontogeny of human drug-metabolizing enzymes: phase II conjugation enzymes and regulatory mechanisms. J Pharmacol Exp Ther, 2002. 300(2): p. 361-6.

7. Hines, R.N., The ontogeny of drug metabolism enzymes and implications for adverse drug events. Pharmacol Ther, 2008. 118(2): p. 250-67.

8. Smits, A., P. Annaert, and K. Allegaert, Drug disposition and clinical practice in neonates: Cross talk between developmental physiology and pharmacology. Int J Pharm, 2012.

9. Anderson, G.D. and A.M. Lynn, Optimizing pediatric dosing: a developmental pharmacologic approach. Pharmacotherapy, 2009. 29(6): p. 680-90.

10. van den Anker, J.N., M. Schwab, and G.L. Kearns, Developmental pharmacokinetics. Handb Exp Pharmacol, 2011. 205: p. 51-75.

11. van den Anker, J.N., Developmental pharmacology. Dev Disabil Res Rev, 2010. 16(3): p. 233-8.

12. Kearns, G.L., et al., Developmental pharmacology--drug disposition, action, and therapy in infants and children. N Engl J Med, 2003. 349(12): p. 1157-67.

13. Leeder, J.S. and G.L. Kearns, Interpreting pharmacogenetic data in the developing neonate: the challenge of hitting a moving target. Clin Pharmacol Ther, 2012. 92(4): p. 434-6.

14. Bartelink, I.H., et al., Guidelines on paediatric dosing on the basis of developmental physiology and pharmacokinetic considerations. Clin Pharmacokinet, 2006. 45(11): p. 1077-97.

15. Anderson, G.D., Developmental pharmacokinetics. Semin Pediatr Neurol, 2010. 17(4): p. 208-13.

16. Porter, M.L. and B.L. Dennis, Hyperbilirubinemia in the term newborn. Am Fam Physician, 2002. 65(4): p. 599-606.

17. Geaghan, S.M., Critical values for the maternal-fetal unit, fetus, infant, child and adolescent: bilirubin reporting practice in North American Children's Hospitals as a paradigm for critical value reporting assessment. Clin Biochem, 2011. 44(7): p. 483-4. 
18. Alcorn, J. and P.J. McNamara, Ontogeny of hepatic and renal systemic clearance pathways in infants: part I. Clin Pharmacokinet, 2002. 41(12): p. 959-98.

19. Johnson, P.J., Neonatal pharmacology--pharmacokinetics. Neonatal Netw, 2011. 30(1): p. 54-61.

20. Blake, M.J., et al., Ontogeny of drug metabolizing enzymes in the neonate. Semin Fetal Neonatal Med, 2005. 10(2): p. 123-38.

21. Barter, Z.E., et al., Scaling factors for the extrapolation of in vivo metabolic drug clearance from in vitro data: reaching a consensus on values of human microsomal protein and hepatocellularity per gram of liver. Curr Drug Metab, 2007. 8(1): p. 33-45.

22. Hines, R.N. and D.G. McCarver, The ontogeny of human drug-metabolizing enzymes: phase I oxidative enzymes. J Pharmacol Exp Ther, 2002. 300(2): p. 35560 .

23. Koukouritaki, S.B., et al., Developmental expression of human hepatic CYP2C9 and CYP2C19. J Pharmacol Exp Ther, 2004. 308(3): p. 965-74.

24. Gui, C., et al., Effect of pregnane X receptor ligands on transport mediated by human OATP1B1 and OATP1B3. Eur J Pharmacol, 2008. 584(1): p. 57-65.

25. Stevens, J.C., et al., Developmental changes in human liver CYP2D6 expression. Drug Metab Dispos, 2008. 36(8): p. 1587-93.

26. Blake, M.J., et al., Ontogeny of dextromethorphan $\mathrm{O}$ - and $\mathrm{N}$-demethylation in the first year of life. Clin Pharmacol Ther, 2007. 81(4): p. 510-6.

27. Ince, I., et al., Developmental changes in the expression and function of cytochrome P450 $3 \mathrm{~A}$ isoforms: evidence from in vitro and in vivo investigations. Clin Pharmacokinet, 2013. 52(5): p. 333-45.

28. de Wildt, S.N., et al., Cytochrome P450 3A: ontogeny and drug disposition. Clin Pharmacokinet, 1999. 37(6): p. 485-505.

29. Stevens, J.C., et al., Developmental expression of the major human hepatic CYP3A enzymes. J Pharmacol Exp Ther, 2003. 307(2): p. 573-82.

30. Johnsrud, E.K., et al., Human hepatic CYP2E1 expression during development. J Pharmacol Exp Ther, 2003. 307(1): p. 402-7.

31. Koukouritaki, S.B., et al., Human hepatic flavin-containing monooxygenases 1 (FMO1) and 3 (FMO3) developmental expression. Pediatr Res, 2002. 51(2): p. 236-43.

32. de Wildt, S.N., et al., Ontogeny of midazolam glucuronidation in preterm infants. Eur J Clin Pharmacol, 2010. 66: p. 165-170.

33. de Wildt, S.N., et al., Glucuronidation in humans. Pharmacogenetic and developmental aspects. Clin Pharmacokinet, 1999. 36(6): p. 439-52.

34. Strassburg, C.P., et al., Developmental aspects of human hepatic drug glucuronidation in young children and adults. Gut, 2002. 50(2): p. 259-65.

35. Miyagi, S.J. and A.C. Collier, The development of UDP-glucuronosyltransferases $1 A 1$ and 1 A6 in the pediatric liver. Drug Metab Dispos, 2011. 39(5): p. 912-9.

36. Rowland, A., J.O. Miners, and P.I. Mackenzie, The UDPglucuronosyltransferases: their role in drug metabolism and detoxification. Int $\mathrm{J}$ Biochem Cell Biol, 2013. 45(6): p. 1121-32.

37. Miyagi, S.J. and A.C. Collier, Pediatric development of glucuronidation: the ontogeny of hepatic UGT1A4. Drug Metab Dispos, 2007. 35(9): p. 1587-92. 
38. Miyagi, S.J., et al., Neonatal development of hepatic UGT1A9: implications of pediatric pharmacokinetics. Drug Metab Dispos, 2012. 40(7): p. 1321-7.

39. Ji, P., et al., Regulatory review of acetaminophen clinical pharmacology in young pediatric patients. J Pharm Sci, 2012. 101(12): p. 4383-9.

40. Duanmu, Z., et al., Developmental expression of aryl, estrogen, and hydroxysteroid sulfotransferases in pre- and postnatal human liver. J Pharmacol Exp Ther, 2006. 316(3): p. 1310-7.

41. Gardner, J.L., et al., Ontogenic differences in human liver 4-hydroxynonenal detoxification are associated with in vitro injury to fetal hematopoietic stem cells. Toxicol Appl Pharmacol, 2003. 191(2): p. 95-106.

42. International Transporter, C., et al., Membrane transporters in drug development. Nat Rev Drug Discov, 2010. 9(3): p. 215-36.

43. Zamek-Gliszczynski, M.J., et al., Highlights from the International Transporter Consortium second workshop. Clin Pharmacol Ther, 2012. 92(5): p. 553-6.

44. van Kalken, C.K., et al., Multidrug resistance gene (P-glycoprotein) expression in the human fetus. Am J Pathol, 1992. 141(5): p. 1063-72.

45. Cizkova, D., et al., Expression of MRP2 and MDR1 transporters and other hepatic markers in rat and human liver and in WRL 68 cell line. Physiol Res, 2005. 54(4): p. 419-28.

46. Fakhoury, M., et al., $m R N A$ expression of MDR1 and major metabolising enzymes in human fetal tissues. Drug Metab Pharmacokinet, 2009. 24(6): p. 529-36.

47. Mooij, M.G., et al., Ontogeny of human hepatic and intestinal transporter gene expression during childhood: age matters. Drug Metab Dispos, 2014. 42(8): p. 1268-74.

48. Klaassen, C.D. and L.M. Aleksunes, Xenobiotic, bile acid, and cholesterol transporters: function and regulation. Pharmacol Rev, 2010. 62(1): p. 1-96.

49. Schuetz, E.G., K.N. Furuya, and J.D. Schuetz, Interindividual variation in expression of P-glycoprotein in normal human liver and secondary hepatic neoplasms. J Pharmacol Exp Ther, 1995. 275(2): p. 1011-8.

50. Tang, L., et al., Age-associated protein expression of P-glycoprotein $(M D R 1 / P$ gp) and MRP2 in human pediatric liver. Clin Pharmacol Ther, 2007. 81: p. S101.

51. Prasad, B., et al., Interindividual variability in hepatic organic anion-transporting polypeptides and P-glycoprotein (ABCB1) protein expression: quantification by liquid chromatography tandem mass spectroscopy and influence of genotype, age, and sex. Drug Metab Dispos, 2014. 42(1): p. 78-88.

52. Chen, H.L., et al., Developmental expression of canalicular transporter genes in human liver. J Hepatol, 2005. 43(3): p. 472-7.

53. Sharma, S., et al., Hepatobiliary disposition of 17-OHPC and taurocholate in fetal human hepatocytes: a comparison with adult human hepatocytes. Drug Metab Dispos, 2013. 41(2): p. 296-304.

54. Deo, A.K., et al., Interindividual variability in hepatic expression of the multidrug resistance-associated protein 2 (MRP2/ABCC2): quantification by liquid chromatography/tandem mass spectrometry. Drug Metab Dispos, 2012. 40(5): p. $852-5$.

55. Konieczna, A., et al., Differential expression of $A B C$ transporters (MDR1, MRP1, $B C R P)$ in developing human embryos. J Mol Histol, 2011. 42(6): p. 567-74. 
56. Yanni, S.B., et al., Higher clearance of micafungin in neonates compared with adults: role of age-dependent micafungin serum binding. Biopharm Drug Dispos, 2011. 32(4): p. 222-32.

57. Prasad, B., et al., Interindividual variability in the hepatic expression of the human breast cancer resistance protein (BCRP/ABCG2): effect of age, sex, and genotype. J Pharm Sci, 2013. 102(3): p. 787-93.

58. Hardikar, W., M. Ananthanarayanan, and F.J. Suchy, Differential ontogenic regulation of basolateral and canalicular bile acid transport proteins in rat liver. J Biol Chem, 1995. 270(35): p. 20841-6.

59. Hayashi M, H.A., et al., Evaluation of uptake transporters in human adult and pediatric hepatocytes. Abstracts of the 17th North American Regional ISSX International Society for the Study of Xenobiotics) Drug Metab Rev, 2011. 43(Suppl 2): p. 37-211.

60. Thomson, M.M., et al., Age-associated expression of OATP1B1 and OATP1B3 in human pediatric liver. Aaps J, 2012. 14(Suppl 2): p. W4301.

61. St-Pierre, M.V., et al., Temporal expression profiles of organic anion transport proteins in placenta and fetal liver of the rat. Am J Physiol Regul Integr Comp Physiol, 2004. 287(6): p. R1505-16.

62. Cui, J.Y., et al., Bile acids via FXR initiate the expression of major transporters involved in the enterohepatic circulation of bile acids in newborn mice. Am J Physiol Gastrointest Liver Physiol, 2012. 302(9): p. G979-96.

63. Maher, J.M., et al., Tissue distribution and hepatic and renal ontogeny of the multidrug resistance-associated protein (Mrp) family in mice. Drug Metab Dispos, 2005. 33(7): p. 947-55.

64. Gao, B., et al., Differential expression of bile salt and organic anion transporters in developing rat liver. J Hepatol, 2004. 41(2): p. 201-8.

65. Lee, H.Y., D. Wei, and M.R. Loeken, Lack of metformin effect on mouse embryo AMPK activity: implications for metformin treatment during pregnancy. Diabetes Metab Res Rev, 2014. 30(1): p. 23-30.

66. Chen, H.L., et al., Expression of hepatocyte transporters and nuclear receptors in children with early and late-stage biliary atresia. Pediatr Res, 2008. 63(6): p. 667-73.

67. Cui, J.Y., et al., RNA-Seq reveals different $m R N A$ abundance of transporters and their alternative transcript isoforms during liver development. Toxicol Sci, 2012. 127(2): p. 592-608.

68. Brouwer, K.L., et al., Human Ontogeny of Drug Transporters: Review and Recommendations of the Pediatric Transporter Working Group. Clin Pharmacol Ther, 2015. 98(3): p. 266-87.

69. Ulvestad, M., et al., Impact of OATP1B1, MDR1, and CYP3A4 expression in liver and intestine on interpatient pharmacokinetic variability of atorvastatin in obese subjects. Clin Pharmacol Ther, 2013. 93(3): p. 275-82.

70. Madadi, P., D. Avard, and G. Koren, Pharmacogenetics of opioids for the treatment of acute maternal pain during pregnancy and lactation. Curr Drug Metab, 2012. 13(6): p. 721-7. 
71. Hicks, J.K., et al., Clinical Pharmacogenetics Implementation Consortium (CPIC) Guideline for CYP2D6 and CYP2C19 Genotypes and Dosing of Selective Serotonin Reuptake Inhibitors. Clin Pharmacol Ther, 2015. 98(2): p. 127-34.

72. Litalien, C., Y. Theoret, and C. Faure, Pharmacokinetics of proton pump inhibitors in children. Clin Pharmacokinet, 2005. 44(5): p. 441-66.

73. Peyvandi, F., et al., CYP2C9 genotypes and dose requirements during the induction phase of oral anticoagulant therapy. Clin Pharmacol Ther, 2004. 75(3): p. 198-203.

74. Takanashi, K., et al., CYP2C9 Ile359 and Leu359 variants: enzyme kinetic study with seven substrates. Pharmacogenetics, 2000. 10(2): p. 95-104.

75. FDA, FDA Public Health Advisory on Crestor. 2005.

76. Neville, K.A., et al., Developmental pharmacogenomics. Paediatr Anaesth, 2011. 21(3): p. 255-65.

77. Lin, Y.S., et al., Co-regulation of CYP3A4 and CYP3A5 and contribution to hepatic and intestinal midazolam metabolism. Mol Pharmacol, 2002. 62(1): p. 162-72.

78. Zheng, H., et al., Tacrolimus dosing in pediatric heart transplant patients is related to CYP3A5 and MDR1 gene polymorphisms. Am J Transplant, 2003. 3(4): p. 477-83.

79. Hirschfield, G.M. and G.J. Alexander, Gilbert's syndrome: an overview for clinical biochemists. Ann Clin Biochem, 2006. 43(Pt 5): p. 340-3.

80. Krishnaswamy, S., et al., UDP glucuronosyltransferase (UGT) $1 A 6$ pharmacogenetics: II. Functional impact of the three most common nonsynonymous UGT1A6 polymorphisms (S7A, T181A, and R184S). J Pharmacol Exp Ther, 2005. 313(3): p. 1340-6.

81. Sawyer, M.B., et al., A pharmacogenetic study of uridine diphosphateglucuronosyltransferase $2 B 7$ in patients receiving morphine. Clin Pharmacol Ther, 2003. 73(6): p. 566-74.

82. Madadi, P., et al., Pharmacogenetics of neonatal opioid toxicity following maternal use of codeine during breastfeeding: a case-control study. Clin Pharmacol Ther, 2009. 85(1): p. 31-5.

83. Maeda, K. and Y. Sugiyama, Impact of genetic polymorphisms of transporters on the pharmacokinetic, pharmacodynamic and toxicological properties of anionic drugs. Drug Metab Pharmacokinet, 2008. 23(4): p. 223-35.

84. Picard, N., et al., The role of organic anion-transporting polypeptides and their common genetic variants in mycophenolic acid pharmacokinetics. Clin Pharmacol Ther, 2010. 87(1): p. 100-8.

85. Hagenbuch, B. and C. Gui, Xenobiotic transporters of the human organic anion transporting polypeptides (OATP) family. Xenobiotica, 2008. 38(7-8): p. 778-801.

86. Drenberg, C.D., et al., Inherited variation in OATP1B1 is associated with treatment outcome in acute myeloid leukemia. Clin Pharmacol Ther, 2015.

87. Cheng, X., et al., Tissue distribution and ontogeny of mouse organic anion transporting polypeptides (Oatps). Drug Metab Dispos, 2005. 33(7): p. 1062-73.

88. Bradford, M.M., A rapid and sensitive method for the quantitation of microgram quantities of protein utilizing the principle of protein-dye binding. Anal Biochem, 1976. 72: p. 248-54. 
89. Cui, Y., et al., Detection of the human organic anion transporters SLC21A6 (OATP2) and SLC21A8 (OATP8) in liver and hepatocellular carcinoma. Lab Invest, 2003. 83(4): p. 527-38.

90. van de Steeg, E., et al., Complete OATP1B1 and OATP1B3 deficiency causes human Rotor syndrome by interrupting conjugated bilirubin reuptake into the liver. J Clin Invest, 2012. 122(2): p. 519-28.

91. Cui, Y., J. Konig, and D. Keppler, Vectorial transport by double-transfected cells expressing the human uptake transporter SLC21A8 and the apical export pump ABCC2. Mol Pharmacol, 2001. 60(5): p. 934-43.

92. Konig, J., et al., Localization and genomic organization of a new hepatocellular organic anion transporting polypeptide. J Biol Chem, 2000. 275(30): p. 23161-8.

93. Schwarz, U.I., et al., Identification of novel functional organic anion-transporting polypeptide 1B3 polymorphisms and assessment of substrate specificity.

Pharmacogenet Genomics, 2011. 21(3): p. 103-14.

94. Nies, A.T., et al., Genetics is a major determinant of expression of the human hepatic uptake transporter OATP1B1, but not of OATP1B3 and OATP2B1.

Genome Med, 2013. 5(1): p. 1.

95. $\mathrm{Xu}, \mathrm{C} ., \mathrm{C} . \mathrm{Y}$. Li, and A.N. Kong, Induction of phase I, II and III drug metabolism/transport by xenobiotics. Arch Pharm Res, 2005. 28(3): p. 249-68.

96. Nishiura, H., et al., Developmental pattern of urinary bile acid profile in preterm infants. Pediatr Int, 2010. 52(1): p. 44-50.

97. Jonker, J.W., C. Liddle, and M. Downes, FXR and PXR: potential therapeutic targets in cholestasis. J Steroid Biochem Mol Biol, 2012. 130(3-5): p. 147-58.

98. Jung, D., et al., Analysis of bile acid-induced regulation of FXR target genes in human liver slices. Liver International, 2007: p. 137-144.

99. Jung, D., et al., Human organic anion transporting polypeptide 8 promoter is transactivated by the farnesoid X receptor/bile acid receptor. Gastroenterology, 2002. 122(7): p. 1954-66.

100. Wagner, M., et al., CAR and PXR agonists stimulate hepatic bile acid and bilirubin detoxification and elimination pathways in mice. Hepatology, 2005. 42(2): p. 420-30.

101. Huang, W., et al., Induction of bilirubin clearance by the constitutive androstane receptor (CAR). Proc Natl Acad Sci U S A, 2003. 100(7): p. 4156-61.

102. Meyer zu Schwabedissen, H.E. and R.B. Kim, Hepatic OATP1B transporters and nuclear receptors $P X R$ and CAR: interplay, regulation of drug disposition genes, and single nucleotide polymorphisms. Mol Pharm, 2009. 6(6): p. 1644-61.

103. Sorensen, K., et al., Recent secular trends in pubertal timing: implications for evaluation and diagnosis of precocious puberty. Horm Res Paediatr, 2012. 77(3): p. 137-45.

104. Yao, J., et al., $N$-Glycosylation dictates proper processing of organic anion transporting polypeptide 1B1. PLoS One, 2012. 7(12): p. e52563.

105. Letschert, K., D. Keppler, and J. Konig, Mutations in the SLCO1B3 gene affecting the substrate specificity of the hepatocellular uptake transporter OATP1B3 (OATP8). Pharmacogenetics, 2004. 14(7): p. 441-52.

106. Mooij, M.G., et al., Development of Human Membrane Transporters: Drug Disposition and Pharmacogenetics. Clin Pharmacokinet, 2016. 55(5): p. 507-24. 
107. Barrett, J.S., et al., Physiologically based pharmacokinetic (PBPK) modeling in children. Clin Pharmacol Ther, 2012. 92(1): p. 40-9.

108. Laer, S., J.S. Barrett, and B. Meibohm, The in silico child: using simulation to guide pediatric drug development and manage pediatric pharmacotherapy. J Clin Pharmacol, 2009. 49(8): p. 889-904.

109. Weber, A., et al., Increased prevalence of functional minor allele variants of drug metabolizing CYP2B6 and CYP2D6 genes in Roma population samples. Pharmacol Rep, 2015. 67(3): p. 460-4.

110. Wolking, S., et al., Impact of Genetic Polymorphisms of ABCB1 (MDR1, PGlycoprotein) on Drug Disposition and Potential Clinical Implications: Update of the Literature. Clin Pharmacokinet, 2015. 54(7): p. 709-35.

111. Ahmed, S., et al., Pharmacogenomics of Drug Metabolizing Enzymes and Transporters: Relevance to Precision Medicine. Genomics Proteomics Bioinformatics, 2016. 14(5): p. 298-313.

112. Niemi, M., M.K. Pasanen, and P.J. Neuvonen, Organic anion transporting polypeptide 1B1: a genetically polymorphic transporter of major importance for hepatic drug uptake. Pharmacol Rev, 2011. 63(1): p. 157-81.

113. Gong, I.Y. and R.B. Kim, Impact of genetic variation in OATP transporters to drug disposition and response. Drug Metab Pharmacokinet, 2013. 28(1): p. 4-18.

114. Hartkoorn, R.C., et al., HIV protease inhibitors are substrates for OATPIA2, $O A T P 1 B 1$ and $O A T P 1 B 3$ and lopinavir plasma concentrations are influenced by SLCO1B1 polymorphisms. Pharmacogenet Genomics, 2010. 20(2): p. 112-20.

115. Zhang, W., et al., Effect of SLCO1B1 genetic polymorphism on the pharmacokinetics of nateglinide. Br J Clin Pharmacol, 2006. 62(5): p. 567-72.

116. Kalliokoski, A., P.J. Neuvonen, and M. Niemi, SLCO1B1 polymorphism and oral antidiabetic drugs. Basic Clin Pharmacol Toxicol, 2010. 107(4): p. 775-81.

117. Smith, N.F., et al., Variants in the SLCOIB3 gene: Interethnic distribution and the association with paclitaxel pharmacokinetics. Clinical Pharmacology and Therapeutics, 2007. 81(1): p. 76-82.

118. Tsujimoto, M., et al., Polymorphisms and linkage disequilibrium of the OATP8 (OATP1B3) gene in japanese subjects. Drug Metabolism and Pharmacokinetics, 2006. 21(2): p. SNP8 (165)-SNP12 (169).

119. Miura, M., et al., Influence of SLCO1B1,1B3, 2B1 and ABCC2 genetic polymorphisms on mycophenolic acid pharmacokinetics in Japanese renal transplant recipients. Eur J Clin Pharmacol, 2007. 63(12): p. 1161-9.

120. Tsujimoto, M., et al., Influence of SLCO1B3 gene polymorphism on the pharmacokinetics of digoxin in terminal renal failure. Drug Metab Pharmacokinet, 2008. 23(6): p. 406-11.

121. Couvert, P., et al., Association between a frequent allele of the gene encoding $O A T P 1 B 1$ and enhanced LDL-lowering response to fluvastatin therapy. Pharmacogenomics, 2008. 9(9): p. 1217-27.

122. He, Y.J., et al., Rifampicin alters atorvastatin plasma concentration on the basis of SLCO1B1 521T>C polymorphism. Clin Chim Acta, 2009. 405(1-2): p. 49-52.

123. van der Deure, W.M., et al., Organic anion transporter 1B1: an important factor in hepatic thyroid hormone and estrogen transport and metabolism. Endocrinology, 2008. 149(9): p. 4695-701. 
124. Buyukkale, G., et al., Neonatal hyperbilirubinemia and organic anion transporting polypeptide-2 gene mutations. Am J Perinatol, 2011. 28(8): p. 61926.

125. Huang, M.J., et al., Risk factors for severe hyperbilirubinemia in neonates. Pediatr Res, 2004. 56(5): p. 682-9.

126. Lin, Z., J. Fontaine, and J.F. Watchko, Coexpression of gene polymorphisms involved in bilirubin production and metabolism. Pediatrics, 2008. 122(1): p. e156-62.

127. Huang, C.S., et al., Genetic factors related to unconjugated hyperbilirubinemia amongst adults. Pharmacogenet Genomics, 2005. 15(1): p. 43-50.

128. Hamada, A., et al., Effect of SLCO1B3 haplotype on testosterone transport and clinical outcome in caucasian patients with androgen-independent prostatic cancer. Clin Cancer Res, 2008. 14(11): p. 3312-8.

129. Franke, R.M., et al., Influence of solute carriers on the pharmacokinetics of CYP3A4 probes. Clin Pharmacol Ther, 2008. 84(6): p. 704-9.

130. Li, N., et al., Tissue expression, ontogeny, and inducibility of rat organic anion transporting polypeptide 4. J Pharmacol Exp Ther, 2002. 301(2): p. 551-60.

131. Hagenbuch, B., Drug uptake systems in liver and kidney: a historic perspective. Clin Pharmacol Ther, 2010. 87(1): p. 39-47.

132. van de Steeg, E., et al., Organic anion transporting polypeptide 1a/1b-knockout mice provide insights into hepatic handling of bilirubin, bile acids, and drugs. $\mathrm{J}$ Clin Invest, 2010.

133. Meyer Zu Schwabedissen, H.E., et al., Identification, Expression, and Functional Characterization of Full-Length and Splice Variants of Murine Organic Anion Transporting Polypeptide 1b2. Mol Pharm, 2009.

134. Zaher, H., et al., Targeted disruption of murine organic anion-transporting polypeptide 1 b2 (Oatp1b2/Slcolb2) significantly alters disposition of prototypical drug substrates pravastatin and rifampin. Mol Pharmacol, 2008. 74(2): p. 320-9.

135. Sanofi-Aventis, U.S.L., Allegra Product Label. 2006.

136. Tahara, H., et al., P-glycoprotein plays a major role in the efflux of fexofenadine in the small intestine and blood-brain barrier, but only a limited role in its biliary excretion. Drug Metab Dispos, 2005. 33(7): p. 963-8.

137. Matsushima, S., et al., Investigation of the inhibitory effects of various drugs on the hepatic uptake of fexofenadine in humans. Drug Metab Dispos, 2008. 36(4): p. 663-9.

138. Shimizu, M., et al., Contribution of OATP (organic anion-transporting polypeptide) family transporters to the hepatic uptake of fexofenadine in humans. Drug Metab Dispos, 2005. 33(10): p. 1477-81.

139. Jaisue, S., J.P. Gerber, and A.K. Davey, Pharmacokinetics of fexofenadine following LPS administration to rats. Xenobiotica, 2010. 40(11): p. 743-50.

140. Niemi, M., et al., Fexofenadine pharmacokinetics are associated with a polymorphism of the SLCO1B1 gene (encoding OATP1B1). Br J Clin Pharmacol, 2005. 59(5): p. 602-4.

141. Hamman, M.A., et al., The effect of rifampin administration on the disposition of fexofenadine. Clin Pharmacol Ther, 2001. 69(3): p. 114-21. 
142. Swift, B., X. Tian, and K.L. Brouwer, Integration of preclinical and clinical data with pharmacokinetic modeling and simulation to evaluate fexofenadine as a probe for hepatobiliary transport function. Pharm Res, 2009. 26(8): p. 1942-51.

143. Hagenbuch, B. and P.J. Meier, The superfamily of organic anion transporting polypeptides. Biochim Biophys Acta, 2003. 1609(1): p. 1-18.

144. van de Steeg, E., et al., High impact of Oatpla/1b transporters on in vivo disposition of the hydrophobic anticancer drug paclitaxel. Clin Cancer Res, 2011. 17(2): p. 294-301.

145. Cvetkovic, M., et al., OATP and P-glycoprotein transporters mediate the cellular uptake and excretion of fexofenadine. Drug Metab Dispos, 1999. 27(8): p. 866-71.

146. Nozawa, T., et al., Functional characterization of pH-sensitive organic anion transporting polypeptide OATP-B in human. J Pharmacol Exp Ther, 2004. 308(2): p. 438-45.

147. Csanaky, I.L., et al., Organic anion-transporting polypeptide 1 b2 (Oatp1b2) is important for the hepatic uptake of unconjugated bile acids: Studies in Oatp1b2null mice. Hepatology, 2011. 53(1): p. 272-81.

148. Lam, J.L., et al., In vitro and in vivo correlation of hepatic transporter effects on erythromycin metabolism: characterizing the importance of transporter-enzyme interplay. Drug Metab Dispos, 2006. 34(8): p. 1336-44.

149. Simpson, K. and B. Jarvis, Fexofenadine: a review of its use in the management of seasonal allergic rhinitis and chronic idiopathic urticaria. Drugs, 2000. 59(2): p. 301-21.

150. Campbell, S.D., S.M. de Morais, and J.J. Xu, Inhibition of human organic anion transporting polypeptide OATP $1 B 1$ as a mechanism of drug-induced hyperbilirubinemia. Chem Biol Interact, 2004. 150(2): p. 179-87.

151. Hirano, M., et al., Contribution of OATP2 (OATP1B1) and OATP8 (OATP1B3) to the hepatic uptake of pitavastatin in humans. J Pharmacol Exp Ther, 2004. 311(1): p. 139-46.

152. Degorter, M.K., et al., Disposition of atorvastatin, rosuvastatin, and simvastatin in oatp1b2-/- mice and intraindividual variability in human subjects. J Clin Pharmacol, 2012. 52(11): p. 1689-97.

153. Bachmakov, I., et al., Interaction of oral antidiabetic drugs with hepatic uptake transporters: focus on organic anion transporting polypeptides and organic cation transporter 1. Diabetes, 2008. 57(6): p. 1463-9.

154. Du, W., et al., An Algorithm to Detect Adverse Drug Reactions in the Neonatal Intensive Care Unit: A New Approach. J Clin Pharmacol, 2012.

155. Becker, M.L. and J.S. Leeder, Identifying genomic and developmental causes of adverse drug reactions in children. Pharmacogenomics, 2010. 11(11): p. 1591602.

156. Pauli-Magnus, C. and P.J. Meier, Hepatobiliary transporters and drug-induced cholestasis. Hepatology, 2006. 44(4): p. 778-87.

157. Rath, A., et al., Detergent binding explains anomalous SDS-PAGE migration of membrane proteins. Proc Natl Acad Sci U S A, 2009. 106(6): p. 1760-5.

158. Rath, A., F. Cunningham, and C.M. Deber, Acrylamide concentration determines the direction and magnitude of helical membrane protein gel shifts. Proc Natl Acad Sci U S A, 2013. 110(39): p. 15668-73. 
159. van de Steeg, E., et al., Methotrexate pharmacokinetics in transgenic mice with liver-specific expression of human organic anion-transporting polypeptide 1B1 (SLCO1B1). Drug Metab Dispos, 2009. 37(2): p. 277-81.

160. van de Steeg, E., et al., Influence of human OATP1B1, OATP1B3, and OATP1A2 on the pharmacokinetics of methotrexate and paclitaxel in humanized transgenic mice. Clin Cancer Res, 2013. 19(4): p. 821-32. 


\section{VITA}

Margaret Thomson, daughter of George and Alice Schiffer, was born in 1976 in Winfield, IL. She grew up in Wheaton, IL. Upon graduation from Wheaton North High School in 1994, Margaret attended Cornell College in Mount Vernon, IA. After obtaining a Bachelor of Arts degree in 1998 majoring in Chemistry and Psychology, she worked at Avon Products, Inc. in the Quality Assurance Laboratory before moving to The University of Iowa Department of Biology as a Research Assistant. At the University of Iowa, Margaret studied double stranded DNA breaks and histone placement in Saccharomyces cerevisiae under the guidance of Dr. Robert Malone. In 2003 Margaret enrolled at the University of Tennessee College of Pharmacy and earned her Doctor of Pharmacy in 2007. She has been enrolled at the University of Tennessee College of Graduate Health Sciences since that time in the Department of Pharmaceutical Sciences working towards her Ph.D. under the guidance of Dr. Bernd Meibohm. 